
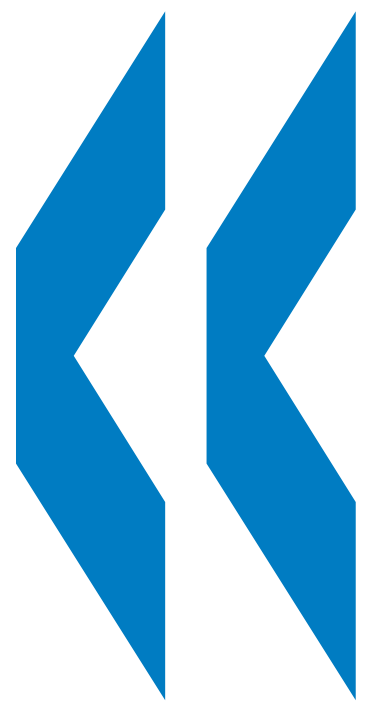

\title{
OECD Reviews of Tertiary Education
}

NEW ZEALAND

Leo Goedegebuure, Paulo Santiago,

Laara Fitznor, Bjørn Stensaker

and Marianne van der Steen 



\section{OECD Reviews of Tertiary Education}

\section{New Zealand}

Leo Goedegebuure, Paulo Santiago, Laara Fitznor,

Bjørn Stensaker and Marianne van der Steen 


\section{ORGANISATION FOR ECONOMIC CO-OPERATION AND DEVELOPMENT}

The OECD is a unique forum where the governments of 30 democracies work together to address the economic, social and environmental challenges of globalisation. The OECD is also at the forefront of efforts to understand and to help governments respond to new developments and concerns, such as corporate governance, the information economy and the challenges of an ageing population. The Organisation provides a setting where governments can compare policy experiences, seek answers to common problems, identify good practice and work to co-ordinate domestic and international policies.

The OECD member countries are: Australia, Austria, Belgium, Canada, the Czech Republic, Denmark, Finland, France, Germany, Greece, Hungary, Iceland, Ireland, Italy, Japan, Korea, Luxembourg, Mexico, the Netherlands, New Zealand, Norway, Poland, Portugal, the Slovak Republic, Spain, Sweden, Switzerland, Turkey, the United Kingdom and the United States. The Commission of the European Communities takes part in the work of the OECD.

OECD Publishing disseminates widely the results of the Organisation's statistics gathering and research on economic, social and environmental issues, as well as the conventions, guidelines and standards agreed by its members.

This work is published on the responsibility of the Secretary-General of the OECD. The opinions expressed and arguments employed herein do not necessarily reflect the official views of the Organisation or of the governments of its member countries.

Corrigenda to OECD publications may be found on line at: www.oecd.org/publishing/corrigenda (c) OECD 2008

OECD freely authorises the use, including the photocopy, of this material for private, non-commercial purposes. Permission to photocopy portions of this material for any public use or commercial purpose may be obtained from the Copyright Clearance Center (CCC) at info@copyright.com or the Centre français d'exploitation du droit de copie (CFC) contact@cfcopies.com. All copies must retain the copyright and other proprietary notices in their original forms. All requests for other public or commercial uses of this material or for translation rights should be submitted to rights@oecd.org. 


\section{Table of contents}

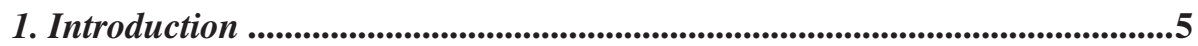

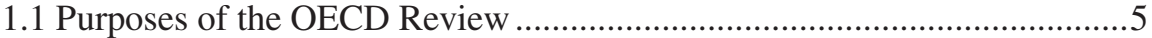

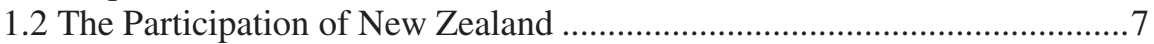

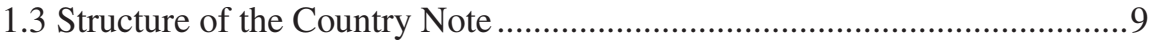

2. National Context - Introduction to the Land of the Long White Cloud: Aotearoa or New Zealand .............................................................................................11

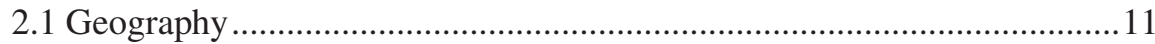

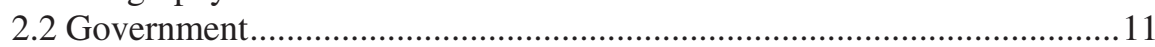

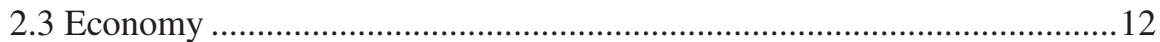

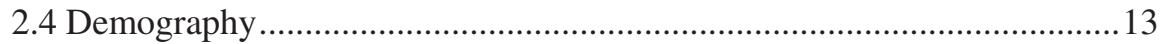

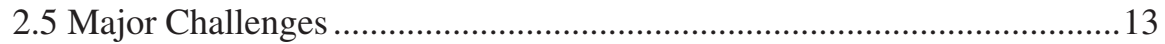

3. Context and Main Features of Tertiary Education Policy ...............................15

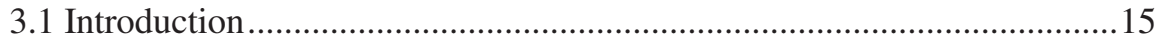

3.2 Tertiary Education Policy: Two Decades of Change ………….................16

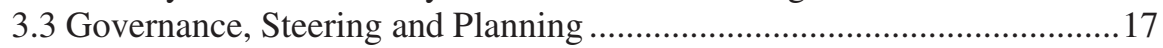

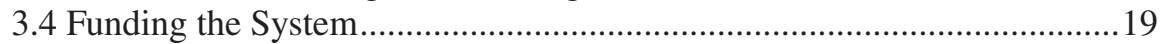

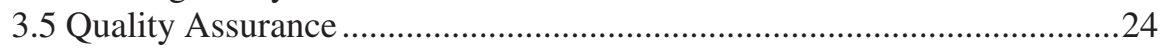

3.6 Equity and Links to the Community ......................................................26

3.7 Research, Innovation and Industry Relationships ..................................28

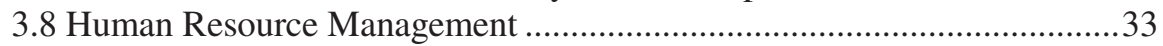

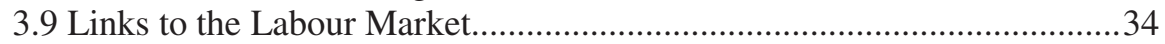

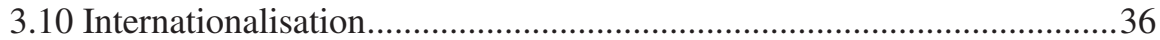

4. Strengths and Challenges of Tertiary Education Policy ................................39

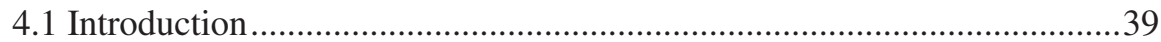

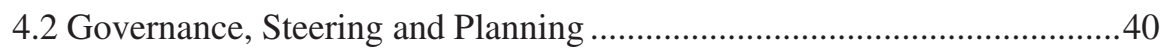

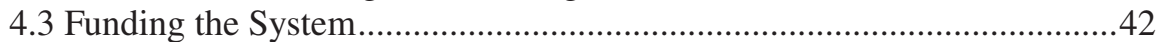

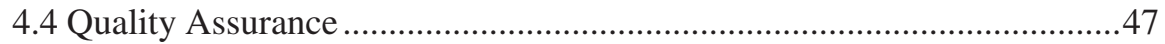

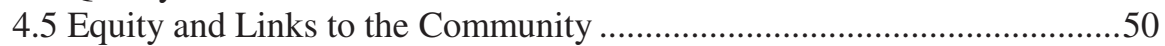

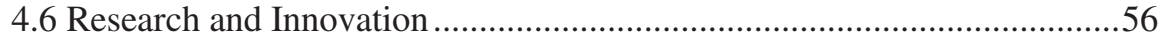

4.7 Human Resource Management ...............................................................60 


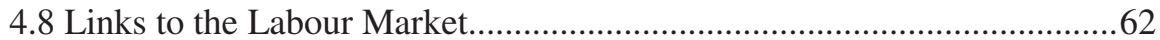

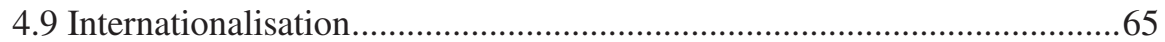

5. Pointers for Future Policy Development............................................................69

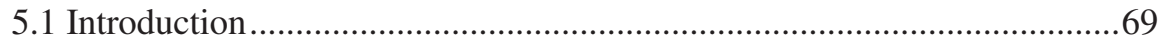

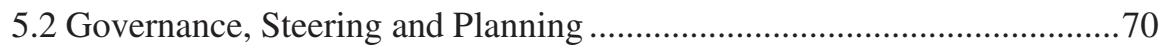

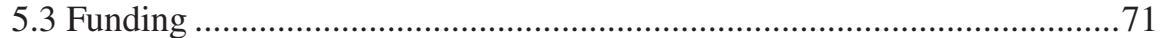

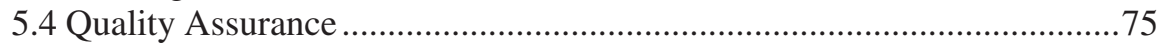

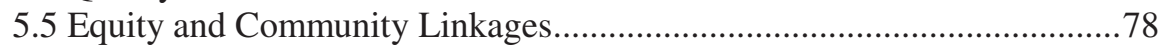

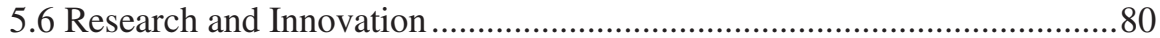

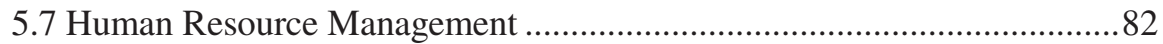

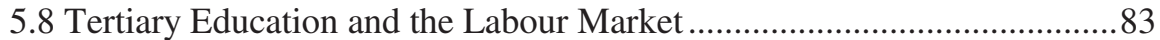

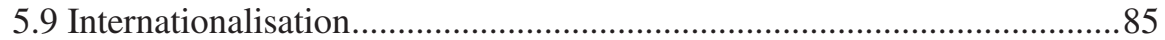

6. Concluding remarks.....................................................................................................87

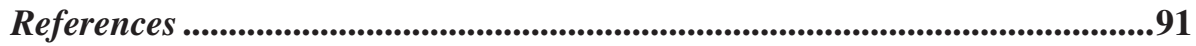

Appendix 1: The OECD Review Team .............................................................95

Appendix 2: National Co-ordinator, National Advisory Committee, and Authors of the Country Background Report......................................................97

Appendix 3: Programme of the Review Visit ...................................................99

Appendix 4: Chronology of Key Reforms of the New Zealand Tertiary Education System ................................................................................................................103

Appendix 5: Comparative Indicators on Tertiary Education ............................107

This report is based on a study visit to New Zealand in February 2006, and on background documents prepared to support the visit. As a result, the report reflects the situation up to that point. 


\section{Introduction}

\subsection{Purposes of the OECD Review}

This Country Note on New Zealand forms part of the OECD Thematic Review of Tertiary Education. This is a collaborative project to assist the design and implementation of tertiary education policies which contribute to the realisation of social and economic objectives of countries.

The tertiary education systems of many OECD countries have experienced rapid growth over the last decade, and are experiencing new pressures as the result of a globalising economy and labour market. In this context, the OECD Education Committee agreed, in late 2003, to carry out a major thematic review of tertiary education. The principal objective of the review is to assist countries to understand how the organisation, management and delivery of tertiary education can help them to achieve their economic and social objectives. The focus of the review is upon tertiary education policies and systems, rather than upon the detailed management and operation of institutions, although clearly the effectiveness of the latter is influenced by the former.

The project's purposes, methodology and guidelines are detailed in OECD (2004a). ${ }^{1}$ The purposes of the review are:

- To synthesise research-based evidence on the impact of tertiary education policies and disseminate this knowledge among participating countries;

- To identify innovative and successful policy initiatives and practices;

- To facilitate exchanges of lessons and experiences among countries; and

- To identify policy options. 
The review encompasses the full range of tertiary programmes and institutions. International statistical conventions define tertiary education in terms of programme levels: those programmes at ISCED $^{2}$ levels $5 \mathrm{~B}, 5 \mathrm{~A}$ and 6 are treated as tertiary education, and programmes below ISCED level 5B are not. ${ }^{3}$ In some countries the term higher education is used more commonly than tertiary education, at times to refer to all programmes at levels $5 \mathrm{~B}, 5 \mathrm{~A}$ and 6 , at times to refer only to those programmes at levels $5 \mathrm{~A}$ and 6. An additional complication is presented by the practice, in some countries, of defining higher education or tertiary education in terms of the institution, rather than the programme. For example it is common to use higher education to refer to programmes offered by universities, and tertiary education to refer to programmes offered by institutions that extend beyond universities. The OECD thematic review follows standard international conventions in using tertiary education to refer to all programmes at ISCED levels $5 \mathrm{~B}, 5 \mathrm{~A}$ and 6 , regardless of the institutions in which they are offered. ${ }^{4}$

The project involves two complementary approaches: an Analytical Review strand; and a Country Review strand. The Analytical Review strand is using several means - country background reports, literature reviews, data analyses and commissioned papers - to analyse the factors that shape the outcomes in tertiary education systems, and possible policy responses. All of

The International Standard Classification of Education (ISCED) provides the foundation for internationally comparative education statistics and sets out the definitions and classifications that apply to educational programmes within it.

Programmes at level 5 must have a cumulative theoretical duration of at least 2 years from the beginning of level 5 and do not lead directly to the award of an advanced research qualification (those programmes are at level 6). Programmes are subdivided into 5A, programmes that are largely theoretically based and are intended to provide sufficient qualifications for gaining entry into advanced research programmes and professions with high skills requirements, and into 5B, programmes that are generally more practical/technical/occupationally specific than ISCED 5A programmes. Programmes at level 6 lead directly to the award of an advanced research qualification. The theoretical duration of these programmes is 3 years full-time in most countries (e.g. Doctoral programme), although the actual enrolment time is typically longer. These programmes are devoted to advanced study and original research. For further details see OECD (2004b).

It should be noted that the definition of tertiary education in New Zealand is broader than the OECD's definition and includes all post-school education: foundation education (such as adult literacy), certificates and diplomas, bachelors degrees, industry training (including apprenticeships), adult and community education; and postgraduate qualifications. However, the review visit to New Zealand focussed on programmes covered by OECD's definition. 
the 24 countries involved in the Review are taking part in this strand. In addition, 13 of the tertiary education systems have chosen to participate in a Country Review, which involves external review teams analysing tertiary education policies in those countries.

New Zealand was one of the countries, which opted to participate in the Country Reviews and hosted a review visit in February 2006. The reviewers comprised an OECD Secretariat member, and academics and policy-makers from Canada, the Netherlands and Norway. The team is listed in Appendix 1.

\subsection{The Participation of New Zealand}

New Zealand's participation in the OECD Review is being co-ordinated by Roger Smyth, Head of the Tertiary Sector Performance Analysis and Reporting Unit, Ministry of Education with the assistance of Jason McClelland, Senior Research Analyst at the same Unit, in the role of Project Manager. New Zealand's Country Background Report (CBR) for the OECD Review was prepared by Ministry of Education staff and independent contractors, and was supported by the National Advisory Committee, an Advisory Committee within the Ministry of Education and various other stakeholders of the tertiary education system (details provided in Appendix 2).

The Review Team is very grateful to the authors of the CBR, and to all those who assisted them for providing an informative, analytical and policyoriented document. The CBR covered themes such as the background and content of tertiary education reforms; the structure of the tertiary education system; the role of tertiary education in regional development, the research effort of the country, and the shaping of labour markets; the challenges faced in resourcing, governing, achieving equity in and assuring the quality of the tertiary education system. Some of the main issues identified by New Zealand's CBR, and which are taken up in this Country Note, include:

- Achieving the appropriate balance between governmental steering and institutional autonomy in the pursuit of a better alignment between the system and the nation's economic and social development goals;

- Providing relevant tertiary education necessary for a knowledge society in an environment of limited resources;

- Developing an effective system of institutional monitoring and quality assurance; 
- Realigning the funding system with the goals of the tertiary education strategy;

- Ensuring equity of tertiary education outcomes among all socioeconomic and ethnic groups;

- Improving the capability of the sector and agencies to manage the complexities of relationships in the system.

The New Zealand CBR forms a valuable input to the overall OECD project and the Review Team found it to be very useful in relation to its work. The analysis and points raised in the CBR are cited frequently in this Country Note. ${ }^{5}$ In this sense, the documents complement each other and, for a more comprehensive view of tertiary education policy in New Zealand, are best read in conjunction.

The review visit took place from 6 to 14 February 2006. The detailed itinerary is provided in Appendix 3. The Review Team held discussions with a wide range of educational authorities and relevant agencies and visited several institutions of tertiary education in the country. Discussions were held with representatives of Ministries such as education, research science and technology, finance, labour, economic development, and social development; tertiary education institutions; student organisations; representatives of academic staff; employers; the business and industry community; and agencies responsible for funding and quality assurance. This allowed the team to obtain a wide cross-section of perspectives from key stakeholders in the system on the strengths, weaknesses, and policy priorities regarding tertiary education in contemporary New Zealand society.

This Country Note draws together the Review Team's observations and background materials. The present report on New Zealand will be an input into the final OECD report from the overall project. We trust that the Country Note will also contribute to discussions within New Zealand, and inform the international education community about developments in New Zealand that may hold lessons for their own systems.

The Review Team is very appreciative of the hospitable, informative and frank meetings that were held during the visit, and the helpful documentation that each group provided. The New Zealand education system is well known for its openness to external perspectives, and its lively internal debates. The team benefited greatly from these traditions. A special word of appreciation is due to the National Co-ordinator, Roger Smyth, and Zealand's Country Background Report (Ministry of Education, 2006). 
to the Project Manager, Jason McClelland, for going to great lengths to respond to the questions and needs of the Review Team. We were impressed by their efficiency and expertise and enjoyed their kindness and very pleasant company. The courtesy and hospitality extended to us throughout our stay in New Zealand made our task as a Review Team as pleasant and enjoyable as it was stimulating and challenging.

Of course, this Country Note is the responsibility of the Review Team. While we benefited greatly from the New Zealand CBR and other documents, as well as the many discussions with a wide range of New Zealand stakeholders, the conclusions as well as errors or misinterpretations in this Country Note are our responsibility.

\subsection{Structure of the Country Note}

The remainder of the report is organised into four main Sections. Section 2 provides the national context. Section 3 outlines the key contextual factors shaping tertiary education in New Zealand and tries to assist international readers by identifying what is distinctive about tertiary education policy in New Zealand. Section 4 then identifies the main strengths of New Zealand tertiary education policies, but also the challenges and problems that the system faces.

Section 5 uses the analysis in the previous Sections to discuss priorities for future policy development. The suggestions draw on promising initiatives that the team learned about during the visit. Section 6 has some concluding remarks.

The policy suggestions attempt to build on and strengthen reforms that are already underway in New Zealand, and the strong commitment to further improvement that was evident among those we met. The suggestions are also offered in recognition of the difficulty facing any group of visitors, no matter how well briefed, in grasping the uniqueness and complexity of New Zealand and the factors that need to be taken into account. 



\section{National Context - Introduction to the Land of the Long White Cloud: Aotearoa or New Zealand}

\subsection{Geography}

The Country Background Report (Ministry of Education, 2006) describes New Zealand as a small country in the South Pacific with the third lowest population in the OECD: four million. Consisting of two large islands - the North and South Islands - and a number of smaller ones, it is separated by some 2000 kilometres of Tasman Sea from Australia. A country of spectacular natural beauty spread over $268680 \mathrm{~km}^{2}$, it is sparsely populated with only 15 persons per square kilometre. The largest concentrations of people are to be found in the cities of Auckland (1.2 million), Wellington (370 thousand) and Christchurch (370 thousand). Whilst the first Europeans set eyes on the country in 1642 as part of Abel Tasman's exploits in the southwestern Pacific, Polynesian settlers commonly are assumed to have established the Māori culture in Aotearoa about the $11^{\text {th }}$ century. Today, New Zealand is a culturally diverse country with about $75 \%$ of its population identifying as European, some $15 \%$ identifying as Māori, 9\% identifying as Pasifika and 7\% identifying as Asian. ${ }^{6}$

\subsection{Government}

New Zealand is a constitutional monarchy with Queen Elizabeth II the Head of State, represented by a Governor-General appointed by her on recommendation of the government. An independent dominion since 1907 following its colony status in 1840 after being administered as part of the colony of New South Wales (Australia), New Zealand was granted full independence in 1931. This was effectuated in 1947 by the New Zealand counting is used so the shares will add to more than $100 \%$. 
Parliament. Regardless of the formal legal aspects, most New Zealanders consider that New Zealand became a nation, independent de facto, in 1907. The Parliament constitutes a single house and since 1996 is elected through a system of mixed member proportional representation. The Government is headed by a Prime Minister. The current government is a minority Labour/Progressive coalition government, with Helen Clark in her third term as Prime Minister.

Of particular importance in terms of governance arrangements is the Treaty of Waitangi, New Zealand's founding document. Signed between the Crown and the Māori people in 1840 at Treaty House in Waitangi, Bay of Islands, it established a partnership between the two peoples. Consisting of three articles, the Treaty granted the Crown sovereignty over New Zealand, the Māori signatory chiefs ownership of their lands, treasures and continued chieftainship, and it stated that Māori will sell land only to the Crown. Though deceivingly simple, the different interpretations of the Treaty in its two languages (Māori and English) has resulted in many contestations over the years, which in part reflect the tensions existing between the two peoples, of which the Māori - inter alia - at the end of the $19^{\text {th }}$ century were expected to cease to exist because of population decline. To deal with these tensions, in 1975 the Treaty of Waitangi Act came into force, establishing the Waitangi Tribunal where claims of violation of the Treaty were heard and settled. Though unclarity and different interpretations of the Treaty remain to this day, there is no denying of the important social function attributed to it. Concrete outcomes are the acceptance of te reo Māori (the language of Māori), the incorporation of Māori protocols in carrying out business, and the emergence and growth of a semi-independent Māori education system that extends into tertiary education.

\subsection{Economy}

Like the tertiary education sector, New Zealand's economy in general has undergone major change and reform since the middle of the 1980s. Originally an economy characterised by government regulation, protection and subsidies, two decennia of reform policy have changed and liberalized the economic structure of the country. Protected industries, such as car manufacturing, have disappeared. Today's industries are mostly (very) small to medium sized enterprises concentrated in the export and services sectors, resulting in particular challenges when it comes to investment in research and development. In terms of exports, agricultural products have remained dominant with Australia, Japan and the United States being the main importing countries. As to the service sector, tourism has become a major industry. 
The current government continues with the reform agenda initiated in the mid 1980s. Focussed on economic diversification, improved efficiency and entrepreneurship, the present Growth and Innovation Framework (GIF) has identified biotechnology, information and communication technology, design and screen production as the four critical areas to national economic growth.

The results of the reform agenda have been quite spectacular. Unemployment is the second lowest in the OECD area despite the fact that New Zealand is vulnerable to international market fluctuations (as evidenced by the Asian financial crisis in the late 1990s), being one of the smallest economies within the OECD. During the period 2003-2004 the economy was the $7^{\text {th }}$ fastest growing among OECD countries and growth has been the characteristic feature throughout the new millennium (see OECD 2005b).

\subsection{Demography}

Although ageing like many other countries, New Zealand's population is projected to grow by around $12 \%$ over the next 20 years, a growth that appears to be particularly concentrated in the Māori and Pasifika populations because of their younger age structure, and in Asian populations because of migration. This will result in a more ethnically diverse population, which in turn poses a challenge for the education system, as up to now educational outcomes for Māori and Pasifika people have been below average. This has been recognised by the New Zealand government and incorporated in the overall development strategy for tertiary education.

\subsection{Major Challenges}

Whilst not doing justice to the complex issues facing any developed country, the challenges facing New Zealand appear to be a direct reflection of the particular characteristics of this country: small size, relative isolation, a resurgence and recognition of traditional cultures and values within a context of growth and relative affluence, but with the absence of many major industries. These challenges have been addressed through a major socio-economic reform agenda in which deregulation and liberalization are key features. Tertiary education policy reforms have reflected this overall trend, resulting in a system that in both size and shape bears little resemblance to that existing some 20 years ago. 



\section{Context and Main Features of Tertiary Education Policy}

Tertiary education in New Zealand in 2006 is vastly different from the federated University of New Zealand structure that existed from 1870 to 1961, with distributed colleges and its headquarters at Senate House in Wellington. The present tertiary education sector with well over 900 institutions is a diverse amalgam of small and large, comprehensive and specialised, and private and public providers catering for over half a million predominantly domestic students. Major policy change has affected the tertiary education sector since the late 1980s, with substantive shifts in policy directions. The system that this Note examines currently is undergoing the latest of these policy changes that attempt to stabilise a system that has expanded at a very rapid pace in a context of liberalisation and deregulation.

\subsection{Introduction}

Contrary to many other countries, New Zealand has adopted a very broad definition of tertiary education. It includes all post-school education in the international literature commonly identified as post-secondary education - and thus covers the full spectrum from adult literacy and second chance education for those without previous formal or low schooling, through to certificates, diplomas, bachelors, masters and PhD's. It also covers industry training, apprenticeships and adult and community education.

This very encompassing definition also makes the tertiary education sector a diverse amalgam of institutions, in New Zealand commonly identified as tertiary education organisations (TEOs). The sector comprises public tertiary education institutions (TEIs), private training establishments (PTEs), other tertiary education providers (OTEPs), industry training organisations (ITOs), and adult and community education (ACE) providers. In addition to this, a vast array of workplace training and industry-related education takes place. 
TEIs can further be divided into universities (8), institutes of technology and polytechnics (ITPs) (20), colleges of education (CoEs) (2), and $\mathrm{W}^{-}$ananga ${ }^{7}$ (3). PTEs predominantly operate in niche areas, by and large are small to very small institutions - with some noticeable exceptions - and number close to 900 . They are private by nature and comprise not-for-profit and for-profit institutions. OTEPs (16) are organisations that deliver programmes of tertiary education (or in support of) that are of national significance and recognised by government agencies. ITOs (41) are spread around the country and are established by specific (groups of) industries. ${ }^{8}$

In line with the diverse organisational nature of the system, the student population is diverse as well. Of the half million students, $68 \%$ study at subdegree certificate and diploma level, $25.6 \%$ at bachelor level and a small proportion $(6.4 \%)$ at the post-graduate level. The largest body of students can be found in the ITPs (42\%), followed by universities (33\%), PTEs and Wānanga (14\%), with a small group in the two CoEs (3\%).

\subsection{Tertiary Education Policy: Two Decades of Change}

If one thing characterises New Zealand's tertiary education policy it is change. As argued by McLaughlin (2003, p. 10) since the late 1980s "On average, a major review of tertiary education has occurred every two years". As has been the case in many other countries, tertiary education reform is tied into more general public sector reform, which in the New Zealand case has been combined with major macro-economic reform. Whilst the economy moved from a strongly regulated and protected economy to a liberalized market economy, the tertiary education sector transformed from an elite university system to a mass tertiary system that has become part and parcel of the international tertiary education sector.

Taking a broad-brush approach to categorizing tertiary education reform, it can be argued (McLaughlin, 2003) that the system has gone through distinct periods of change focussed on different themes. From 1990, competition and private contributions have been introduced with the objective of broadening participation. This can be seen, apart from a political-ideological change, as a reaction against the up to then prevalent

Wānanga are Māori centres of tertiary learning, which acquired their status as TEIs in the last decade. They offer study at all levels, from foundation education to postgraduate study and research where ahuatanga Māori (Māori tradition) and tikanga Māori (Māori custom) are an integral part of the programme.

For a more elaborate description, see Chapter 2 of the Country Background Report (Ministry of Education, 2006). 
elite characteristics of the system. This direction of policy change has continued during the 1990s with emphasis on market-like competition, student choice (diversity) and an emphasis on private returns to tertiary education. ${ }^{9}$ From 2000 onwards, while maintaining the general thrust of competition and markets, the emphasis has shifted more towards governmental steering in an attempt to closer align tertiary education with New Zealand's socio-economic development. ${ }^{10}$

For the sector, this has culminated in the 2002-2007 Tertiary Education Strategy (TES) setting the direction (Ministry of Education, 2002). The TES is "a high-level strategy that articulates the key goals for New Zealand's tertiary education system and defines how the system will help give effect to the government's vision and goals for New Zealand" (Ministry of Education, 2006, p. 29). Six "sub-strategies" comprise the current TES: strengthening of the system capability and quality; contributing to achieving the Māori development aspirations; raising foundation skills to allow participation in the knowledge society; developing the skills needed for a knowledge society; educating for Pacific people's development and success; and strengthen the research knowledge creation and uptake function.

To appreciate the concept of the TES and to understand the way it plays out in the New Zealand tertiary education system - and beyond - it is necessary to discuss the governance, steering and planning system in some more detail.

\subsection{Governance, Steering and Planning}

Although New Zealand is a relatively small country, its governance, steering and planning structure to the outsider's eye is relatively complex and involves a large number of actors. The main agencies are the Ministry of Education (MoE), the Tertiary Education Commission (TEC), the New Zealand Qualifications Authority (NZQA) and Career Services Rapuara. TEC, NZQA and Career Services are so-called Crown Agencies with their boards appointed by the Minister. TEC is a combined policy implementation agency, involved in institutional capacity building, overall policy advice, and allocation of government funding. It also negotiates charters and profiles with the institutions (see further). NZQA provides overarching

9

For a further elaboration on private returns to tertiary education, see $e$.g. Johnstone et al. (1998), Jongbloed and Vossensteyn (2001), Maani (1997, 2000) and Vossensteyn (2005).

Appendix 4 provides a chronology of recent key reforms of the New Zealand tertiary education system, reproduced from the Country Background Report. 
quality assurance, administers the national qualifications framework (Register of Quality Assured Qualifications), registers private providers and evaluates overseas qualifications. ${ }^{11}$ The main instruments are the TES discussed above, operationalised in the three-yearly Statement of Tertiary Education Priorities (STEP, Ministry of Education, 2004), and the institutional charters and profiles - charters contain the institution's mission and role in the system, whilst the profile is the more detailed operation of this in terms of strategic direction, activities, policies and performance targets - that all operate within the context of an integrated funding framework. This will be outlined below.

But governance, steering and planning is not limited to these actors. Also active are the New Zealand Teachers' Council, the Ministry of Social Development, Inland Revenue Te Tari Taake, the Ministry of Research, Science and Technology, the Department of Labour, the New Zealand Vice Chancellors' Committee, as well as a wide range of stakeholder organisations taking part in policy discussions, formal platforms, informal meetings, and the like, ranging from employers' organisations to trade unions and student organisations.

Whilst many of the dynamics, intricacies and unique features of the New Zealand tertiary education system will be revealed and discussed in the subsequent Sections of this report, its basic modus operandus can be summarised as follows. The cornerstone is formed by the TES, which is derived from the country's national development goals, and operationalised in the STEP. It is this triad that sets tertiary education policy in this millennium apart from that in the latter two decennia of the $20^{\text {th }}$ century. Through linking the STEP to institutional charters and profiles, the last to be revised on a regular basis, the basis for articulation of national goals and priorities into institutional actions is laid. The resultant is a rather unique mix of central steering within an overall context of market-oriented dynamics. As will be argued later on, it also is a unique mix of policy rhetoric and reality.

In principle, the MoE advises government on strategic policy for the sector, with the TEC acting as implementing agency, negotiating charters and profiles with the TEOs, supported in various ways by NZQA, Career Services and other key government departments such as the Ministry of Social Development and Department of Labour. In Section 4 of this report we will return to this structure and the ensuing strengths and challenges in more detail. The paragraphs that follow are intended to provide an (Ministry of Education, 2006), p. 30-31. 
introduction to the remaining aspects of the tertiary education system featuring in the OECD Thematic Review.

\subsection{Funding the System}

\subsubsection{General overview}

In 2002, public expenditure on tertiary education (both on institutions and subsidies to households) stood at $1.7 \%$ of GDP, the $5^{\text {th }}$ highest percentage among the $28 \mathrm{OECD}$ countries for which data are available (only behind Denmark, Finland, Norway and Sweden, see Appendix 5). This level of spending amounted to $5.2 \%$ of total public expenditure (the highest share among 26 OECD countries, see Appendix 5). Public current expenditure on tertiary education grew $27 \%$ in real terms between 1999/2000 and 2004/05. This reflects a period of significant expansion of enrolments: $64 \%$ growth of total enrolments, $54 \%$ growth of domestic enrolments, and $42 \%$ growth of government-funded EFTS (equivalent-full-time students) in public tertiary education institutions.

In 2004/05, public spending on tertiary education was distributed between subsidies to institutions $(51.3 \%)$, student loans $(26.8 \%)$, student allowances (10.2\%), and other expenses (11.7\%, e.g. training incentive allowance, training for designated groups, administration). In New Zealand, another aspect which stands out is the proportion of spending on tertiary education coming from private sources: in 2002, 37.5\% of expenditure on tertiary education institutions reflects private household expenditure $\left(5^{\text {th }}\right.$ highest share for the 27 OECD countries for which data are available, see Appendix 5).

In 2004, $41 \%$ of government-funded EFTS were in Universities (down from $55 \%$ in 2000), 33\% in Institutes of technology and polytechnics (up from $29 \%$ in 2000), $14 \%$ in Wānanga (up from $1.6 \%$ in 2000), $8.3 \%$ in Private Training Establishments (down from 8.8\% in 2000), 3\% in Colleges of Education (down from $4.7 \%$ in 2000), and $0.7 \%$ in Other Tertiary Education Providers (up from $0.5 \%$ in 2000).

Trends in the overall resourcing for teaching and learning have been favourable to tertiary education institutions. Following a decline during the period 1991-2000, the average tuition-subsidy (public subsidies for the instruction of domestic students per EFTS) has consistently risen. From 2000 to 2004, the average per-EFTS subsidy in tertiary education institutions rose $5.9 \%$ (15.2\% rise in Universities, $5.3 \%$ in ITPs, 3.0\% in Wānanga, and $6.3 \%$ in PTEs). The increase in the overall funding of tuition- 
related activities - adding revenues from domestic and international student fees to the public subsidy - during the same period of time was a more modest $0.4 \%$ for public institutions. This reflected the trend to fee discounting in the ITPs and the Wānanga and a drift in enrolments from higher-funded categories to lower-funded categories. While the combined tuition revenue per EFTS increased in Universities by $16 \%$, it decreased in ITPs and the Wānanga by $6.7 \%$ and $23.5 \%$ respectively.

The rationale for funding tertiary education rests on two main principles. On the one hand, reflecting public and private benefits of tertiary education, the costs of tertiary education activities are shared between the users and the State. Part of the funding is provided by the government to both institutions and students, and part by students and their families. On the other hand, the extent to which tertiary education is publicly subsidised depends on the relevance of activities - the extent to which they bring benefits to society. An assessment of strategic relevance is used to publicly fund courses and qualifications in tertiary education institutions. Offerings with similar relevance, irrespective of whether they are provided publicly or privately, are subsidised at similar level.

\subsubsection{Funding Institutions}

Institutions derive their revenues from four major sources: government subsidies (48\%), student tuition fees (29\%), external research contracts (9\%) and other income (e.g. provision of services, industry training) (13\%) (2004 figures). The proportion of income derived from government funds has declined from 52\% in 1997 to $39 \%$ in 2004 for the university sector and from $64 \%$ to $60 \%$ for the ITP sector over the same period of time.

Government subsidies are allocated to tertiary education institutions according to an integrated funding framework. This funding framework seeks to resource and steer the system towards the goals of the Tertiary Education Strategy, and to provide institutions with the flexibility to operate in a responsive and innovative way. It has three main components:

\section{Funding for teaching domestic students}

The public subsidy to teach domestic students comes predominantly from the Student Component (other sources are the Industry Training Fund and a number of targeted programmes such as Training Opportunities and Youth Training, defined by contracts between the TEC and the institution). The level of funding under the Student Component is proportional to the number of EFTS in each institution weighted by funding rates that are differentiated by field of study and qualification (e.g. certificate, diploma, 
degree). The number of funded EFTS is subject to some limits. For instance, the government establishes a limit for EFTS funded in PTEs, and since 2005 , limits enrolment growth at the certificate and diploma levels. There are also institutional limits on increases in funded EFTS in public tertiary education institutions: if, in any year, there is an increase of more than $15 \%$ in EFTS or 1000 EFTS (whichever is greater), places over and above that limit will not be funded. Similar principles apply to high-cost areas such as dentistry and medicine.

\section{Funding for research}

Until 2004, the main funding for research was provided as part of the Student Component funding for degree and postgraduate enrolments. This funding system is being phased out (2004-07) as the new PerformanceBased Research Fund (PBRF) is introduced. Under the PBRF, funding is allocated to institutions on the basis of their research performance, using a set of indicators complemented by peer review quality assessment. Other sources of income for research include funds for Centres of Research Excellence (CoREs) and competitive grants from the Ministry for Research, Science and Technology. More details are provided in Section 3.7.

\section{Targeted funding}

The Strategic Development Component allocates public funding on a targeted basis to improve the extent to which institutions align with the Tertiary Education Strategy. It comprises a number of funds, including Special Supplementary Grants (e.g. to support the participation and achievement of Māori and Pasifika students; to support students with disabilities), Partnerships for Excellence (to engage in partnerships with the private sector), the ITP Business Links Fund (to foster connections of ITPs with business and industry groups), the Innovation Development Fund, and the e-Learning Collaborative Development Fund.

Responsibilities for the implementation of the integrated funding framework are shared. The government sets the total amount of funding available for tertiary education and defines the broad funding policies. While the Ministry of Education monitors the financial performance of tertiary education institutions, this function is set to be transferred to the Tertiary Education Commission to enable a better overview of tertiary institutions and their performance, with educational outcomes being monitored alongside financial, governance and leadership indicators. The TEC sets the operational rules for funding and allocates the funding to institutions. Its key instruments are the institutions' charters and profiles. 
Charter approval is the first pre-requisite for eligibility for public funding. Through the annual negotiations to define the profiles, institutions have to demonstrate that their provision and activities align with the Tertiary Education Strategy. The Assessment of Strategic Relevance is the key tool for demonstrating such alignment. It consists of a set of broad assessment criteria that determine whether a provider may receive government tuition subsidies, whether a provider should receive strategic development support, and whether a provider should rationalise its supply of programmes.

Practically all institutions, whether public or private, charge tuition fees. In 2004, the average domestic annual tuition fee per EFTS was NZD 3934 in Universities, NZD 2254 in ITPs, NZD 2646 in Colleges of Education, and NZD 405 in Wānanga. ${ }^{12}$ Average fees increased $170 \%$ over the period 1991-99, compared to a rise of the consumer price index of $13 \%$. Since 1999, fee stabilisation policies have been introduced. From 2004, the government introduced a policy of fee- and course-costs maxima (FCCM), which limits the extent to which institutions can raise their fees. Under the FCCM policy, there is a set of upper limits for undergraduate fees, with a maximum in each field. Fees can be increased to this maximum provided that the increase is no more than 5\% in any year. Separate limits exist for postgraduate fees. Since 2000, there has been considerable discounting of fees in ITPs and Wānanga. International students are not publicly subsidised and institutions are expected to charge full cost fees. Between 2000 and 2004 , international student fees increased by $24 \%$ and international fee revenues increased from less than $5 \%$ of total institutional revenues to around $13 \%$.

\subsubsection{Student Support}

Students rely on four major sources to finance their studies: student loans; student allowances; part-time and vacation employment; and assistance from their families. The current model of student financial aid consists of a combination of a loan scheme and a means-tested student allowance scheme.

The largest student financial aid system is the Student Loan Scheme, introduced in 1992. It is characterised by its open access and incomecontingent repayment features. Any domestic student who is enrolled in an approved programme is able to borrow from the government the full amount of the fees charged by the institution, a fixed amount to cover course-related costs such as textbooks and materials (up to NZD 1000 per year, in 2006), (NZD 1=EUR 0.52) and USD 1=NZD 1.45 (NZD 1=USD 0.69). 
and a weekly amount to cover living costs. In 2006, full-time students could access a living-costs entitlement of NZD 150 per week for each week of studies, less any entitlement to student allowances. No interest is charged during the period of study (for full-time students and for part-time students on low incomes) and, as of 1 April 2006, all borrowers who are not studying, irrespective of whether or not they have graduated with a qualification, do not pay interest provided they are living in New Zealand.

Repayments are income-contingent. For borrowers living in New Zealand, they are based on income. Any borrower earning over the repayment threshold during an income year is required to make repayments towards the loan at a rate of 10 cents for every dollar of income over the income threshold. For borrowers not resident in New Zealand, the required repayments are unrelated to income. The collection of repayments is handled through the tax system.

In 2004, 53\% of eligible students opted for a student loan (74\% for eligible full-time students and $15 \%$ for eligible part-time students). The median amount borrowed was NZD 5424 in 2004. Around 14\% of all New Zealanders aged 15 or over had undischarged loan balances at 30 June 2005, the median cumulative student loan balance being NZD 10 404. In 2005, the forecast median loan-repayment time was 6.7 years. Under the rules of the Loan Scheme, before the no-interest policy came into force in April 2006, the Loan system implied a governmental subsidy of about $19 \%$. Under the new policy, this will increase.

The second main form of government assistance is the Student Allowances Scheme. It is a means-tested scheme targeted at promoting the participation of full-time students from lower socio-economic backgrounds. It provides a weekly payment from the government. There is a range of different allowance types depending on individual circumstances: single students under 25 are subject to a parental income test to determine their entitlement; all student allowances applicants are subject to a personal income test; there are adjusted rates for student allowance recipients with dependents; and student allowance recipients who are not living with their parents may also qualify for an accommodation benefit. The scheme provides every tertiary student with a 200 -week lifetime entitlement, subject to eligibility criteria. In 2004, there were 72000 students (16\% of all domestic students) receiving these allowances.

Students who receive student allowances may also take up student loans, with the living-costs entitlement decreasing by the amount of the allowance. In $2004,80 \%$ of student allowance recipients also took out a student loan. Those who received only a student allowance on average received 
NZD 6742 in 2004; those using the living-costs entitlement under the Student Loan Scheme on average borrowed NZD 1765.

The government supports a wide range of other schemes for particular purposes. The Training Incentive Allowance provides financial assistance to support people receiving specific forms of State assistance (e.g. assistance for low-income sole parents) so that they can undertake training for future employment. Other initiatives include scholarships for students from lowincome backgrounds to study in fields such as science and technology, scholarships targeted at improving the participation of Māori and Pasifika peoples in the tertiary sector, scholarships targeted at encouraging people to acquire qualifications in given areas (e.g. teaching, health care), fellowships to support students undertaking projects in collaboration with business, scholarships for high-achievers, and post-doctoral fellowships.

Loans, allowances and other income support are administered by StudyLink, a service of the Ministry of Social Development.

In addition to loans and grants, most students support themselves through part-time and vacation employment and with the assistance from their families. According to a survey by the New Zealand University Students' Association, in 2004 67\% of full-time students had a part-time job (compared to $41 \%$ in 2001), working an average of 13 hours a week. About $64 \%$ of students worked during Summer vacation (compared to $77 \%$ in 2001). Students who receive student allowances may receive the Unemployment Benefit Student Hardship if they are not able to find vacation employment.

\subsection{Quality Assurance}

Quality assurance of tertiary education has a long and proud history in New Zealand. While most OECD countries only within the last decade have developed a national comprehensive system for assuring the quality of tertiary education provision, New Zealand can be considered as one of the international innovators in the field.

Initially, the most visible part of the quality assurance system rested on two pillars. The first one is the requirement that TEOs establish a quality management system demonstrating the existence and functioning of necessary policies and procedures for teaching and learning. The second one is an external review of these quality management systems through an audit procedure. Over time, and much as a result of the expansion of tertiary education in New Zealand, quality assurance has developed into a complex and multifaceted area. 
At present, quality assurance has four levels: registration; approval; accreditation; and monitoring and audit. These functions reflect the diversified tertiary education system in the country. The need to be registered is only required for PTEs and OTEPs, while the remaining functions are universal to all TEOs for obtaining government funding (approval), deliver a particular qualification (accreditation), and to provide accountability (monitoring and audit).

To provide integration and standardisation, both across the different types of TEOs and across the different levels of tertiary education, New Zealand has developed a Register of Quality Assured Qualifications. This Register identifies all quality assured qualifications in New Zealand and their relationship with each other in terms of complexities and expected learning outcomes. The Register is still under development by the organisation responsible for it, the NZQA.

There are two organisations primarily responsible for quality assurance in tertiary education in New Zealand. While NZQA has the overall responsibility for non-university TEOs, quality assurance within universities is the responsibility of the New Zealand Vice-Chancellors Committee (NZVCC). These two bodies have further delegated the practical follow-up of quality assurance to a number of quality assurance bodies (QABs) with subsequent responsibility for assuring the quality for a defined group of TEOs. There are three QABs: ITPQ (Institutes of Technology and Polytechnics Quality), AAA (Approvals, Accreditation and Audit Group of NZQA covering PTEs, Wānanga, government training organisations and Colleges of Education), and CUAP (The Committee on University Academic Programmes of NZVCC). ITPQ and AAA have developed quality standards drawn from the general quality assurance standard (Standard one) developed by NZQA. All of the QABs also use official criteria for course approval and accreditation which are developed by the Qualifications Authority in consultation with the NZVCC and other sector bodies. Accordingly, quality assurance is diversified with special procedures attached to each category of TEOs. To ensure that the delegation of authority to and responsibility of the QABs is taken seriously, NZQA regularly monitors the activities of the QABs excluding the CUAP.

In general the procedures include requirements covering management follow-up procedures, development and review of qualifications and educational programmes, human resource management, resources and infrastructure, student information and guidance, and programme delivery. To check that standards in each area are upheld, each QAB carries out an external audit on a regular basis. The external audit committees visiting TEOs usually consist of evaluation experts from the QABs and academic experts from other TEOs. 
A TEO, independent of category, is still required to establish a quality management system aimed at continuous improvement of teaching and learning. For public institutions, the establishment of a special academic board is also required to stimulate teaching and learning within the institution. It is expected that stakeholder views, such as those of students, industry and employers are built into the quality management system.

For research, a much more simplified procedure exists through the PBRF, phased in during the latter years. This is a procedure scrutinising research quality through an indicator informed peer review process of individual researchers "best" products. These are aggregated to the institutional level determining each TEO's quality in research.

Information on the quality of the tertiary education system is provided through publicly available reports, either provided by the QAB, the Ministry of Education or the TEC through annual survey reports, usually on websites. Analysis at the system level and of system performance is reported to the media.

Currently, quality assurance is high on the agenda in New Zealand tertiary policy making. This is a result of several developments. The new steering approaches within the sector have directed attention more to the output dimension of tertiary education. Increased enrolments in tertiary education in addition have put pressure on completion rates and highlighted the dilemma between access and completion. Furthermore, internationalisation and globalisation of tertiary education in New Zealand, and the importance of the export of tertiary education to the sector and the economy, stress the need for New Zealand to be regarded as a high quality provider.

\subsection{Equity and Links to the Community}

Issues articulated around the topic of equity and links to the community are highlighted under various themes that are further developed in Section 4 of this report. They relate to demographics, documented sources that articulate policies, legislated acts such as the Treaty of Waitangi, Māori self-determination, Māori participation and leadership, and a public consciousness about the value of equity and community relations. A brief discussion of the concept and definition of Equity and Community Links is presented here to frame the discussion of how these factors are engaged within the New Zealand tertiary education system.

Equity as indicated in the 2002-07 TES would suggest that New Zealand's tertiary education system has an articulated mandate in developing all learners to their fullest capacity through education and 
training. Special attention is focused on learners who might not have had the opportunity for success due to various barriers for access to education. For example, Māori and Pasifika Peoples are some of the groups targeted for equity programming. The tertiary education sector of New Zealand is engaging in powerful and strategic leadership initiatives in redressing systemic disparities through reforms in education principles, policies and legislation.

New Zealand's tertiary education has taken proactive and positive steps to increase the participation and engagement of "designated groups" including, Māori and Pasifika Peoples, women, and people from low income situations (Ministry of Education, 2002). These principles are articulated throughout the tertiary education system's legislation, charters, profiles, policies and practices. They respond to the current New Zealand demographics and economic realities identified earlier so that its people can apply skills and knowledge "to generate economic growth and improve social outcomes" (Tertiary Education Strategy, 2002/07, Monitoring Report, p. 31).

The argument here is that equity principles and practices (including equality of education and access opportunities, linking and collaborating with community groups) embrace the presence of members of the targeted groups through tertiary education equity policy by enacting positive measures that redress historically low participation in, engagement with and achievement in the education system. As the concept of equity is applied across the dynamic aspects of enacting educational pathways across all tertiary levels it also includes acknowledging and articulating the unique position of New Zealand's obligations with the Treaty of Waitangi. By association then, the education sector is responsible to engage with these obligations arguably much like the following statement related to New Zealand's health care policy:

Partnership is a core component of the Treaty of Waitangi, the original agreement intended to protect the interests of both the original inhabitants and the incomers. The treaty has not always been honoured by the New Zealand government or pakeha, and examples of institutional and personal racism are well documented. Over the past few decades, the responsibilities of leadership have been challenged, and many steps have been taken towards redressing the lack of responsiveness to the treaty shown throughout the $19^{\text {th }}$ and $20^{\text {th }}$ centuries. Experience from other countries indicates that without the treaty New Zealand may well not have tackled much of the implicit and explicit discriminatory practice. Things are by no means perfect, and without continued effort the improvements made so far may be transitory. However, healthcare 
policy, clinical practice, and research processes are now all influenced by the treaty, and attention to the impact of ethnicity on health is growing. (Mcpherson et al., 2003)

The active intervention to equality of access and equity to educate all New Zealanders in methods to implement employment equity appears to be actively pursued, rather than treated as accidental. This proactive strategy for tertiary education appears to be valued and actualised within the various levels of the tertiary education sector. Furthermore, working with equity principles necessarily includes engaging with the community: interactively, collaboratively, and relationally with the very people that it purports to benefit. For example engaging with the leadership for Māori and Pasifika peoples has become a commonplace practice to enact differentiated and relevant education strategies according to their needs and aspirations. The links to these communities are critical to the ongoing development of all New Zealanders. The contention is, therefore, that engaging in principles and practices of equity and linking with the community does make a difference in affecting the economic, social, and employment outcomes of the designated groups and bridging relationships between all New Zealanders.

\subsection{Research, Innovation and Industry Relationships}

\subsubsection{General overview}

The role of tertiary education in research and innovation is twofold. First, the sector develops new knowledge through research and development that eventually leads to innovation within industry. Second, the sector generates trained and skilled human capital that becomes the talent pool for research and innovation activities in society.

TEOs play a key role in furthering research and innovation in New Zealand. A large share of the gross domestic expenditure on R\&D $(28.4 \%)$ is taken up by higher education, well above the OECD average of $18.7 \%$ (see Appendix 5). ${ }^{13}$ However, the total level of the Gross Domestic Expenditure on Research and Development (GERD) as a percentage of Gross Domestic Product which New Zealand set aside in 2003 was $1.16 \%$ below the OECD average of $2.24 \%$ (see Appendix 5). The TEOs also

"Higher Education" also includes research institutes, experimental stations and clinics operating under the direct control of or administered by or associated with higher education institutions. For details, see OECD (2002a). 
undertake significant efforts in adapting, transferring and diffusing domestic and international knowledge and technology.

The great majority of the research completed by TEOs in New Zealand is conducted in the universities. The universities are the largest contributor to research and innovation in New Zealand in terms of research output they are responsible for about $63 \%$ of the country's output of research papers. ${ }^{14}$ Moreover, in 2004, universities accounted for around $98 \%$ of the research income earned by the tertiary education sector (Ministry of Education, 2006, table 40). Their research income has increased significantly over the period $1997-2004$ by $126.5 \%$ (Ministry of Education, 2006, table 42).

Within the university sector, $R \& D$ performance is concentrated in a small number of universities. The top two universities in terms of R\&D are the Universities of Auckland and Otago. These universities contributed about $50 \%$ of the reported R\&D outputs in 2004. Moreover, the universities of Auckland and Otago also contributed to almost half of the growth in R\&D over the period 1994-2004. Massey University and Victoria University of Wellington contributed a further $25 \%$ to the R\&D growth.

ITPs and PTEs support their degree teaching with research activity, and some ITPs and PTEs have research programmes - primarily focused in the area of applied research. Two of the largest producers of research among the ITPs are Unitec New Zealand and the Waikato Institute of Technology.

Furthermore, the tertiary education sector plays a crucial role in developing skills and competencies which are needed to sustain a growing economy (Knight and Yorke, 2004). According to the Growth and Innovation Framework (GIF) - i.e. the national innovation strategy innovation, skills and talent are crucial to lead New Zealand towards a knowledge-based economy that can compete globally. TEOs play an important role to deliver and meet the (short-term) skill and knowledge needs of the economy. In 2002, the proportion of persons within a given age cohort obtaining an advanced research degree in New Zealand was $0.9 \%$ compared to the OECD country mean of $1.2 \%\left(14^{\text {th }}\right.$ figure out of 26 OECD countries; OECD, 2004c).

The percentage is of research papers produced over the period 2001 to 2004 and indexed in the Thomson ISI index. To put that figure in perspective, the Crown Research Institutes (CRIs) collectively produced about $23 \%$ of the total number of such research papers. 


\subsubsection{Research funding of tertiary education}

Research funding has changed significantly over the last ten years, moving towards an allocation system primarily reflecting research excellence and research quality. The introduction of performance-based funding through the Performance Based Research Fund (PBRF) and the Centres of Excellence (CoREs) are important drivers in this process. These funding mechanisms focus not only on supporting research excellence and areas of strategic capacity; they also underpin high quality and relevant teaching within the tertiary education sector.

TEOs have two types of research income. First, income through Vote: Education (the governmental budget for Education) to support TEO's core research activities and second, income from sources external to Vote: Education. The latter is intended to finance particular research projects and is known as "external research income". It can be disaggregated further into several types. First, funding provided by the government through Vote: RST (Research, Science and Technology, the governmental budget for these areas) and awarded through competitive bidding rounds. Second, funding provided by philanthropists and philanthropic organisations to foster research activities. Third, income earned by TEOs as subcontractors in large research contracts where other organisations such as the Crown institutes (CRIs) are the principal contractor. Finally, 'contract research' is another form of external research income, i.e. TEOs conduct specific research for firms or other purchasers.

Between 2000 and 2003, the allocation of the Vote:Education research funding to TEOs was based on student enrolments in degree and postgraduate level courses, with the funding for all domestic degree and postgraduate level enrolments being supplemented by a research "top-up". As of 2004, the government separated research funding from funding for teaching and learning, introducing the PBRF as the main instrument to allocate Vote:Education research funding to TEOs. The PBRF is being phased in over the period 2004 to 2007, with an increasing proportion of the research "top-up" funding being reallocated to the PBRF over that time. It is planned that by 2007 the research "top-up" system will have disappeared.

The PBRF allocates research funding according to three components. First, the quality of the research outputs produced in a TEO - assessed through a "quality evaluation". Second, the number of "research degree completions' the TEO has achieved over the three most recent years. The final performance component is the amount of external research income generated by the TEO over the two most recent years. The three components are weighted as follows: $60 \%$ for the quality evaluation assessment, $25 \%$ for 
research degree completions and $15 \%$ for external research income. Funding is then allocated amongst TEOs according to their relative performance.

The PBRF allocations are primarily a reflection of research quality. They acknowledge that the universities' role in the science and technology system is primarily one of pure basic research, and that such research has economic returns in the longer term. But there is also the strategic dimension to this funding in that the "relevance" of a TEO's research is recognised through its ability to earn external research income. Relevance of research refers to two aspects. First, it includes research with a strategic dimension; i.e. aligned with government priorities that in turn reflect national economic and social goals as mentioned earlier. Second, external research income of a TEO provides an indication that the value of the research output is perceived as relevant by industry.

In addition to the PBRF, the government allocates some Vote: Education funding in a more targeted way such as with the support for seven Centres of Excellence (CoREs). These Centres intend to establish worldclass research groups in New Zealand. They are research networks based in universities, but incorporating researchers from other TEOs and other research organisations, each focused on a field of established research capability and in areas well aligned with national priorities. The CoREs provide incentives for researchers in the tertiary education sector to conduct research of excellence, which contributes to New Zealand's development, and which provides opportunities for knowledge-transfer activities.

\subsubsection{Tertiary Education in New Zealand's innovation system}

TEOs are part of New Zealand's science and technology system or, in short, the 'innovation system'. The national innovation system consists of individuals and organisations that carry out or manage research and science activities for New Zealand. Key players include New Zealand's 15000 research staff in universities, the Crown Research Institutes (CRIs), other tertiary education organisations, hospitals, research associations and private firms.

The innovation system also includes the various government bodies that design and implement the range of legislation, regulations and policies relating to science and technology as well as those involved in the investments in science, research and development, such as the Ministry of Education, the Tertiary Education Commission, the Ministry of Research, Science and Technology and the Ministry of Agriculture and Forestry (Ministry of Research, Science and Technology, 2005, p. 16). 


\subsubsection{Policy priorities}

The period of 1995 to 2005 was dominated by new policy priorities posing new challenges for TEOs. Research priorities were aligned with the main strategies and objectives in the TES and STEP (see Section 3.3) as the Growth and Innovation Framework (GIF) was developed in parallel with the TES. The GIF is designed to deliver long-term sustainable growth to improve the quality of life of all New Zealanders. It is the overall national policy framework for economic development, and the tertiary education sector is expected to play a pivotal role in achieving its goals. ${ }^{15}$ Both the TES and the GIF share a common vision and highlight similar key themes to be advanced across the economy and, by definition, across government agencies. Both the TES and the GIF express their intentions at a high level (Webb and Grant, 2003).

Amongst the national priorities, tertiary education is to increase excellence and relevance in research, to build up research capabilities and to increase the relevance of skills and knowledge to meet national goals as stated in the GIF and the TES. Moreover, tertiary education is expected to enhance the commercial value from publicly funded research and to be instrumental in the rapid diffusion of new ideas and technologies to all sectors of the economy (Ministry of Education, 2005). In order to do so, new research funds have been introduced in support of the wider role for science, research and technology, namely the PBRF and the CoREs, as discussed earlier.

Another goal of the government for research, science and technology is to better coordinate research and innovation policy in recognition of the need for a more coherent approach across government to turn priorities into successful actions. Government's investments need to be effectively targeted and co-ordinated (Webb and Grant 2003) so as to enable the economic transformation to occur in a relevant timeframe supported by sound (macro) economic policy settings.

Finally, workforce productivity has been identified as a particular national priority area, because New Zealand's growth in the last 15 years has been primarily driven by increased labour utilisation rather than labour productivity. As further improvements in labour utilisation are limited, it is important that TEOs contribute to the development of specific (trade) skills and the broader competencies at all levels of the workforce, ultimately enhancing productivity. Weak areas in the New Zealand innovation system include low levels of senior management capacity, general skills, and persistent skills shortages.

See http://www.gif.med.govt.nz 


\subsection{Human Resource Management}

The primary responsibility for defining the terms and conditions of employment in the tertiary education sector rests with the tertiary education institutions. They negotiate human resource policies with staff representatives. Aspects covered include recruitment and appointments; performance and career management; professional development; research and teaching obligations; leave entitlements; remuneration; and consultation with staff representatives. There is no such thing as a career structure at the national level. The agreed arrangements at the institutional level need to comply with the Employment Relations Act of 2000 and the State Sector Act of 1988, which make the institutions' chief executive the formal employer of staff. While in the 1990s many institutions offered individual employment contracts to their staff, most public institutions have now moved to institutional collective agreements. Some staff associations have been calling for multi-institution collective agreements but only one such agreement currently exists among six ITPs.

Despite this decentralised approach many of the broad features of the academic career structure are shared among institutions. For example, there is a reasonably shared approach to the nomenclature used to describe staff positions. In broad terms, the titles 'professor', 'associate professor', 'senior lecturer' and 'lecturer' reflect the different stages of the academic career in Universities. Criteria for promotion of academic staff are typically based on 'sustained competence' in three areas: 'teaching, assessment and curriculum development', 'research and/or professional practice and scholarship activities' and in 'service to the University and the community' (taking the particular example of the University of Otago which is broadly representative of the University sector). Academic staff apply for promotion when they feel they meet the requirements for the new category - they do not need a vacancy at a higher level to move up.

In 2004, public tertiary education institutions employed about 29000 full-time-equivalent (FTE) staff, compared with about 22000 in 1997 -- a $32 \%$ increase which contrasts with a rise of around $60 \%$ in the number of EFTS over the same period. These figures vary between different types of institutions. For example, in the universities over that period FTE staff numbers grew by $26 \%$ while EFTS rose by $25 \%$. In 2004, $62 \%$ of FTE staff in public institutions was based in Universities, $28.5 \%$ in ITPs, $6.7 \%$ in Wānanga and 2.8\% in Colleges of Education. In 2004, academic FTE staff constituted $45 \%$ of total FTE staff in Universities and Wānanga while that figure stood at around 53\% in ITPs and Colleges of Education. The ratio of EFTS to academic FTE staff increased from 14.6 in 1997 to 19.3 in 2003 for public tertiary institutions (from 15.3 to 15.8 in Universities, from 14.0 to 
21.4 in ITPs and from 17.4 (in 2000) to 48.2 in Wānanga), the extent of change being mostly driven by shifts in delivery approach in ITPs and Wānanga.

Academic FTE staff has been falling as a proportion of total FTE staff in public institutions - from 53\% to $48 \%$ in 2004. In 2004, the majority (64\%) of academic staff in public institutions were employed on a full-time basis. In the same year, for public institutions, while women accounted for $58 \%$ of the total staff, men accounted for the majority (52\%) of academic staff. Women were also under-represented among the senior academic positions in Universities and Wānanga -- in the universities in 2003, around 14\% of the professors and $17 \%$ of the associate professors were women.

Expenditure on staffing is the largest budget item for public tertiary education institutions, having remained relatively constant between 1997 and 2004 - at around 59\% in Universities, 54\% in ITPs and $41 \%$ in Wānanga. Staffing expenditure per FTE increased by 35\% between 1997 and 2004 while the consumer price index increased $14.4 \%$ over the same period.

\subsection{Links to the Labour Market}

Today, the New Zealand labour market, when set against that of other OECD countries, is set apart by four major characteristics (OECD, 2006):

- Very high labour force participation rate (in 2004, $73.5 \%$ of individuals aged between 15 and 64 were in employment, the fifth highest figure among OECD countries).

- A high proportion of self-employed as a percentage of total civilian employment $\left(19.2 \%\right.$ in $2004,6^{\text {th }}$ highest share among the 24 OECD countries for which data are available).

- Long working hours (in 2004, the average person in employment worked 1826 hours in a year, the $8^{\text {th }}$ highest figure among the 26 OECD countries for which data are available).

- Very low unemployment rates $\left(3.9 \%\right.$ in 2004 , the $2^{\text {nd }}$ lowest figure in the OECD area).

The New Zealand labour market has relatively few large employers. The dominant feature of the pattern of enterprise structure is the large number of small and medium-sized businesses, which shapes both the nature of the labour market for graduates and the ways in which much research and development takes place and is funded. The labour market is heated. There 
is a strong and continuing demand for skilled labour, unemployment is at a 20 year low, and concerns have been expressed at skill and labour shortages.

In relation to the tertiary education sector, despite the fact that through further massification of the system increasing numbers of graduates leave the TEOs, demand remains strong. Unemployment rates have significantly decreased regardless of the level of qualification of individuals. The wage premia for tertiary graduates have also been relatively constant over recent years. Various studies have shown that there is a significant correlation between educational attainment and annual income, which has been a powerful support for the government's policy of cost sharing.

As to the international dimension of the labour market and its apparent tensions, there is little evidence of brain drain in New Zealand. Studies indicate that brain exchange would be a more appropriate descriptor. Yet, a series of policy initiatives have been launched and implemented to stimulate graduates to stay within the country, interest-free loans for those who stay being one of the most prominent and visible instruments, and to attract high achieving international students through the provision of fellowships, scholarships and more liberal immigration policies.

The articulation between the tertiary education system and the labour market is made essentially at three levels. First, there is an explicit policy objective of ensuring that tertiary educational offerings are relevant to the labour market. This is reflected in the current TES which establishes the requirement for TEOs to achieve a match between their provision of tertiary education programmes and: (i) the requirements of employers and industries; (ii) current skill needs at the national, regional and local level; and (iii) the need to equip all New Zealanders with the foundation skills they require for employment. This requirement is supported by the priorities articulated in the STEP which the TEC gives effect to through the annual funding negotiation with TEOs.

Second, partnerships between institutions and employers are encouraged. The institutional charters and profiles are used to encourage engagement between TEOs and their stakeholders, including the business community. These include internship opportunities for students and teachers in industry, the contribution of professionals from industry to the delivery of programmes in institutions, the participation of representatives of employers and businesses in governing bodies of institutions, and the participation of relevant industrial and professional communities in curriculum development. The TEC also administers specialised initiatives such as the ITP Business Links Fund or the Partnerships for Excellence programmes to strengthen the ties between TEOs and the business community. 
Third, ample information about tertiary education offerings and labour market outcomes is produced and made available to students, employers, institutions and policy makers. This is complemented with advice and guidance on careers to students. Career Services supports tertiary education by providing services to help students make informed career choices. These services include the provision of labour market information (e.g. job profiles and industry outlooks) and tertiary and trade training information. NZQA provides information about qualifications and the quality of institutions. The New Zealand Register of Quality Assured Qualifications provides a comprehensive list of all quality assured qualifications in New Zealand. In addition, most institutions offer specialised career guidance to students and conduct surveys of graduates to inform the organisation of their programmes. All institutions are expected to have a student information policy. The Department of Labour collects and analyses information about the skills needed in the labour market and about how the tertiary education system interacts with the labour market. Using this information with that from other sources, the TEC produces annual "portraits" of tertiary education and training in New Zealand, including indicators of possible under- and over-supply in provision.

\subsection{Internationalisation}

Although New Zealand can be characterised as a very international oriented country, a more systematic focus on internationalisation of tertiary education is a rather new feature starting in the late 1980s. Currently, the Educational Act 1989 allows TEOs to charge international students full fees to cover the costs of their study. The use of public funding to subsidise the cost of international student is prohibited.

During the latter years, it is the export dimension of internationalisation that has been brought to the fore. From 1999 to 2004 the number of full-fee paying international students in New Zealand increased by $263 \%$ from around 31000 students to 113000 . However, about $40 \%$ of the foreign students in 2004 were enrolled in English language schools - PTEs specialising in such offerings.

Export of tertiary education services is of growing importance for the financial viability of tertiary institutions, and much of the improvement, especially in public institutions during the last years has been associated with a rapid rise in international student numbers.

Policy developments in New Zealand have emphasised both the extrinsic and intrinsic aspects of internationalisation. The establishment of Education New Zealand, a national coordinating body for the marketing and 
profiling of New Zealand as a tertiary education provider in the international market, and the use of offshore educational counsellors to build and strengthen international partnerships, are examples of national and institutional policy responses intended to support the extrinsic aspects of internationalisation. Policy developments with a more intrinsic focus have been to establish a Code of Practice for the Pastoral care of International Students, assisting TEOs in developing adequate models for setting up and delivering international education, and protecting the interests of international students (e.g. PTEs required to have adequate protection for students in the event of a closure).

At the institutional level, internationalisation currently is a key area in missions and future strategies. Although a relatively new phenomenon, internationalisation appears well integrated in the activities and daily work of the TEOs. In several of the TEOs visited by the Review Team, ambitious plans and initiatives for future development in this area could be identified. 



\section{Strengths and Challenges of Tertiary Education Policy}

\subsection{Introduction}

Having provided a basic description of the main features of the tertiary education system and the national policy context in the previous Section, in this Section these aspects are further analysed and discussed. Whilst Section 3 predominantly was based on the background information provided to the visiting team by our hosts, Section 4 incorporates the discussions the team has had with the vast number of stakeholders it met during its visit. It also reflects the many discussions and debates amongst the members of the Review Team.

Section 4 is structured along the same format as Section 3. We thus begin by discussing the strengths and challenges that the team considers to be characteristics of the governance, steering and planning arrangements currently in place in New Zealand. This is followed by our observations on the funding of the system, the quality assurance mechanisms in place, the way equity issues and the links with the community are addressed, the functioning of the innovation and research system and its relationships with industry, the way in which human resource management is handled, the relationships between tertiary education and the labour market, as well as the international dimension of tertiary education in New Zealand.

Again it needs to be emphasised that the observations made are those of the team. We believe we have, through the comprehensive documentation provided to us combined with the extensive discussions we have had with all of those occupying a particular place in New Zealand's tertiary education system, obtained as good an insight as an outsider may get. Yet it always will remain an outsiders' perspective. However well prepared any team enters into an exercise like this, some of the local idiosyncrasies remain difficult to grasp. But a certain 'foreignness' also allows for the opportunity to provide a mirror based on collective insights and comparative experiences and reflections. It is this mirror function we hope the next paragraphs will serve. 


\subsection{Governance, Steering and Planning}

Without any doubt the major strength of the policy framework within which tertiary education operates is the set of clearly stated objectives at the national level. There is an obvious alignment of the tertiary education sector with the country's objectives. And the team has noted that there is a definite realization of this within the TEOs.

A second major feature is the recognition of the need for diversity and the associated differentiation of roles and functions within the system. Whilst tendencies for 'academic drift' can be observed - as is the case in any tertiary education system that has distinct sectors and institutional types - by and large TEOs as well as government agencies appear extremely conscious of what their particular function in the larger picture of New Zealand's tertiary education system is. This is no mean achievement and should not be underplayed nor undervalued. It can be observed that systemic and institutional diversity is reflected in the institutional governance structures of the TEOs, including the representation of external stakeholders and their influence on the identity of the institutions they govern.

Certainly from a tertiary education policy analytical perspective, the concept of the TES-STEP-Charter-Profile string is fascinating. Not only does it provide the opportunity for systemic coordination, the articulation of national priorities into institutional priorities and - something we consider to be of profound value - the possibility to translate and relate this to the fundamental concept of systemic and institutional diversity. Both charters and profiles appear well-suited instruments within the dynamic policy environment characteristic of New Zealand.

This important feature is reflected in the very observable intention of the actors engaged in steering the system to interact with each other, and to communicate across agencies and sectors. Clearly the size of the system facilitates this. The New Zealand tertiary education policy network is small, with people knowing each other well and meeting in various (policy) settings on a more than regular basis. The tertiary education policy network thus is a dense one, with many links and lines between the actors. A noticeable exception appears to be the position of the PTEs in this network. To the outsider they seem less part of and integrated in this network.

A fifth feature of strength, and an important one on all international comparators, is the focus on institutional autonomy. TEOs appear to be granted substantive autonomy - and responsibility - when it comes to managing their own affairs. Human Resource structures are left to individual institutions, financial regimes appear flexible allowing institutions to indeed operate on and in markets, and buildings and properties are owned by the 
institutions, thus cutting them a fair bit of economic space in which to move, though again not without responsibilities.

Finally, there appears to be an emerging set of policy indicators and information to underpin the government's move to re-enter the steering arena. Clearly, there still is a way to go - recognised by the actors and agencies involved - but again the size of the system facilitates such an approach.

At the same time, many of the strengths in terms of governance, steering and planning also contain elements of weakness and pose major challenges.

The intention to align the tertiary education sector with the overarching national goals and objectives is commendable. Yet we are left with the distinct impression that there has been some underestimation of what it takes at the agency level to effectively and efficiently engage in steering vis-à-vis the tertiary education sector. A number of factors appear to be at play in this respect.

First, tertiary education sectors over the world are characterised by a high degree of intelligence. Because of the intelligence of its constituent parts they are not easy to steer. Crude measures do not work and even the more sophisticated instruments run the risk of being perverted or used for other purposes than those intended. Tertiary education systems inherently are complex and resilient, which makes steering a daunting task.

One response - again witnessed in a fair number of countries - is to exercise government control, based on the false presumption that what is regulated for will shape reality. Compliance is not synonymous with achieving nationally set goals and objectives as compliance often remains at the surface level of policy and institutional action. Moreover, this approach to control runs contrary to the flexibility and adaptivity required of today's TEOs.

This in turn highlights the importance of communication and dialogue. Small systems offer much in this respect, for distances - real and symbolic are limited. But it also becomes easy to move from substantive dialogue to 'going through the motions', to avoid confrontation because of past alliances, and to stay within the old boys network.

Charters and profiles have a vast potential to become policy instruments that really impact on achieving national goals and objectives, and on the concept of institutional diversity that underpins this notion. But for this to be realized, they need to be used in a creative and open manner, as the centre point of policy debate and negotiation between government, its agency (TEC) and the TEOs. Current practices with the charter and profiles raise doubt as to whether they are used to their fullest potential, as the overall 
process does appear to emanate a certain "barrenness": process seems to prevail over content. This is an obvious, but also easy comment to make from the outside. Capacity at the agency level obviously is an issue, and it is recognised that TEC itself still is in an evolutionary state. Signals received clearly indicate that the tertiary sector would welcome a content debate on goals, objectives, charters and profiles. But at the same time it is not as obvious that actors within the sector are fully prepared and equipped to engage in such a content debate. In theory, dialogue could well become the dominant mode of steering given the structures put in place combined with the assumptions underlying them. But the system needs to mature as all involved seem to realize and acknowledge.

Should this dialogue take off and translate in diversified charters and profiles - which indeed would be a truly major achievement - this poses challenges for the funding framework as it needs to reflect diversity rather than homogeneity. It would also challenge some of the legal requirements such as research being a necessary condition for offering and awarding degree programmes, in particular at the bachelor level. We will return to these issues in Section 5.

\subsection{Funding the System}

The approach to tertiary education funding in New Zealand is highly commendable in a number of ways. The principle of cost sharing is appropriate and has gained considerable acceptance among stakeholders. In light of the firm evidence of the private benefits of a degree, graduates should bear some of the cost of tertiary education. The relative financial private benefits from some types of tertiary education are significant in New Zealand. In 2003, earnings of individuals with a tertiary-type A degree exceeded those of individuals with an upper-secondary education degree by 50\% (see Appendix 5). Cost-sharing also allowed the system to continue expand with no apparent sacrifice to quality -- expenditure per EFTS increased on average 10.6\% in public institutions from 1997 to 2004 -- at a time when other priorities such as pensions, medical care, or combating social exclusion exert pressure on the education budget. Another benefit is that institutions become less reliant on taxpayer money and are able, within certain limits, to raise their own funds. Having students contribute to the costs of their education, in theory also makes institutions more responsive to the preferences and needs of students. Finally, cost sharing provides savings to the government, which can help broadening access to tertiary education for previously underrepresented groups.

Another merit of the current funding approach is the principle of allocating funds on the basis of relevance to society at large. In ideal terms 
this would translate into: $(i)$ the public funding of any educational activity, irrespective of the nature of the provider, which brings benefits to society; and (ii) levels of public funding which reflect the magnitude of societal benefits relative to private benefits. Given the difficulty to measure the societal and private benefits of educational activities, in practice, this principle is implemented, quite appropriately, as follows: (i) a wide range of educational activities receive public funding (e.g. pre-school, school, foundation education, tertiary education, industry training, adult and community education, postgraduate qualifications) with proportions of public funding attempting to reflect the significance of public versus private benefits; (ii) public funding is allocated to private institutions whose educational offerings generate societal benefits; and (iii) the Assessment of Strategic Relevance is used to authorise offerings which are in accordance with the mission and profile of the institution - e.g. by identifying those offerings that better reflect the regional priorities of the institution.

The allocation of public funds on the basis of relevance is a courageous measure by New Zealand authorities given the multiple challenges its implementation raises. This was well exposed by the effects of the 1999 decision to fund PTEs on the same basis as public institutions. Whilst this broadening of public funding benefited a large number of students from traditionally under-represented groups who were enrolled at PTEs, and whilst it extended public funding to niche areas covered by PTEs, there is a general view that in some cases public funding was going to courses which seemed to be of low value, or of less relevance, or where the level of funding appeared very high in relation to the costs of course provision. This resulted from a lack of instruments in place to assess course relevance and the insufficient mechanisms to assure the quality of the provision. Recognising this, from 2003 onwards, the government has undertaken a series of policy changes to control growth in areas of concern and to realign provision to strategic goals, particularly at the sub-degree certificate and diploma levels. The current Statement of Tertiary Education Priorities underpins these changes, by signalling the government's intent over 2005 to 2007 to shift funding away from provision that does not contribute to national goals.

Positive features also can be found in the institutional funding setting. First, there is considerable transparency in institutional allocations - the criteria for the distribution of funds typically are clear to all involved. Core funds are distributed on the basis of a formula or through competition. Second, these funds are delivered directly to institutions as a lump sum and institutions decide on their internal allocation of resources. This provides institutions with flexibility and autonomy. Third, the Strategic Development Component is instrumental in aligning objectives of particular institutions 
with the Tertiary Education Strategy. It targets particular needs such as facilitating access of underrepresented groups (through a premium in the funding formula for students with a particular background -- e.g. Māori and Pasifika students, students with disabilities), fostering the engagement between institutions and businesses (e.g. the ITP Business Links Fund, the Partnerships for Excellence, the Innovation Development Fund), or improving the relevance of offerings (e.g. the Quality Reinvestment Programme which supports ITPs and Wānanga in aligning their certificate and diploma courses with the STEP and the TES). Another positive trend has been the growing diversity of funding sources, though from an institutional perspective this will always remain a moot point (the proportion of income derived from government revenue has gone down from 52 to 39\% in Universities and from 64 to 60\% in ITPs over the period 1997-2004). Yet, there is no denying the fact that a diversity of income streams makes an institution less dependent on one particular paymaster, be it government or the international student.

Current fee stabilisation policies are appropriate to ensure cost containment and moderation. This minimises the effects of institutional pricing strategies in a situation where student's entitlement to financial aid is tied with the total costs of attendance (the risk being that institutions continue to raise their fees if more financial aid becomes available to students). The FCCM policy while precluding excessive fee escalation, still grants institutions some room for raising their own funds.

The student finance system in New Zealand is exemplary in many ways. First, it facilitates access by reducing liquidity constraints faced by students. The mixed system of allowances and loans assists students in covering living costs, alleviating excessive hours spent on part-time work, or disproportionate reliance on family support. Other than the loans provided to cover tuition fees, students are entitled to borrow up to NZ\$150 per week for living costs. This is abated for students who receive a student allowance. The rate of student allowance depends on the student's circumstances; a single student under 25 living with his or her parents received NZ\$116 per week and hence, could borrow up to NZ\$34 a week. However, during the review visit, many students expressed concern that such amounts were not sufficient to cover realistic costs of living, in particular in areas such as Auckland and Wellington. A positive feature is that the student aid system is universal as all students are entitled to financial support - the Student Loan Scheme is not means-tested. Also, quite appropriately, there is a ceiling on the amount available for borrowing every year and a limit on the number of weeks a student can receive a student allowance.

The income-contingent nature of the loans system addresses the risk and uncertainty faced by individuals and improves the progressiveness of the 
overall system. In such a system graduates make monthly repayments in relation to their earnings for a limited period of time. As a result, low earners make low or no repayments and graduates with low lifetime earnings end up not repaying their loans in full. Income-contingent loans protect borrowers from excessive risk as they provide insurance against inability to repay. They also make the system more progressive. Those individuals who derive greater private benefits from a tertiary degree see the level of their public subsidy reduced vis-à-vis that of other students.

The student allowance system promotes the access of those with greater financial need but also those who are more risk averse as a result of a socioeconomic disadvantage. Particularly vulnerable to debt aversion are students who underestimate the benefits of tertiary education and/or overestimate the costs as a result of a disadvantaged background. This is more likely to occur when they live in a low-income family, when parents have low education levels, when the information from which they benefit is poor or when they have fewer school opportunities. The targeted nature of student allowances promotes access by more vulnerable groups.

Students who attend private institutions benefit, quite appropriately, under the same conditions, from the same basic financial support to cover living costs and tuition fees. This clearly facilitates students' freedom of choice and enables diversity of provision through institutions that have distinct approaches and purposes. Also, the current liberal eligibility rules of the loans system allows for the expansion of lifelong learning opportunities by granting mature students access to financial aid for further studies on a full-time basis. The recently introduced incentive to stay in New Zealand after the completion of studies - interest not charged on loans during the repayment period - seems suitable to encourage graduates to enter the labour market in New Zealand.

Despite the overall proper framework for funding tertiary education, New Zealand policy makers are still faced with some important challenges. A major issue is the lack of alignment between the Student Component of government subsidies to institutions with the goals and objectives of the tertiary education strategy. The funding basis - number of EFTS -encourages institutions to favour quantity of enrolments over quality of courses. This provides institutions with the incentive to deliver courses in ways that minimise expenditure (by cutting back quality). Furthermore, it leads to a tension between being financially viable -- by enrolling as many students as possible in courses of high demand - and maintaining identity by offering courses aligned with their profile. The government has signalled its intention to move the Student Component of the funding framework towards greater alignment with the goals of the Tertiary Education Strategy. As signalled earlier, other components and tools of the funding framework 
(e.g. Strategic Development Component, Assessment of Strategic Relevance) already reflect such approach.

A couple of aspects cast doubt on possible distortions to competition in the tertiary education sector. On the one hand, PTEs seem to concentrate on courses where margins for profit are higher (i.e. the public subsidy is generous relative to the actual cost of provision) given that no requirements exist regarding the range of their offerings. This is possibly the result of the intention of the government to keep PTEs operating in niche areas not covered by public providers. During the review visit some public providers, in particular ITPs, expressed their discomfort over the terms of competition with PTEs in light of the fact that they had to cover a wider range of fields, often in not so "profitable" areas. On the other hand, there are no restrictions on the proportion of international students who can enrol in institutions, the result of which is the deliberate strategy of some institutions to considerably raise their income through international fees with a subsequent crosssubsidisation of other activities but possibly with some sacrifice of instructional quality.

Two other aspects make the administration of institutions more challenging. First, funding decisions are made annually when the profile is negotiated between the institution and the TEC. This leads to a lack of predictability of funding which causes difficulties for the long term planning of institutions. Second, some institutions also raised the issue of whether part-time students are funded at appropriate levels. In particular, those institutions with an important proportion of part-time students (e.g. ITPs) indicated that fixed-costs such as laboratories, libraries or equipment were not fairly covered.

The student support system is reaching maturity and is seen as a fundamental part of the overall funding system. In 2002, it accounted for about $44 \%$ of total public expenditure on tertiary education $(13.3 \%$ in grants and $30.9 \%$ in loans), the highest percentage in the OECD area (see Appendix 5). ${ }^{16}$ Some of its features, however, still raise questions. First, as described earlier, both the living costs loan entitlement and the maximum student allowance seem too low to effectively fully remove liquidity constraints on students. Second, the rationale for providing a non-meanstested loan subsidy is not clear. Third, granting a student the possibility of borrowing funds from the Loan Scheme for an unlimited number of years

Of the student loan money, roughly $61 \%$ is paid directly to tertiary education organisations by way of borrowing to cover tuition fees. Adjusting for this, the split between funding for institutions and funding for student support shifts from $56: 44$ to $75: 25$. 
without being charged an interest is questionable. Fourth, in a country where children become fairly independent from their parents around their late teens, the age threshold at which parents' income is taken into account for allowances' eligibility seems too high. And finally, it is surprising that student financial aid does not take into account the considerable differences in the cost of living across regions and cities.

\subsection{Quality Assurance}

In many OECD countries there often is a lack of coherence between the governance approach towards tertiary education and the existing national systems of quality assurance. A clear strength within the New Zealand system is that the emphasis on institutional autonomy for years has been followed up through an audit procedure making institutional leadership primarily responsible for the quality of teaching and learning. By emphasising the responsibility TEOs have in establishing well-functioning systems for quality assurance, quality assurance not only becomes a governmental check-point for the efficiency and effectiveness of the sector, but also an instrument for change and renewal for the institutional leadership.

The existing qualifications framework in New Zealand can also be considered a strength of the system. Acknowledging that most of the expansion in tertiary education in recent years has taken place at the certificate and diploma level of study, and acknowledging the increase of part-time and mature students in tertiary education, with an increase in more flexible study programmes, there undoubtedly is a need for an instrument recognising the various qualifications that may be achieved. For students, this system also provides a "bridging" possibility to further studies at various levels.

A third noticeable strength in the system is the high awareness of quality as an essential dimension at the institutional level. Although there are some mixed views on the relevance of the various procedures and evaluations conducted nationally, the academic leadership, staff and students at the TEOs demonstrate a high level of agreement on the need for continuous attention and work related to keeping up and improving academic standards. Perhaps an effect of the long-term national emphasis on quality assurance (see Section 3.5), one can notice a strong quality culture in many TEOs. At the institutions visited such quality cultures were often embodied in staff commitment to teaching and learning, their attention towards student needs, and their ambitions on the further development of study programmes. 
Still, one can also identify some challenges with respect to quality assurance. First, the current system of quality assurance, as seen from a system perspective, is very complex providing little transparency and accountability to the New Zealand society. The fact that there are so many QABs, with various tasks and procedures results in little oversight from an outside perspective. The many quality standards developed for each category of TEOs, and the lack of a more unified approach in how to disseminate information and knowledge on quality to external stakeholders are the two most pressing issues in this respect. For those knowing the system, NZQA, the Ministry and the TEC, the current system is more understandable, but for other external stakeholders (e.g. future students and employers), the current system is less transparent. Although the qualifications framework has created some transparency with respect to expected learning outcomes and qualification levels, qualifications frameworks still have limitations with respect to quality assurance and how quality is maintained in practice (McInnis, 2005).

The complexity of the current system of quality assurance also produces two unwanted side effects. An important point is that the transaction costs in the current system are considerable. In several of the institutions visited, it was reported that external demands concerning quality assurance should be better integrated with on-going internal work related to quality assurance. An often-reported effect of the current system is that the existing quality assurance actually can be divided into an "external" and an "internal" dimension. The external dimension is more related to the reporting and complying to $\mathrm{QAB}$ demands and requirements. The internal dimension is related to objectives to realise academic ambitions, linked to institutional charters and profiles required under the new TES. The argument about relative high transaction costs also goes for the whole organisation of quality assurance. The many QABs, the need to follow up on their activities, and the need to coordinate their actions are resource demanding and take attention away from the primary objective: securing and enhancing quality in the TEOs.

Another side effect of the current quality assurance system is that learning within the system is not enhanced due to the high numbers of bodies responsible (QABs), and the separation of quality assurance according to institutional type (universities, colleges of education, PTEs, etc.). Although the QABs are in the process of improving their coordination and collaboration, and with evidence emerging as to the positive learning effects of such collaboration among the QABs, learning across organisational borders is not a dominant feature in the current system. The new national teaching and learning centre which is being set up, can illustrate the need to enhance learning across organisational borders, but one 
could also argue that such learning should be stimulated within quality assurance. To identify and spread good practice is essential for organisational learning, but the possibilities for TEOs to pick up on new practices and innovations, today seems to be more limited.

A related challenge with respect to quality assurance is the impression that institutions seem to gain little extra value from the current audit system. Although the audit system was a milestone and an innovation when introduced, the continuous development of this system seems to be lacking. If one considers national systems for quality assurance as part of the national governance of the sector, one can also question to what extent the current audit system is adjusted to the new tertiary education strategy, and the more "tailor-made" governmental approach that can be identified in the governance of the sector. The result is that quality assurance is in danger of becoming a somewhat isolated activity in the system.

In relation to the size of the country, there is a relatively high number of TEOs in New Zealand. Especially with respect to PTEs, New Zealand is a rather special case. One can identify a capacity problem within the system: the number of TEOs triggers a focus on formal requirements and procedures without having the time and resources to undertake in-depth analysis of institutional performance and output quality. With respect to the size and resources of some PTEs, one could also question their capacity to maintain quality standards if they experience problems related to staff mobility and student recruitment. Hence, the level of quality in some PTEs is highly dependent that 'business is conducted as usual'.

The PBRF can be considered rather well functioning (see also Section 4.6). The emphasis on in-depth analysis of research conducted at the individual level through an informed peer review process is sensible and has gained legitimacy within the sector. However, while the current procedure is strongly focused on outcomes i.e., research quality per se, it also is a procedure that is less relevant for those at the institutional level interested in developing their research activities from a more organisational and institutional point of view. Thus, while the PBRF provides knowledge on quality, it provides much less knowledge on the processes and features leading to quality. Issues related to organisational learning can, therefore, again be emphasised as a problematic area. Given the resources that are used on the PBRF, one could ask whether the present arrangement should not also contribute to enhancing institutional learning as regards the organisation and management of research. 


\subsection{Equity and Links to the Community}

The TES establishes an articulated mandate to develop the tertiary system in such a way that equity goals are achieved. Special attention is focused on learners who might have not had the opportunity for success due to various barriers for access to education. The focus is not only on building equity in terms of patterns of participation, but also on promoting social mobility through tertiary education.

The overall levels of participation in tertiary education are among the highest within the OECD area - in 2002, 6.3\% of all persons aged 15 and over were enrolled in tertiary programmes, the fifth highest figure among the OECD countries for which data are available (see Appendix 5). In 2003, about $80 \%$ of persons of a synthetic age cohort could expect to enter a certain level of tertiary education at one point during their lives (the second highest figure within the OECD area, see Appendix 5).

The review visit and the documentation examined highlighted a number of themes that could be linked to the principle of equity and community links. Each theme is highlighted followed by a brief discussion regarding emergent strengths and challenges.

\subsubsection{Articulation of objectives and awareness}

The diversity of New Zealand's people is highly articulated throughout many of the documents, particularly as they relate to participation rates of various groups within tertiary education. The recognition of the variety of cultures that exist in New Zealand is acknowledged throughout documents and from the voices of the institutional visits. A strong awareness of who is participating in education at the various levels and the well-stated demographic profiles of all learners, are important to meet the needs of learners and to understand what are the future needs and aspirations of New Zealand. The documents demonstrate how learners have grown with the system and having documented information will help with future planning.

There is a prolific production of documents that articulates New Zealand's tertiary education sector in a comprehensive coverage of national development goals, inclusive of the tertiary education strategy, charter and profile guidelines, monitoring reports, a discussion on excellence, relevance and access, learner profiles and trends, and relationships/links to the Māori population. These publications are available to the stakeholders at all levels. Equity and access are clearly articulated values within the documents. For example four of the six strategies articulated for tertiary education are related to issues of equity and access. Specifically these are: 1) Strategy one: 
Strengthen system capability and quality for our knowledge society, 2) Strategy two: Contribute to achieving Māori development aspirations, 3) Strategy three: Raise foundation skills so that all people can participate in our knowledge society, and 4) Strategy five: Educate for Pacific Peoples' development and success. Institutional documents that were distributed to the Review Team clearly articulated the strategies for Māori and Pasifika Peoples' participation and leadership in tertiary education. Discussions with participants also demonstrated their awareness of and engagement with the various documents to help them with their respective institutional equity principles, policies and design inclusion. It is difficult to identify a major weakness with the documentation other than asking the question: Are these documents understood by all who need to be informed from which effective planning can take place?

The TES has identified four specific groups where increasing participation in the tertiary sector is of key concern: Māori students (at degree level and higher), Pasifika students, students with a disability and students from lower socio-economic backgrounds moving from school to tertiary education.

\subsubsection{Dominance and value of Māori participation and leadership in tertiary education}

It is clear that one of the greatest strengths of equity principles in action is the high level of engagement that the Māori people have had within tertiary education over the last fifteen years. ${ }^{17}$ The high profile of documented information regarding Māori participation in the tertiary sector is a positive attribute to developing access, equity, and Māori needs and aspirations. Given the nature of New Zealand with its people from precontact to current realities of the country demographics and history anchored in the Treaty of Waitangi, coupled with the advocated determination of the Māori People to govern themselves, it is not surprising that current tertiary education documents include strong, proactive and engaging statements that speak to equity, Māori leadership and mutual collaborations for building human capacity, albeit from different cultural/linguistic perspectives. One example of such a statement is taken from a brochure published by the National Māori Tertiary Students' Association:

By legislating Te Tiriti $O$ Waitangi in the Education Act tertiary education institutions will become more accountable to Māori and vice versa. Institutions will then be run in a Treaty based ethnic group in New Zealand - 23.6\% in 2004 against a country average of $14.3 \%$. 
partnership. Māori will be included in all major decision making processes. Māori will be involved in course planning and development. Māori will hold positions of power within institutions. Most importantly, institutions will operate in acknowledgement of Aotearoa [New Zealand] as a bicultural nation.

The high profile of Māori Peoples is heavily documented in other publications, all of which address aspects of treaty obligations, Māori selfdetermination, language and cultural restoration and maintenance, Māori leadership in educational needs and aspirations, and the development of Māori led and inspired educational institutions such as the Wānangas. ${ }^{18}$ Partnerships between Māori groups and institutions are seen as valid and important to the economic and socio-cultural development of Aotearoa [New Zealand]. The high profile of how the Māori language, culture and artistic expressions are articulated in various documents, public events and public places is a proactive and positive contribution to New Zealand. Equity principles clearly operate in that previously excluded aspects of Māori lifeways are now manifested within the tertiary education system. Māori based, developed and controlled Wānangas are in place, grounded in Māori philosophies, stories, culture, language, and history. Other aspects of New Zealand lifeworlds take in Māori determined planning and design of their own institutions. Practices abound in tertiary education and other related disciplines that speak to this trend of self-determination that necessarily includes principles of equity. One example is taken from Harmsworth (2002):

One of the best responses to globalisation pressures is for indigenous peoples to take control of their own lives and destiny through some form of strategic direction...that can be used as a pathway to empowerment, less dependency, and more active engagement and participation in planning, policy and research. A strategy for sustainable development, with a focus on building human and social capacity in areas such as education and research, provides one mechanism for empowerment. Māori Sustainable Development in Aotearoa-New Zealand is a term reflecting the aspirations of contemporary Māori. It describes holistic development and a strategic direction towards advancement and

There is a growing Māori education stream with semi-independent status. At the pre-school level, there are kohanga reo and there are also kura kaupapa Māori, schools that teach in te reo Māori and that teach with Māori pedagogy as its base. This has led to the creation of Wānanga, indigenous tertiary education institutions. There are three Wānanga recognised as public tertiary education institutions, while a number of iwi (tribal) groups have established PTEs. 
Māori self-determination...providing a pathway toward cultural revitalisation, resilience, and the building of human and social capacity...(p. 2)

These words are echoed in the many documents and voices of Māori Peoples' needs and aspirations in tertiary education. The identification of Māori leadership in the tertiary education system is powerful as there are Māori people in high profile positions who are taking strong leadership roles to enact Māori advancement and participation. The need for differentiated planning is recognised within the tertiary education system. Māori are influencing not only tertiary education in New Zealand, they also are influencing indigenous education needs and aspirations of indigenous peoples from places like Hawaii and Canada: a powerful contribution to the international engagement of New Zealand.

The one challenge shared here is that of the danger of developing from only one perspective and of not valuing the other parts of what life has to offer in Aotearoa for all its citizens.

\subsubsection{Pasifika Peoples}

Many of the needs and aspirations that the Māori hold dear are unlikely to be attained for the Pasifika Peoples in the immersed and sustained way that the Māori are able to engage. ${ }^{19}$ The reason for this is that the Pasifika Peoples are settlers/incomers to New Zealand from various historic immigration circumstances where they have been resident from a few years to a few generations. The situation is similar to the Māori in that the Pasifika Peoples are under-represented at degree and post-degree levels, have lower tertiary completion rates, and have a higher proportion of students who leave school with low or no qualifications. The Pasifika Peoples face much of the same barriers to tertiary education as do the Māori. Efforts at increasing their participation and leadership in the tertiary education system are apparent through public documents and through programmes targeted for their needs in various institutions. Pasifika peoples are the third fastest growing group of tertiary education students (behind Asian and Māori students) and in order that they succeed at all levels and not just at the lower educational levels, equity and access programmes must prevail. against a country average of $14.3 \%$ ) but not to the same extent as Māori. 


\subsubsection{Other achievements and concerns}

New Zealand has been successful in improving the geographical accessibility to tertiary education. In particular many PTEs, which developed to complement the provision of the public sector, were established outside the main urban areas. Also, in recent years TEIs have moved away from focussing all of their provision on 'home' campuses. Distributed access to learning using flexible or electronic delivery has expanded.

Another positive feature are the opportunities offered to adults to undertake tertiary studies. The provision for the admission on the basis of non-formal training (the recognition of non-credentialed prior learning, part of the National Qualifications Framework assessment model) and the access to the student support system for individuals of all ages has greatly benefited the participation of adults in tertiary education. The average age of tertiary students has increased from 27.6 years in 1994 to 30.9 years in 2003.

There is some indication that socio-economic background affects access to tertiary education. Little research exists on this particular relationship but it has been observed that a smaller proportion of students of schools located in areas of disadvantage goes directly from school to tertiary education. Gender disparities have become more pronounced over the period 19942003. While in 1994 women made up 52\% of total tertiary enrolments, in 2003 that proportion had reached 57\%. In 2003, the gender distribution at postgraduate level was more balanced ( $49 \%$ females).

There have been positive developments regarding the participation of students with disabilities in tertiary education. From 1998 to 2003, the number of students with disabilities in tertiary education grew $185 \%$, and reached $5 \%$ of all students in 2003. However, students aged 15 to 44 with disabilities participated at about a quarter of the rate of people aged 15 to 44 who did not have disabilities.

As noted in detail in Section 4.3, the student support system facilitates access to those students with financial need. It reduces the influence of financial circumstances on individuals' tertiary participation and therefore improves equity of access.

Several initiatives have contributed to enhance equity in tertiary education. There has been a policy to expand the supply of tertiary programmes in such a way that the enrolment of underrepresented groups if favoured. Examples are PTEs and OTEPs being granted greater access to public funding in 1999 and the creation of Wānangas as providers of tertiary education. There has also been the concern to provide pathways for upper secondary school students who are at risk of leaving school with low or no 
qualifications (e.g. STAR and Gateway programmes). Most institutions offer bridging education programmes, designed to assist students in developing the skills necessary for success in tertiary education. Quite appropriately, there are also specific programmes to encourage institutions to improve equity for Māori and Pasifika students and students with disabilities. Special supplementary grants (SSGs) tie institutional funding to the number of students with a given background (e.g. Māori origin). Another example is the SSG for tertiary students with disabilities, which is provided to enable institutions to provide additional support for disabled students. Many TEOs engage in "affirmative action" whereby given quotas for underrepresented groups are established for the entry class.

\subsubsection{A public consciousness of the ethos of inclusion, purposeful thinking, equity and love for people of Aotearoa-New Zealand}

The observations from the discussions that took place during the review visit and articulated in the public tertiary education documents illustrate a strong ethos of the following values:

- The love for the land and its people.

- Getting people to think strategically about tertiary education and life in New Zealand and its contributions to the international scene.

- An ethos of working together to support economic and educational development of regions.

- The integrity of 'going beyond lip service' to enact certain goals and objectives related to equity and Māori and Pasifika Peoples engagement with tertiary education.

- The validation of human potential.

- The principles of equity, excellence and access are seen as added value.

- The ethos of commitment, pride, relationships, variety, and international and intersectional working.

- The willingness for all those involved in tertiary education to engage in the struggles of implementing a vision. 


\subsection{Research and Innovation}

\subsubsection{Towards Research Excellence: transformation of research funding}

As described in Section 3.7, research funding has changed significantly over the last years, moving towards an allocation system primarily reflecting research excellence and research quality. The introduction of performancebased funding through the PBRF and the establishment of the CoREs are important drivers in this process.

As analysed in the Country Background Report (Ministry of Education, 2006), the previous system for funding research - based on student enrolments in degree and postgraduate level courses and research 'top-ups' had several negative effects. First, research allocation based on student enrolments resulted in extensive internal cross-subsidization that in turn created market distortions and tensions in the tertiary education sector. Second, the fields that were most successful in generating enrolments - and thus research funding - were not necessarily those that were most active in research or of high strategic importance. Overall, the research funding system did not encourage excellence, nor did it ensure that top researchers received adequate resources. ${ }^{20}$

The shift in the approach to fund research - using the PBRF and initiatives such as the CoREs - presents a number of advantages. It aligns research funding with research performance of TEOs, rewarding excellence in research and it provides incentives for research to be undertaken in areas of priority for the country. Competition in these programmes to distribute research money ensures both excellence of academic research as well as the dynamics of university-industry networks with an open eye for its practical application. It is in fact, the competitive pressure and risk to lose grants in the longer term, that limits the risks of institutional rigidities in research programmes and university-industry cooperation. Also, as is the case with CoREs, programmatic policy instruments that stimulate particular multidisciplinary research or cooperation between specific TEOs and firms are useful additional instruments to create a policy-mix of research funding.

The shift in the approach to research funding was also an opportunity to increase resources invested in R\&D. The total PBRF budget is expected to be over NZD 220 million by 2009, compared to the research 'top-up'

See Boston (1999) for a fuller account of the criticism of a number of leading academics and the responses of the tertiary education sector to the government's green and white papers on tertiary education reform in 1997 and 1998. 
funding of NZD 132 million in 2003. The first PBRF assessment took place in 2003, with its first funding allocations being made from 2004 onwards. As expected the outcomes showed a considerable gap between the seven older universities on the one hand and the 15 other participating TEOs on the other (Ministry of Education 2006, table 5.1).

An issue of concern, however, is the large extent to which research support is allocated on a competitive basis. In most other OECD countries, a good proportion of research funds are distributed on a non-competitive basis according to a number of institutional criteria (first stream or basic funding). This stream of money is better suited for long-term infrastructure development in the TEOs and provides stability useful for the establishment of more long-term research strategies. The limited funding allocated on a non-competitive basis may cause problems for TEOs research in at least three different respects: (i) Undergraduate education is the pipeline for new researchers and may weaken when basic funding declines (it is, for example, important that undergraduate laboratories are up-to-date and that equipment used by young students is not outdated); (ii) Recruitment of permanent academic staff suffers when the number of permanent positions is reduced; (iii) Research equipment, especially the important service equipment that is not dedicated to a single project, is usually not provided through the competitive funding.

\subsubsection{Bringing tertiary education to local industry}

There is a high awareness, both at the system and institutional level, of the importance of knowledge transfer and interaction between tertiary education and industry. Many new schemes have been introduced to encourage knowledge transfer and knowledge interaction.

There are several ways to encourage knowledge transfer. First, one can increase the quality and relevance of knowledge transfer if large proportions of public funding require industry co-funding. This lowers the risk for firms and provides a high level of commercial accountability to public funding. Second, one can stimulate the mobility of researchers between TEOs and industry, encourage public-private research networks and cooperation to enhance tacit knowledge flows and (informal) linkages that are very important for innovation processes. Examples of schemes that encourage these two aspects are the CoREs and Regional Partnerships for Excellence. Finally, one can improve the quality and relevance of the teaching programmes by better matching curricula to industry requirements. Examples of this are the Growth Pilots and the ITP Business Links Fund.

The CoREs serve two important purposes. First, a CoRE encourages collaboration between researchers, within TEOs and between TEOs and 
other research organisations, considered to be rather low in New Zealand. It also increases the relevance of research in TEOs through directing strategic funding to those areas that matter most to New Zealand (Ministry of Research, Science and Technology et al., 2003). Partnerships for Excellence bring together partners from TEOs and businesses in those fields that are relevant and strategic for New Zealand's economy. Examples are the Agriculture and Life Sciences Partnership for Excellence of Massey and Lincoln universities with key industry groups; and the ICT Innovation Institute of the University of Canterbury with industry partners including Jade Software and other national and international ICT companies. The Growth and Innovation Pilot Initiatives programme (Growth Pilots) is another example of a stimulus for knowledge transfer. It promotes the sharing of knowledge and expertise between the education and industry sectors in order to deliver economic benefits to New Zealand. The ITP Business Links Fund seeks to build closer ties between the ITPs and businesses. The Fund has been set up to help ITPs understand what businesses need so they can tailor their courses to meet those needs. An important criterion to access the ITP fund is the link to regional development activities, for instance to meet the needs of local industry.

Over the last five years, many new initiatives and incentive schemes have been introduced to bring TEOs closer to industry. This clearly demonstrates that technology and knowledge transfer is high on the agenda in New Zealand.

\subsubsection{Capitalizing on scientific knowledge}

Commercialisation of scientific knowledge has also received increased attention both at the system and institutional level. The most important structures of national patent laws and regulation, technology transfer offices at TEOs and regional development schemes to link up TEOs and industry, are in place in New Zealand. Patent laws and regulations are aligned with the international practice of other OECD countries (OECD, 2003).

At the institutional level, many TEOs are developing competencies for commercialisation and have established business units to commercialise technology. Different commercialisation approaches are used by institutions, partly depending on their technological specialisation and partly on their identity and strategy. Most TEOs stimulate the creation of spin-offs, the number of which has increased significantly since 2000. They predominantly tend to be in the medical and health technologies and engineering-related sectors, which is the case in most OECD countries (OECD, 2003). 
However, the mere presence of a structure for commercialisation of scientific knowledge is no guarantee for industrial and regional development (Van der Steen, 2001). A strategic approach to diffusion of research outputs is required, both at the system and institutional levels. A particular problem in the case of New Zealand is that industry often does not possess the downstream capabilities to exploit new technologies, which are crucial for the commercialisation. The relatively low absorption capacity of firms is related to the low private $R \& D$ levels in New Zealand and reflect its SMEdomination.

There are, however, complex trade-offs between providing incentives for TEOs and firms to develop intellectual property rights (IPRs) and reap the benefits for investment versus creating incentives for diffusion of IPRs across the economy. Much (but not all) of New Zealand's intellectual property is developed overseas, which is at least partly related to New Zealand's sectoral specialisation. There are important 'spill-in' benefits from imported Intellectual Property. In an econometric analysis of the benefits of investments in research in agriculture over a 74-year period, Hall and Scobie (2006) argue that the benefits of imported Intellectual Property are realised in the presence of domestically created knowledge. Moreover, given that nearly all intellectual property is developed outside of New Zealand, incentives for diffusion appear more important (Beckers et al., 2006).

In New Zealand, universities and ITPs are part of the same research funding framework. However, research seems to have a different meaning for universities and ITPs. In general, research conducted at universities and their knowledge transfer activities are similar to those across OECD countries (OECD 2002b, 2003). We observed however, that 'research' at ITPs refers to specialised knowledge or expertise, often trade-related. For ITPs such expertise is often developed in close interaction with industry. The existing incentive schemes applicable to their knowledge development appear appropriately located in the sphere of matching teaching curricula with industry demand. Technology transfer instruments such as the Growth Pilots and ITP Business links Fund likewise seem to serve that purpose.

Some ITP staff and representing organisations expressed their dissatisfaction with the current research funding system, feeling excluded from the main funds for research excellence, such as the PBRF and the CoREs. The lack of a clear vision on ITP research and herewith a lack of guidance for ITPs on how to pursue a strategy for research excellence might explain this dissatisfaction.

Another challenge for New Zealand is how excellent basic academic research can be combined with an entrepreneurial culture in academia and 
attention to its practical applications. In university-industry knowledge networks and their knowledge transfer, universities and firms have distinct roles. Universities are, in that respect, responsible for research excellence and international academic peer reviews are an important instrument for national innovation performance in the longer run.

University research excellence - especially in 'high tech' technologies such as biotechnology and nanotechnology - determines to a great extent whether firms are interested in cooperating with a particular university. Auckland University is a good example of how research excellence attracts international investments such as those of pharmaceutical US-based firms. Development-based technologies, such as engineering and ICT, which have a multidisciplinary character require different types of technology transfer mechanisms, often trustworthy informal interactions within networks.

Additional conditions for successful knowledge transfer between TEOs and industry include an open and cooperative attitude of the TEO, technology transfer offices (TTOs) and policy instruments to stimulate multidisciplinary research and interaction between TEOs and firms. These conditions are largely fulfilled in the New Zealand context, such as with the establishment of TTOs at institutions of tertiary education and the development of a wide range of specific initiatives. In particular, the PBRF and CoREs provide incentives for research excellence, dynamic TEOsindustry networks with an open eye for practical applications. The challenge for these instruments is not to include all sectors of the economy and all TEOs in order to create focus and mass in research areas that are important for New Zealand society.

\subsection{Human Resource Management}

The Review Team met many able and committed academic staff in New Zealand institutions. In part, this derives from the fact that the system has been effective in maintaining the traditional values of academic freedom and institutional autonomy. The academic career is given ample flexibility and there are instruments to provide recognition to individual academics. For instance, there is an overall satisfaction with the principles and objectives of the PBRF scheme among the academic population. International linkages are strong, especially in research, mitigating problems of academic isolation that might otherwise arise in a small system in a small society. We also formed the impression that most institutions have put in place mechanisms to respond to underperforming teachers, making good use of student evaluations which is reflected in the overall satisfaction of students about the extent to which their concerns are addressed. 
Another strength of the tertiary education system in New Zealand is that institutions have autonomy over most aspects of managing their staff. They can set individual salaries, determine the proportion of time spent by individual staff on teaching and research, design promotion systems, set their own assessment systems and define a professional development strategy.

There are good examples of institutions making good use in their programmes of experts from business and industry (as with professional practice fields in ITPs) and from community leaders (as with communitytargeted programmes offered by Wānanga). This enriches the teaching by bringing diversity of perspectives and by exposing students to the application of the ideas they are being taught.

There are also a number of concerns. During the review visit, academic staff and their representatives often expressed that expectations and demands placed upon academics have been rising. The pressure to respond to societal and student needs, the growing levels of accountability, the mounting competitive environment, while delivering at three levels teaching, research, and service - have possibly led to higher levels of stress and heavier workloads. A study undertaken at a University in New Zealand (Houston et al., 2006) reveals that $94 \%$ of academic staff who completed the 2003 "Work Environment Survey" indicated that that they had worked after hours in the week preceding the survey (39\% by more than 10 hours beyond full-time). Five main areas where work demands were perceived to be expanding were identified: compliance requirements and information requests; administrative duties associated with the introduction of new systems and changes to University policies; increasing numbers of programme and paper offerings; increased workload resulting from the variety of delivery modes supported by the University; and increasing demand for a longer teaching year (i.e. Summer school) (for a description of demands on the academic profession in other countries, see Huisman and Bartelse, 2001). An example of a requirement which exacerbates these pressures on academics is the legislation which stipulates that teaching at degree level is to be undertaken by people active in research. Lecturers at degree level do have the obligation to be active in research in the domain taught.

Some individuals also expressed some concern at the level of casual and fixed-term employment agreements in the sector. In some cases, there is high reliance in the teaching programme on casual staff on short term contracts. In some cases, the short-term contracts have been rolled over on a repeated basis. In the longer term, excessive reliance on short-term staffing poses a quality risk. 
There has also been some concern expressed that the PBRF may distort some selection and promotion processes in favour of research outcomes. While this system has had the benefit of strengthening a culture of performance, it risks reducing the weight given to a broader range of activities. It might create disincentives for staff to undertake some kinds of other valuable activities such as quality teaching, community service, technology transfer, and dissemination activities. The study by Houston et al. (2006) reveals that staff at a particular institution in New Zealand expressed general disagreement that promotion processes recognised the variety of academic work and that teaching and research achievements are considered equally in promotions processes.

There are also signs that the academic workforce is ageing. Information based on the census of all PBRF-eligible staff in the 22 institutions which participated in the 2003 PBRF quality evaluation, reveals that the average age of PBRF-eligible university staff in 2003 was 46.9 years and around $70 \%$ of staff were aged between 39 and 60 . Over the next decade, the system will face a wave of retirements - at the same time as systems in many countries lose a large number of staff. This may place pressure on the system in the longer term.

There is also the general recognition that there is very limited mobility of academic staff in New Zealand. Typically, an individual starts a career in a given institution - often the one from which the postgraduate degree was obtained - and remains there throughout his or her career. This is without doubt not facilitated by career structures which are defined at institutional level.

\subsection{Links to the Labour Market}

There is a number of positive developments regarding the links between the tertiary education system and the labour market. First, notably there is a policy emphasis in making educational offerings relevant to the needs of the labour market. The TES establishes such requirement for TEOs' programme supply. The TEC implements this requirement through charter and profile negotiations. Individual TEOs are required to work closely with their region's businesses, professional associations, industry training organisations, and local authorities to identify skill needs and respond to the future shape of the regional and national workforce. This approach is to be supported. However, the review team formed the impression that practice is not systematic across the system.

Second, given its breadth of provision, the tertiary system is able to accommodate the needs of a diverse set of learners. Education, training and 
upgrading is taking place in a variety of settings: within formal education institutions, in the workplace, through short- and part-time programmes, and via a diversity of providers, both public and private. This results in a wide variety of learning and training opportunities available to the population. In a manner of speaking, there appears to be 'something for everyone': ample choice for a variety of needs. This translates into the emergence of a demand driven system rather than one in which the supply side dominates. This allows students to better respond to labour market signals and to adapt rapidly to the markets' changing characteristics. It appears logical to relate this feature to the emphasis placed on markets and competition by the government over the past decades.

Third, there is rich information about the outcomes of graduates in the labour market. Most institutions conduct surveys of graduates which provide useful information about career paths, views of graduates on their preparation and sometimes employers' assessment of graduates' competencies for work. These have the potential to inform the design of institutions' programmes and put them in better relation with labour market needs. Students also have access to ample information on educational offerings, course costs, quality of courses, eligibility for student loans and allowances, kinds of jobs available, and the forms of preparation for these jobs. This information is available from individual institutions and agencies such as Career Services and NZQA. The availability of this information is key in matching the supply of educational programmes by institutions to the demand for programmes by students.

Fourth, career guidance is widely available in the system. Career Services provides information, advice and guidance services that are designed to help people make informed career choices. Individual institutions also provide career advice, including assistance to students in finding jobs. Career and placement offices exist in most institutions.

Fifth, the existence of the national qualifications framework administered by the NZQA facilitates the articulation between the demands of employers, the expectations of students, and the offerings of tertiary institutions. Such a framework is used to bring together the skill needs of employers, the design of tertiary programmes to prepare students with these skills, and the information about the competencies needed for given occupations.

Sixth, lifelong learning offerings of tertiary institutions are well developed and the system responds suitably to the needs of adult learners. Many institutions supply training for company employees and the supply of continuing education is spread across the tertiary sector. The opportunities for adults to undertake tertiary education after an experience in the labour 
market are also facilitated by provisions to allow attendance on the basis of a person's assessed competencies and the access to the student support system. Over the last five years, half of the enrolment growth has been attributable to the increased enrolments of people over 40 years of age. In $2004,29 \%$ of students enrolled in tertiary study at a government-funded TEO were aged 40 years or older.

Seventh, there are good examples of partnerships between institutions and industry. These can take the form of internships for students and teachers in industry, consulting services, joint research projects, and periods of time spent by professionals of industry in institutions. For professional areas there seem to be close ties between faculties and communities of professional practice. A significant number of people employed in industry teach at ITPs and PTEs. Curriculum development is influenced by relevant industrial and professional communities. All courses leading to approved and accredited qualifications must have stated aims, learning outcomes, nomenclature, content, and structure that are acceptable to the relevant industries and professions.

Finally, industry appears as a legitimate and active stakeholder on the policy stage. Both at the national and the regional and institutional level, industry features as an equal partner. There is also a tradition of their involvement in the daily activities of institutions. This is illustrated by the formal participation of employers and representatives of industry as external members of institutions' governing bodies.

But again, as has been argued before, strengths do have their counterparts in terms of challenges. In this respect four aspects have come to the fore during the review visit.

First, despite all the positive indicators related before as to the way in which tertiary education has responded to the need for more and higher skilled graduates, there appears to remain a prevailing negative perception by industry of the TEOs not meeting its needs. Two observations can be made in this respect. Earlier on, it has been noted that external stakeholders, including industry, take up a prominent place in the governance structure of TEOs. One can but conclude that apparently this does not guarantee an effective articulation of needs or alternatively an insufficient follow through at the institutional level. At the same time, discussions about "meeting industry needs" must be carefully framed. Past experiences over the world indicate that time lags and demand cycles often show a mismatch. This is particularly true for the debate on generalist versus specialist skills. Likewise, a discussion like this should not be separated from the different roles and missions that different types of institutions have. Whilst it can be argued that 'employability' and 'relevant and up to date skills' should 
feature prominently in vocationally oriented education at all levels, there is an equally strong case to be made for universities focussing on a somewhat different set of values and graduate attributes. The existing SME industry structure in this respect poses an additional challenge.

Second, attempts to optimise education provision with labour market requirements is an area wrought with difficulties and complexities. It is recognised that New Zealand's tertiary education policy appears to place value and effort into aligning sector outputs with labour market demands. But the level of detail to which this is achievable remains an issue. Labour markets are volatile - and that certainly is the case for an open economy like New Zealand has - and unpredictable. Time lags already have been mentioned, and future labour market demands are fairly difficult to predict, in particular when the focus is on the knowledge economy where today's cutting edge skills and capacities can be outdated tomorrow.

Third, whilst a diverse tertiary education system conceptually is a major asset when it comes to being open, responsive and able to cater for a wide variety of needs, it poses a major challenge in terms of transparency. Both students and employers cherish transparency. But to realise this within a framework characterised by flexibility and low transaction cost is no mean task.

Fourth, despite the substantive increase in tertiary education participation and completion rates, skill shortages are a serious issue. Studies undertaken by the Department of Labour indicate shortages in major professional and trade occupations (e.g. IT professionals, pharmacists, social workers, occupational therapists, nurses). Causes for these shortages are deemed to be retirement and occupational wastage in combination with growing demand that cannot be met by the increase in supply.

\subsection{Internationalisation}

Within a more globalised world with respect to tertiary education, New Zealand is an active and visible player with several strengths in the area of internationalisation.

First, and documented through the rising number of international students in on- and off-shore educational provisions offered by various TEOs, New Zealand is clearly one of the leading exporters of tertiary education in the world benefiting not only the national economy and the society in general, but also the TEOs in the country through bringing new academic perspectives, cultural contexts and an enriched learning environment to the country. Over the last decades, New Zealand is ranked third in terms of growth in international students, and is second only to 
Australia in terms of export earnings from foreign students as a percentage of total export earnings from services (Patterson 2005, p. 366). The high number of foreign nationals in the academic staff of many TEOs is also a sign of the country's attractiveness in the international competition for students and staff, recognising that salary levels are not that dominant in this respect.

A second strength related to the internationalisation of tertiary education is the distribution of foreign students throughout the system. Given the diversity of the TEOs in the country, one could imagine that internationalisation only was a phenomenon relevant to TEOs of a certain size, and with certain (infrastructural) characteristics. However, international students seem spread throughout the system, and having considerable impact on most TEOs within the sector. Hence, in this respect, internationalisation may be said to be an "internalised" dimension in tertiary education.

Finally, and supported by evidence collected during the review visit, there is a high awareness of the specific needs of international students within the TEOs. This awareness is often apparent through programmes and procedures put in place to cater for this, either in the form of preparatory arrangements or through a special follow up during their studies. Staff and domestic students the Review Team met during the visits in general also had a positive attitude towards the increasing share of international students in New Zealand tertiary education.

However, the positive attitude towards international students, and internationalisation per se, was also quite often nuanced in terms of the challenges caused by internationalisation. One such challenge is that some of the international students do not possess the necessary skills and competences to undertake studies at the level they are signed up for. While many international students have excellent skills and qualifications, there is a segment in this market with few of these characteristics. A special problem in this respect are poor language skills. In meetings with staff and domestic students, the consequences were said to be that courses sometimes are "dumbed-down" as an adjustment to the skills of the least able students, and that the staff attention is directed away from creating academic progress to a process of "catching up".

There appear to be two causes behind the recruitment of students with poor qualifications. First, a number of TEOs appear to be quite dependent on the income generated by international students. The current level of funding in tertiary education has created a situation where internationalisation for some TEOs is not a process associated with acquiring new cultural and academic perspectives, but a process of generating income. In this situation, some TEOs seem to recruit students with poorer qualifications than the set 
standard. The national focus on tertiary education as an export industry may have created a situation were the TEOs to some extent are forced to think of internationalisation in a financial rather than an academic perspective. While acknowledging that New Zealand immigration laws prevent international students from studying a programme not approved by a QAB, it could be questioned whether the existing approval schemes are relevant for dealing with these problems.

Second, the recruitment of students with poor qualifications partly also is dependent on the institutional capacity to market abroad, and the ability to identify and attract students with better qualifications. This is a problem especially related to smaller TEOs with fewer international contacts and networks, and with a poorer institutional infrastructure (financial resources, staff, etc.). Recruitment of international students is mediated through the use of commercial "agents". Due to the for-profit motive of these agents, academic quality may not always be the factor that is on top of the list determining student selection. As a consequence, neither the interests of students nor those of institutions are met.

An argument presented during the review visit was that Education New Zealand is not always seen as being supportive enough for TEOs in the recruitment process. The core point being made was that while the current mandate of Education New Zealand has a focus on New Zealand as a study destination, it should include the practicalities of the recruitment process, and the identification and selection of students in the preferable market segments.

For the TEOs, the reliance upon internationalisation as a vital part of their income creates challenges with respect to planning and strategic development. When dependent on international students for income, fluctuations in student numbers, or in their qualifications, may generate serious problems for the sustainability of some TEOs. A potential problem in this respect also is that international students seem to come from a limited number of source countries. Hence, most of the recent expansion in the numbers of international students has come from China. 



\section{Pointers for Future Policy Development}

\subsection{Introduction}

Having described and analysed the context, current situation, strengths and challenges of New Zealand's tertiary education system in some detail in the previous Sections, this of course begs the question of what these analyses lead to. In this Section 5, we suggest ways forward to address the issues previously raised. In doing so, two things need to be taken into account.

First, tertiary education policymaking is a dynamic field. This is so across the globe and certainly is the case in New Zealand. The review visit has taken place during a period of political stocktaking and reflection. Already at the end of the review visit it became apparent that further changes to the tertiary education system and its overarching policies were immanent. In the months following the review, these further changes have been announced and currently are being discussed. Obviously, our suggestions for future directions and actions are based on the outcomes of document analysis and the review visit and do not directly address these new developments. But it is noted that much of what is discussed at present relates well to the suggestions that are to follow in the next paragraphs.

Second, making policy suggestions is easy. By contrast, implementing policy is one of the most complex tasks imaginable. We are very well aware of the fact that whilst certain conclusions and their implications may indeed be based on logical reasoning, this does not imply political feasibility. However, the latter is not the domain, nor should it be, of a Review Team. The suggestions made in this Section stem from our own internal debates, are based on our logic and collective comparative tertiary education expertise and experience. 


\subsection{Governance, Steering and Planning}

One aspect that features prominently in policy debates in many countries is accountability. This certainly is true for tertiary education. Whether located within the context of publicly funded tertiary education systems, or publicly supported systems, the demonstration of "value for money" or of "responsible and relevant activities undertaken with the taxpayer's money" are prevalent. There is no debate about the appropriateness of accountability. Yet there is debate about the growing burden of compliance and the detailed reporting associated with accountability.

New Zealand is no exception to the value attached to accountability. It features strongly. In this, it has an in-built tendency for detail and, as some would argue, an over-emphasis on compliance rather than on getting on with the job. The latter perspective is not something the Review Team readily would subscribe to, but it has noticed - and has touched upon this in the previous Sections - the extent of reporting.

Current policies appear to be intended to bring a degree of stability to a system that has been undergoing transformational change during the last two decennia. The system could greatly benefit in terms of both viability and dynamics, if this move towards greater stability was combined with a return of trust as a principle of governance. As has been argued in the previous Sections, there appears to be both evidence and belief in the fact that the actors within the system collectively underwrite the need and value to align the tertiary education system with the nation's goals and objectives. A context that seems conducive to an overall steering philosophy in which trust forms a key component. It goes without saying that this requires efforts from all actors involved. Trust cannot be invoked from one side only.

Following on from this, the potential strengths of the system of TESSTEP-charters-profiles has been noted. This system could greatly benefit if it was based on longer-term contract negotiations that are the result of a dialogue between equal partners. This implies a strategic debate between the TEC and those TEOs that have the administrative and governance capacity to discuss an institutional profile and act on the profile agreed upon. Following this suggestion would imply the introduction of a variety of steering approaches and arrangements, based on institutional capabilities, which in turn would result in diverse policy environments for the TEOs - a diversity that is a reflection of the real variety that exists within the system.

A logical consequence of such an approach, finally, would be a move away from the detailed annual reporting requirements currently in place towards tailor-made, more strategic forms of accountability. This would seriously diminish transaction costs in the system and would free resources 
to contribute to the strategic objectives of the TES and the institutional achievements of these.

\subsection{Funding}

We believe that the main principles underlying the funding of tertiary education in New Zealand - cost sharing, on the basis of relevance, backed by a comprehensive student support system - are appropriate and should be maintained. There are, however, two broad areas that require further attention: the assessment of the relevance of publicly funded courses and the extent to which the funding approach is consistent with the goals of the tertiary education strategy. As regards the allocation of funds, while the reliance on transparent formulas, competition and targeted funds should be retained, there is a need to strengthen the funding on the basis of quality/performance adapted to institutional profiles. As regards student support, while the approach of a universal loan system complemented with means-tested allowances is to be supported, efforts need to be undertaken to further reduce the liquidity constraints that students face in the system.

A guiding principle is to design a funding approach to meet the policy goals sought: excellence, relevance, access and capability, as developed in the STEP. A first difficulty, well exposed in New Zealand, is the ability to assess the relevance of courses to establish the degree of public funding. There needs to be a better understanding of public and private benefits from tertiary education, as well as enhanced ways to identify those offerings which better serve society at large - e.g. those that respond to labour market needs, which foster innovation or serve communities' aspirations. Appropriately, institutions negotiate their profile with educational authorities. This implies that relevance is to be assessed in relation to mission and thus to the institutional profile. Accordingly, the funding strategy is to follow a tailored approach recognising the diversity of roles and missions of institutions. The approach to ensuring relevance is also closely interconnected with quality assurance mechanisms since low quality programmes are unlikely to be relevant, for instance, for the labour market. For an approach based on relevance to be successful a robust system of quality assurance needs to be in place. This is addressed in Section 5.4.

The current approach to the allocation of funds - formula-driven, competition-based and strategically-targeted - is to be supported. But a number of aspects need to be strengthened. To begin with, the basis for allocating "core" funding to institutions, in particular that related to instruction, should become more output-oriented. This would support excellence in teaching and learning. The experience with performance-based allocation mechanisms in various countries (e.g. Denmark, the Netherlands, 
Norway, Sweden) suggests that tying funding to results can bring improvements to institutions' efficiency (e.g. through improved degree completion rates or lower costs of provision).

Indicators used in performance-based funding systems should relate to aspects to be enhanced in institutions such as internal efficiency (e.g. costs, completion rates) and external efficiency (e.g. quality of graduates). Performance indicators should also reflect public policy objectives rather than institutional needs and trigger incentives for institutional improvement. A wide range of indicators are used in countries, which have implemented performance-based allocation mechanisms. Indicators more associated with study completion are student graduation/completion rates, number of credits accumulated by students, average study duration, ratio of graduates to beginners, or number of degrees awarded. Other indicators focus on the labour market outcomes of students: employment rates of graduates, extent to which employment is in a field related to the area of studies or student performance on licensure professional exams. Some countries also use stakeholders' views (e.g. employers, student, government, social partners) of programmes' effectiveness, including assessments of the quality of graduates and about the extent to which a range of needs are being met, and degree of graduate satisfaction.

In Denmark, instruction budgets are exclusively based on output measures, a mechanism known as the 'taximeter' model. Funding is based on the number of credits obtained by students each year. In the Netherlands, universities receive $50 \%$ of their funds for instruction on the basis of the number of masters' degrees awarded. Sweden also uses a combination of input and output indicators - the budget for instruction is computed on the basis of student numbers (40\%) and accumulated student credits $(60 \%)$ (Jongbloed and Vossensteyn, 2001). New Zealand authorities have already recognised the need to move towards a more differentiated funding system related to outcomes by announcing the intention to introduce the Student Component Performance Measure. The idea is to make 5\% of the Student Component funding linked to performance, using three performance indicators - student retention rates, rates of successful completion of courses, and the results of a learner survey. However, with the wider work to reform the tertiary education sector, including the approach to investment and funding, a decision was made not to proceed with the Performance Measure for 2006, but to consider what role it (or its components) should have in a reformed tertiary system.

However, performance-based funding mechanisms should be carefully implemented because they can have adverse effects. If institutions are funded on the basis of degrees awarded or credits accumulated by students, some may be tempted to lower their standards in order to improve their 
funding. This would require adequate quality assurance mechanisms in place. Another possible effect is to induce risk-avoiding behaviour among academics and administrators leading to an emphasis on outputs that are easily attainable and measurable (e.g. effort shifted away from hard-tomeasure activities such as the development of creativity and problemsolving attitude). There are other instances in which the pursuit of a goal (e.g. improving completion rates by offering remedial courses) may have adverse consequences on another important objective (e.g. research activities or public service activities by academics).

One way to address these concerns is to develop a balanced funding mechanism based on a mix of input and output indicators. In this respect, it is important to note that as long as a number of conditions are met, enrolment-based funding may also provide incentives for improving the quality of programmes as a result of having institutions respond to the needs of students who "vote with their feet" (Jongbloed and Vossensteyn, 2001). It happens that the tertiary education system in New Zealand by and large meets such conditions: (i) largely there are no restrictions on enrolment numbers in institutions; (ii) students have access to reliable information on programmes; (iii) credit recognition facilitates student mobility between institutions; (iv) tuition fees are high enough to trigger a wise choice of programme; and $(v)$ student support systems allow for student's choice of institution. Hence, it is appropriate to maintain a given share of the funding formula on the basis of input measures. The share of performance-related funding should be sufficiently large to influence institutional behaviour, while not putting at risk the financial stability of the institution. The current plans of making 5\% of the Student Component linked to performance seem appropriate to introduce the concept of output-based funding.

Some prerequisites need to be in place for the successful introduction of performance-based funding. First, because gathering information is costly, it is important to use simple measures which are more readily available. Second, it is important that indicators are valid measures of performance and can easily be interpreted. If outcomes are poorly measured or measures are not valid, the goals of output-based funding may not be realized. Third, it needs to be ensured that there is administrative capacity in place to manage and interpret a great deal of information. Fourth, it is imperative to ensure that the measures being used are transparent to all stakeholders involved. This highlights the need to achieve political agreement among a broad range of stakeholders regarding the terms for introducing an output-based component for institutional funding. In this respect, it is particularly useful to have the TEC as a buffer body in the allocation of funds to neutralize political pressures. 
Next, as argued before, the basis to allocate funds to institutions needs to be better adjusted to the particular mission of institutions. Measures to define levels of funding should account for the particular role and mission of the institution. For instance, if the mission of the institution stresses links to the community, a performance-based approach should consider including indicators such as the number of graduates in areas critical to the region or the number of faculty involved in community-related projects.

Also, there is a need for institutions to diversify and enlarge their income from sources other than public funds and which are consistent with their mission. Clear guidelines between institutions and the TEC need to be drawn up in relation to how this is to be supported and encouraged.

More stability in funding should be provided in such a way that institutions can engage in a strategic approach to their long-term development, consistent with their strengths and capabilities. An allocation mechanism that guarantees funding over several years is preferable to yearto-year allocations. This allows institutions to plan their investments and introduce reforms over the medium term in accordance with strategic plans.

The potential distortions to competition in the tertiary education sector PTEs concentrating on "profitable" areas and some institutions relying excessively on international fees - can call for responses at the level of quality assurance. There should be an examination of the impact of large proportions of international students on the quality of the instruction. On the other hand, in order to lessen the distortions related to PTEs' competition behaviour it might prove useful to review the basis for estimating the costs on which the funding rates are based to ensure PTEs do not offer courses at a cost lower than the amounts they are provided from the public purse. Finally, there should also be a review of the funding of part-time students to assess whether institutions where part-time students constitute a significant proportion of the student body are particularly disadvantaged by the current approach to funding part-time students.

The student support scheme is founded on a solid approach -- universal, income-contingent loan system complemented with means-tested allowances - and is to be supported. It represents an important component in a system based on the principle of cost-sharing as it can offset the effects of high fees for academically qualified students who are financially needy. However, some of its characteristics need to be reviewed. In particular, as described earlier, the current system does not address to the full extent the financial barriers students face in accessing tertiary education. To address this issue, it is suggested that both the living costs loan entitlement and the student allowance are raised, and that the age-dependency issue is dealt with. 
The sustainability of such measure could be achieved with adjustments such as conferring the existing loan subsidies on the basis of need only or reducing the period during which loan subsidies are provided and direct the associated savings to student allowances; and providing a larger loan entitlement at market interest rates (or the government's cost of borrowing). It is not clear that, under a system of loans with income-contingent repayments, there is a strong basis to maintain the non-means-tested nature of loan subsidies. This is so because the main rationale to keep it - reduction of debt aversion - would be, to a great extent, achieved through the incomecontingent system. Also, the current possibility of borrowing with a subsidy for an unlimited number of years should be eliminated, given its potential for redirecting resources away from educational expenses. These measures would contribute to the sustainability of the system, ensure that aid amounts are larger to cover realistic living costs for all students and that special resources are devoted to those whose access might be more fragile as a result of a given disadvantage.

The overall strategy to improve the perspectives of access of individuals faced with particular circumstances (e.g. family poverty, poorly informed, fewer school opportunities) should also encompass policy responses at other levels - resources in the school system (including information about the benefits of tertiary education) and incentives to institutions to widen participation and provide extra support for students from disadvantaged backgrounds (see Section 5.5).

Also, since in New Zealand children become generally independent from their parents around their late teens, it might be appropriate to set an age threshold considerably lower than 25 at which parents' income is taken into account for allowances' eligibility. It also is recommended that student financial aid be tied to the costs of living in particular cities or regions to negate the adverse effects if indeed substantial differences exist.

\subsection{Quality Assurance}

Possible policy responses to the current challenges within the area of quality assurance include better alignment with the tertiary education strategy, organisational restructuring, and adjustments in the forms and types of evaluations conducted.

First, and as a response to what today seems to be a somewhat isolated system of quality assurance, we recommend a stronger link between quality assurance and the overall governance of the system within a framework of diversity and institutional distinctiveness elaborated upon previously. 
This implies that quality assurance becomes more related to the individual charters and profiles of the institutions, and used more as an evaluation (audit) of the institutional accomplishments with respect to the profiles. TEOs should still be required to have well-functioning quality management systems, but the external audit of these systems should be seen in relation to the aims of objectives of the specific institution.

An advantage of a better alignment between governance and quality assurance is that the current divide between the "external" (compliance) and "internal" (improvement) side of quality assurance would be bridged. Since the profiles are the key to understand the institutional development strategies, there are strong arguments for a closer follow-up of such strategies through systematic evaluation. Another advantage with such a link is that the amount of external reporting within the system could be rationalised, benefiting not only TEOs but also the authorities. In sum, this process could help foster trust within the system, with the relevance of quality assurance becoming more visible to staff and students. However, if such a link is made between the institutional profiles and quality assurance, it would be advisable that the profiles' objectives are formulated in such a way that actual evaluation indeed is possible.

Second, and as a response to the rather fragmented organisational structure surrounding quality assurance at the national level, there are several arguments for merging existing quality assurance agencies and QABs, creating a new single agency with total responsibility for quality assurance in New Zealand. This should further improve communication and coordination between quality assurance activities, the Ministry and TEC. A single agency would most likely also improve the organisational learning within the system - both across the agencies and bodies responsible at the national level, but also between TEOs. The fact that quite identical qualifications can be taken in different types of TEOs, learning across organisational borders is only one indication of the need for better integration and coherence. Another advantage of more organisational integration in quality assurance is that the external accountability function could be further improved. Even though the Ministry and the TEC continuously survey the sector, there is room for improving the information on the quality to students, parents, employers and the society in general. A new single agency would in itself result in a more accessible organisational structure for external stakeholders.

However, it should be underlined that a merger of existing agencies and QABs does not mean that every TEO should undergo the same procedures. As indicated above, an adjustment of current procedures to the institutional profiles actually signals a more "tailored" approach where the objectives of a given evaluation of a TEO could be relatively unique for that particular 
process. We acknowledge the fact that a more "tailored" approach has been used in audits of some of the Wānangas, a solution that seems to work well. The size of the tertiary education system in New Zealand can make such an approach work in a similar way as the current process of developing charters and profiles at the TEOs.

Third, a more tailored approach does not necessarily exclude more standardised forms of quality assurance which may, especially from an accountability perspective, be sought after by external stakeholders. The comprehensiveness of more standardised evaluations, however, should be carefully reflected upon. If the institutional profiles of TEOs are scrutinised regularly, one should be careful with adding comprehensive new evaluations on top. A lighter touch and a more focused process are recommended, addressing particular issues that emerge within tertiary education or in national policy discussions. Examples include evaluations of the transition between tertiary education and work for different studies or comparable analysis of the labour market links in different TEOs (such surveys are, for example, rather common in Denmark, see Kristoffersen, 2004).

Evaluations could also be undertaken to check the status and functioning of the qualifications system both within tertiary education and in the labour market. The qualifications system in New Zealand is a relevant tool for recognition and the continuous building up of qualifications. However, how different qualifications are received in the labour market is an important indicator for their relevance. Systematic evaluation could be of value not only for the authorities but also for the TEOs in their planning and continuous improvement of their educational offerings. In this way, one could also further integrate the qualifications system into the governance of the system. As these examples illustrate, it is suggested that a more resultoriented and labour-market approach is developed, shifting the focus from the input-side (usually emphasised in accreditation procedures) to the output-side of the tertiary education system.

Finally, we would like to underline that the dynamic and internationally-oriented tertiary education system of New Zealand most probably also will need more ad-hoc and "need-based" evaluations in the future. The system proposed above will most likely not exclude the need for evaluations that more rapidly can respond to sudden quality problems appearing in the system. To have such a 'back-up system' should be within the capabilities and capacity of a single agency for quality assurance, and should enable New Zealand to respond quickly to changes and challenges in the tertiary system (e.g. related to problems in the recruitment of students or staff, internationalisation, problems related to the educational infrastructure or resource base). 
Concerning the PBRF, this procedure is in many ways an example of a focused form of evaluation. While there are good reasons to keep such a strong focus, a suggestion is still to think of ways to improve the organisational learning from this procedure. Not least should the present "tacit" insights of the peer review panels be brought more to the fore with respect to how research quality can be more systematically enhanced from an organisational perspective.

\subsection{Equity and Community Linkages}

Throughout our report we have commended the way in which both equity and community linkages are embedded within the overall policy framework as well as the policies and actions of individual TEOs. Certainly from a comparative policy analysis perspective this feature stands out. From this it also follows that our pointers for future policy directions are modest. One should not divert too much from a route of success and engage in frivolous experimentation. The main suggestion therefore is to continue with the policies set in place, possibly with a stronger emphasis on those groups at the lower levels of the tertiary system. In the end, this substantively would strengthen capacity and human potential.

Within our overarching recommendation to continue on the road that has been taken, it is imperative that the understanding of bridging bi-cultural entities receives full attention. This will assist in arriving at a common understanding of values, differentiated planning, equity, and mutually respectful responsibilities for the people and the land of Aotearoa-New Zealand. This must be achieved without losing the essence of what the Treaty of Waitangi has articulated for all. Māori people are concentrated in the lower levels of the tertiary education pathways and this issue can be addressed by looking at principles of equity to move people into proactive, positive, economically enhancing lifelong learning opportunities, as is the case for the Pasifika Peoples. Building foundational skills and knowledge of these learners to move toward the higher levels of the pathways and staircasing model that acknowledges a learners status with his/her educational situation is a challenge that needs to be addressed more systematically.

The emphasis of the response to reduce inequities in the access to and completion of tertiary education should continue to be placed on: (i) schooling policies; (ii) incentives for tertiary education institutions to widen participation and provide extra support for students from disadvantaged backgrounds; (iii) alternative types of provision to account for the cultural diversity of the population; and (iv) financial assistance to needy students. 
The response lies to a great extent on schooling policies. Students whose parents have lower levels of education underestimate more often the net benefits of tertiary education. To offset this information gap, career guidance and counselling services in New Zealand schools should strengthen their role in making poorly informed school children aware of the benefits of tertiary education and in raising their attendance aspirations. As mentioned earlier, New Zealand has already in place active policies in this respect such as a well-established network of career guidance services and programmes for students at risk of leaving school with low or no qualifications.

Incentives for tertiary education institutions to widen participation by less represented groups and assist those groups with extra support should be maintained. Equity-related Special Supplementary Grants, institutional "affirmative action" and bridging programmes are to be supported. These initiatives compensate for the more limited educational opportunities some disadvantaged groups of students are offered prior to entering tertiary education. Possibly more emphasis should now be given to support studies progression by, for instance, extending tutoring services for students with academic difficulties. The overall strategy might also include adapting the learning environment to account for the diversity, for instance by adjusting the curriculum and the tuition for the entire student population. Initiatives include the development of multicultural competencies among the entire academic staff, seminars and courses on multicultural pedagogy and the training of tutors with multicultural knowledge and communication skills.

The further development of the Wānanga is to be encouraged. These institutions respond to a particular need in New Zealand society and are a means to provide aspirations to indigenous communities in harmony with their culture. As indicated earlier, there is a danger of developing these institutions from only one perspective and not valuing the other parts of New Zealand culture. It is imperative that there is an understanding that bridging between the indigenous and non-indigenous communities involves exchange in the two directions. Hence, the policy of opening up these institutions to all New Zealanders is to be preserved. Of course, policies to improve the participation of indigenous populations in tertiary education should encompass attendance in the entire system. More information about the success or failure of specific policies for the indigenous populations would be helpful to expand equity programmes.

Another crucial element for ensuring the equitable provision of tertiary education is the student support system. We support its current approach universal, income-contigent loans system complemented with means-tested allowances. As described in detail in Section 5.3, we suggest that some 
improvements are made to better address the financial barriers students face in accessing the system.

The challenge then becomes to maintain the momentum as the current Tertiary Education Strategy enters its final years. The tertiary education system can benefit from ongoing educational and motivational professional development of these proactive and positive strategies for building equity and access into the system. An approach that positively sets New Zealand apart from other countries.

\subsection{Research and Innovation}

The New Zealand government acknowledges the key role of TEOs in furthering research and innovation. The last ten years have been dominated by new policy initiatives for research and innovation and significant changes in research funding, now more oriented towards research excellence and research quality. Many new funding schemes were introduced to bring TEOs closer to industry. In this respect, the government's policy on the role of TEOs in research and innovation fits that of many other OECD countries (OECD 2002b, 2003, 2005c). In general, the most important structures are in place. However, we feel that there is room for improvement in a number of areas, addressed below.

\subsubsection{Effective and focused research funding}

Despite the significant positive changes in research funding, there is concern about its long-term sustainability. New Zealand is characterised by low private sector $\mathrm{R} \& \mathrm{D}$ ( $40.5 \%$ of total $\mathrm{R} \& \mathrm{D}$ expenditure compared to the $67.3 \%$ OECD mean, see Appendix 5) and, due to its firm and industry structure, limited possibilities to increase this proportion. As research is primarily sponsored by government, there is a continuous concern about the sustainability of its funding. Therefore, it is essential that government research funding is effectively targeted and focused on critical research areas that serve New Zealand best. Instead of broadening successful schemes such as the PBRF and Centres for Research Excellence to ITPs, the development of alternative strategies and mechanisms that take into account the specificities of ITPs should be considered.

In light of the large extent to which research funds are allocated on a competitive basis, it is recommended that the current trend to increase competitive funding be moderated in accordance with the problems that may increase in the coming years, especially in connection with staff, infrastructure and equipment (see Section 4.6.1). Furthermore, even within 
the competitive funding, a higher emphasis must be placed on long term funding, so that planning by individual research groups and individual researchers may be facilitated and strengthened.

\subsubsection{Entrepreneurship and research excellence of ITPS}

There is a challenge for government to develop, in close interaction with ITPs and industry, a vision and appropriate framework for ITP research development to best serve regional development. Entrepreneurship and innovation can be useful general criteria for ITP research development and knowledge transfer. Examples of initiatives are: new teaching programmes to develop entrepreneurial skills and competencies of the New Zealand workforce, entrepreneurial activities of teaching staff and matching teaching programmes to industry demands. This is a good opportunity to translate innovation and research excellence of the tertiary sector, now grounded predominantly in academic criteria, to practical and relevant initiatives that serve local industry, ITPs and regional development.

\subsubsection{Consolidation of knowledge transfer schemes}

During the last five years, many new initiatives and incentive schemes have been introduced to forge stronger relationships between the tertiary sector and industry. This clearly demonstrates that knowledge transfer is high on the agenda and that the government is actively trying to encourage it. A wide range of new policies and incentive schemes have been implemented by different Ministries and agencies. In the immediate future, it is difficult to evaluate the effectiveness of most of these policies because a 'bedding in' period is required.

Moreover, most policies and schemes involve (radical) innovations, characterised by uncertainty and trial and error which require a long period to identify effective and successful cases. In addition, most policies and schemes involve 'soft' aspects of technology transfer such as facilitating information flows, collaboration and networking, which are more difficult to measure.

However, in the longer run it is important to evaluate, align and possibly concentrate these portfolios of government incentive schemes. The observation is that there are currently many schemes, funds and policies and many Ministries and agencies are involved. The system of knowledge transfer schemes should be simplified, the number of schemes reduced, with a more clear focus to increase transparency and horizontal governance. The Tertiary Education Strategy (TES) and the Growth and Innovation Framework (GIF) are very good bases on which to foster these changes. 


\subsubsection{Tertiary education in the national innovation system}

TEOs play a pivotal role in New Zealand's innovation system. Knowledge transfer and commercialisation of scientific knowledge are very important and have rightly received increased attention both at the system and the institutional level. However, in order to overcome systemic flaws in the diffusion of scientific knowledge in the innovation system, there is a strong need for horizontal governance among the incentive schemes for TEOs, CRIs, firms and regional development. This requires not only coordination and communication among the different ministries responsible for the incentive schemes, but also a strong need for a national strategy of the broader national innovation system of New Zealand.

\subsection{Human Resource Management}

Institutions are struggling to find modes of operation to balance the external expectations with their traditional values of academic freedom and institutional autonomy. This might call for a reconceptualisation of academic work within institutions as it becomes more complex and specialised. In achieving this, it might prove useful to concentrate on four main areas: (i) Management processes and leadership; (ii) Definition of roles and workloads; (iii) Staff initiatives and responsibilities; and (iv) Support and recognition of staff.

We believe that institutional leadership and management need to strengthen processes and systems which provide the frameworks for linking individual work to organisational strategic goals. Leadership needs to demonstrate the advantage of change, establish a systematic forwardlooking assessment of organisational direction, and define the requirements and workloads needed to achieve the desired profile. There also needs to be emphasis on greater flexibility on the roles and workloads of academic staff. At present, within various degrees of flexibility, degree-level institutions require academics to cover all together teaching, research and service to the community. Few specialise in any of these roles. Institutions might develop further the range of specialised positions such as teaching-only positions or allow staff to develop their own strengths. In particular the requirement that teaching at degree level is to be undertaken only by those actively involved in research could be relaxed to become the prerequisite that teaching needs to be informed by research.

Within the broader direction provided by institutional leadership, it is important to have individual academics assume responsibility for shaping their role and work profile. Staff are to take responsibility for their learning and to develop professionally by pursuing personal goals that are in 
accordance with the larger organisational and external environment. Within this framework, it is necessary to put in place within institutions mechanisms which support and reward the accomplishments in the interest of the individual, the institution, and the system as a whole. More attention needs to go to performance management which defines expectations for staff and provides feedback and development opportunities. While currently there are good mechanisms to recognise achievement in research, there are more limited means to reward other activities. The teaching performance measures are sketchy - and currently appear very largely reliant on student evaluations. We favour staff incentive systems to include performance in community service and consultancies alongside performance in teaching and research.

Improvements in academic staff mobility might be generated by enhanced the capacity for collaboration among institutions and between institutions and external organisations. Such interaction has the potential to diversify the professional prospects of many academic staff. Initiatives such as the creation of CoREs involving different research groups are steps in this direction as are also the creation of joint degrees between institutions.

The system also needs to make a better assessment of the seriousness and potential consequences of both the ageing trend and the existence of casual employment agreements. Recognising the importance of these issues, the New Zealand government has launched a major strategic review of the tertiary education workforce which will propose ways to monitor workforce issues in the future and various initiatives to face the identified concerns.

\subsection{Tertiary Education and the Labour Market}

As described earlier, many steps have been taken to improve and optimise the relationships between tertiary education and the labour market. And much has been achieved. Yet major issues remain on the table: the level of detail of the steering (and planning), tertiary education's image with firms and industry, the transparency of the tertiary system to students and employers, and skill shortages. The relationship between tertiary education and the labour market is a highly complex one, and it remains one of the least consensual areas of tertiary education policy. However, some broad principles might prove useful for future policy development in this area in New Zealand.

First, as regards steering and planning, an approach that takes into account the diversity in the system and avoids the danger of micro management appears best suited to deal with the current and future challenges of the labour market. In fact such a strategy builds on what we 
have identified as one of the core strengths: the existence of ample choice in the system to meet a variety of student and labour market needs.

Second, a generic way of ensuring that the provision of educational programmes matches employment requirements is to reinforce partnerships between institutions and the business sector. Examples of good practice already exist in New Zealand. They involve internships for students and teachers in industry, participation of employers in the design of educational programmes and in institutional governance. These are all steps in the right direction but there is a need to make them more sustained and systematic across the entire tertiary education system.

Third, the involvement of employers and the business community in the development of tertiary education policy should be sustained. For this dialogue to be effective, it needs to be ensured that businesses and employers develop an interest in participating in this dialogue, and that the views of the latter are valued and taken into account in the formulation of policies. The policy of directly involving the business community in the daily running of institutions, through their participation in institutions' governing bodies, is to be supported as it has the potential to improve the responsiveness of institutions to labour market needs.

Fourth, there needs to be a continuing effort to make information about available programmes, labour market outcomes and employment requirements available to students, institutions and employers. New Zealand has made commendable progress in this respect. The tradition of conducting surveys of graduates and the rich information provided by Career Services are exemplary practices to be supported. Students need to be informed about the labour market, the kinds of jobs available, and the types of educational preparation needed for those jobs. This helps students make well-informed decisions about their fields of tertiary study. It is essential to ensure that career guidance in secondary schools is effective in using the wealth of information available, that it is adequately staffed and undertaken by individuals with the appropriate training. In this respect, a current role of Career Services in providing professional development assistance to school career advisors to support career education programmes is particularly important.

Finally, the Register of Quality Assured Qualifications should be further developed as the reference instrument to co-ordinate the demands of employers, the expectations of students, and the offerings of institutions. The promises of a well-functioning qualifications framework are many: employers can specify competencies for employment; educational institutions can design programmes to develop these competencies in students; and students know what competencies they need in order to 
become employable. A well-functioning qualifications framework also makes transfers among fields of study, and among institutions, more flexible. This allows students who realise they are in the wrong field of study to change, both reducing these kinds of mismatches and potentially allowing greater responsiveness to changing labour market patterns. However, the current framework is not yet meeting these expectations. The knowledge and systematic use of the framework should therefore be further improved.

\subsection{Internationalisation}

Given the growing importance of globalisation in tertiary education and the little understanding of its impact, this area still needs to be followed closely by national authorities. During the last years, several initiatives have been taken at the national policy level to support, enhance and further develop the international dimension of New Zealand tertiary education. Many of these initiatives, concerning both the need to establish more coordinated approaches and actions abroad, as well as promote institutional capacity-building domestically are considered relevant and timely efforts.

However, it is also our impression that the financial and the export dimensions have been the central focus of attention. The time has come to establish a stronger focus on quality. In the competition for international students, reputation is not only important for individual TEOs, but also for the resident country. Even though New Zealand's reputation currently is high, it is a problem if an impression is created that income is the central motive behind the internationalisation of the sector. By building and sustaining an international reputation as a quality provider of tertiary education, positive consequences should be traceable not only in the recruitment of students, but also in terms of study persistence, social integration and academic achievements.

Current policies can be said to address this issue, but a recommendation still is that the quality dimension should be further underlined in the future. There are several initiatives that could be taken to support this development. First, there is a need to support TEOs, and especially the smaller institutions, in their recruitment efforts and strategies. An objective should be that the TEOs should establish more long-term relations with foreign partners resulting in stronger international networks, thus making them less dependent on commercial agents in relation-building and recruitment processes. The Country Background Report (Ministry of Education, 2006) reveals that most tertiary institutions do undertake their own individual marketing and recruitment. A more coordinated effort in this respect could 
well be timely and, for instance, be reflected as an additional role in the mandate of Education New Zealand.

Second, there is a need to protect the TEOs against, and build their capacity to deal with, the significant risks associated with a substantial involvement in the provision of tertiary services internationally. Here, the existing institutional profiles and charters could be valuable as a tool for identifying risk profiles in this respect - i.e. the vulnerability of individual institutions to the fluctuations and vagaries of the international student market in relation to their operation budgets - and establishing workable solutions in the internationalisation area. Hence, there are strong arguments for an even closer cooperation and information exchange between the TEC, the TEOs, and Education New Zealand. The spread of good practice, more coordination, and more targeted actions, should be possible through such collaboration.

Third, and following from this, concerning the building up of good practice, more established links and networks, issues surrounding recognition and quality assurance across national borders should have high priority. Involvement in international networks such as the Asia Pacific Academic Recognition Network (APARNET) (see also OECD, 2004d, p. 117) is important, and policies should support the implementation of emerging guidelines for quality provision across national borders (see e.g. $\mathrm{OECD}, 2005 \mathrm{~d})$. In order to establish a strong international quality culture in transnational education, there is a need for dominant countries such as New Zealand to take the lead.

To stimulate institutional attention to quality in international education, there also appears to be a need to balance the strong export oriented focus with study abroad opportunities and more sustainable exchange programmes for domestic students, for example, through a more systematic development of joint degrees. Such jointly delivered programmes would benefit both domestic and international students, and would have a built-in quality aspect if cooperation between "equal" partners across national borders could be stimulated. Jointly delivered programmes could also provide a possible bridge between the aid and developmental aspects of tertiary education and the more export oriented aspects of tertiary education. 


\section{Concluding remarks}

To the outsider, the New Zealand tertiary education system is one that very much reflects the image of the country that, rightly or wrongly, has been cultivated over the years. The system has some mysterious features well reflecting the deep and dark forests so much in abundance throughout the country. It sparkles, as do the rivers that meander through the mountains. It excites which probably is what one of New Zealand's export products the bungee jump - does to those hanging upside down from a bridge. It is a sight of beauty, something that almost in all aspects is what strikes the visitor about New Zealand. And, as far away and isolated eco-systems exhibit, it has a life of its own.

\section{The mysteries}

Small systems have that same deceiving quality that small villages and communities have. They seem easy to understand but the more one starts looking in, the greater the complexities become and the more layers appear. This also is true for New Zealand's tertiary education system. At face value the structure is relatively straightforward as are the rules of the game. But the more one gets immersed in it, the more complex it becomes.

Actors play on different stages, sometimes consecutively, sometimes simultaneously. They wear different hats, sometimes those of policy advice, sometimes of decision-making. And they meet frequently, and discuss. The visitor observes, interprets, and tries to understand. Sometimes this even leads to insight. But even for the weathered traveler, visiting is not the same as living in.

New Zealand is a well-documented system. This helps understanding. And by and large, our group of visitors feels relatively comfortable with the views expressed in the previous Sections. As we do with the suggestions made. But still we are very aware that we have been visitors. 


\section{The sparkles}

Mysteries may remain, but sparkles by their very nature are hard to miss. It is impossible not to see and respect the major achievements that characterise the country and its tertiary education system when it comes to equity. Of course, further improvements always are possible, but the Treaty in its spirit does appear to resonate throughout the sector.

Nine hundred-plus institutions seem a bit of overkill for a country of four million people. And quite possibly it is. But that should not cloud the realisation that the system contains massive diversity, and in this diversity contains some truly wonderful examples of tertiary education and research. This ranges from small, specialised private institutions that provide students with state of the art equipment stimulating and challenging their creative drives, to multi-organisational, multi-disciplinary research groups that work at the cutting edge of science.

Diversity also relates to quality, which is well respected in its conceptualisation of being multi-dimensional. So quality in New Zealand spans the full spectrum from world class 'traditional' academic research to community-based developmental activities directly contributing to the improvement of peoples' lives.

Were one to pick but one aspect as The Sparkle, diversity probably would be it as it contains within it many of the very strong and specific features of New Zealand's tertiary education system.

\section{The excitement}

For the tertiary education policy researcher, New Zealand has much to become excited about. The overall policy structure and design is innovative, though still there is room for improvement. Cost-sharing is a phenomenon well grounded, and although still open for debate as to the nuts and bolts, well accepted within the larger community. Quality assurance is fascinating, not so much because it is radically new or innovative, but because it has been just that years ago and its evolutionary trajectory now can be traced. Which obviously leaves it open to criticism and renewal. Research and innovation within the specific constellation of New Zealand's firm and industry structure fascinates because of the multiple dilemma's it faces. And the path towards full integration of Māori and Pasifika Peoples, as argued above, sparkles and shines. 


\section{The beauty and the eco-system}

In today's tertiary education policy world isolated eco-systems do not exist anymore. Ministers and government officials meet frequently at international gatherings, as do institutional executives and researchers. Policy borrowing has become a favourite pastime. Yet, New Zealand very much has proven to be able to maintain its own identity and peculiarities. Some of the latter we have referred to under the heading of mystery. Others together constitute the beauty of the system.

The uniqueness of the system has to be the combination of scale, diversity, achievement and policy innovation. Leaving aside our suggestions for improvement, it is a system with a dynamic of its own, a unique signature crafted out of change and tradition, and vibrant despite some of the challenges it faces.

If our suggestions contribute to the further growth and development of the system, so much the better. But much already has been achieved. Some careful nurturing, selective pruning, dosed watering, and protection of unique species will go a long way in keeping this eco-system going. No radical change is needed for that. 



\section{References}

Beckers, R., V. Gilsing and M. van der Steen (2006), Determining Factors of the Effectiveness of University Spin-offs: Comparing the Netherlands and the US. Journal of Technology Transfer, volume 31, number 5, September.

Boston, J. (1999), The Funding of Research in the Tertiary Sector, Access: Critical Perspectives on Cultural and Policy Studies in New Zealand, 18(2) pp. 103-119, New Zealand.

Hall J. and G. M. Scobie (2006), The Role of $R \& D$ in Productivity Growth: The Case of Agriculture in New Zealand: 1927 to 2001, Treasury Working Paper Series 06/01, New Zealand Treasury.

Harmsworth, G.R. (2002), Indigenous concepts, values and knowledge for sustainable development: New Zealand case studies, Presentation at the 7th Joint Conference: "Preservation of Ancient Cultures and the Globalization Scenario", Manaaki Whenua - Landcare Research, www.landcareresearch.co.nz

Houston, D., L. Meyer and S. Paewai (2006), Academic Staff Workloads and Job Satisfaction: Expectations and Values in Academe. Journal of Higher Education Policy and Management, vol. 28 No. 1, March, pp. 1730 .

Huisman, J. and J. Bartelse (eds.) (2001), Academic Careers: A Comparative Perspective. Enschede: Center for Higher Education Policy Studies, University of Twente.

Johnstone, D.B., A. Arora and W. Experton (1998), The Financing and Management of Higher Education: A Status Report on Worldwide Reforms (available from:

www.worldbank.org/html/extdr/educ/postbasc.htm).

Jongbloed, B. and H. Vossensteyn (2001), Keeping up Performances: an International Survey of Performance-Based Funding in Higher Education. Journal of Higher Education Policy and Management, vol. 23 No. 2. 
Knight, P. and M. Yorke (2004), Learning Curriculum and Employability in Higher Education. London: Routledge-Falmer.

Kristoffersen, D. (2004), Ministerial approval and improvement-oriented evaluation in Denmark: An alternative to accreditation? In Schwarz, S. and Westerheijden, D.F. (eds.) Accreditation and evaluation in the European higher education area. Dordrecht: Kluwer Academic Publishers.

Maani, S.A. (1997), Investing in Minds: The economics of higher education in New Zealand. Wellington: Institute of Policy Studies.

Maani, S.A. (2000), Private and Public returns to Investments in Secondary and Higher Education in New Zealand Over Time: 1981-1996. Auckland: University of Auckland.

McInnis, C. (2005), The Australia Qualifications Framework: Public Policy for Academic Quality Research Programme, University of North Carolina (www.unc.edu/ppaq/docs/AUQualifications.pdf)

McLaughlin, M. (2003), Tertiary Education Policy in New Zealand, Ian Axford Fellowship Report, available from: www.fulbright.org.nz/voices/axford/docs/mcLaughlin.pdf

McPherson, K.M., M Harwood and H. K. McNaughton (2003), Ethnicity, equity, and quality: lessons from New Zealand. bmj.bmijournals.com/cgi/content/full/327/7412/443

Ministry of Education (2002), Tertiary Education Strategy, 2002/07. Wellington: Ministry of Education.

Ministry of Education (2004), Statement of Tertiary Education Priorities: 2005-2007. Wellington: Ministry of Education.

Ministry of Education (2005), What determines the research performance of staff in New Zealand's tertiary education: an analysis of the Performance-Based Research Fund Quality Evaluation. Wellington: Ministry of Education.

Ministry of Research, Science and Technology, the Foundation for Research, Science and Technology, the Health Research Council and the Royal Society of New Zealand (2003), The National Bibliometric Report 1997-2001: International Benchmarking of New Zealand Research. Wellington: Ministry of Research, Science and Technology.

Ministry of Research, Science and Technology (2005), Science for New Zealand: an Overview of the RS\&T system 2006, interim version published December 2005. Wellington: Ministry of Research, Science and Technology. 
Ministry of Education (2006), OECD Thematic Review of Tertiary Education, Country Background Report for New Zealand, Wellington (available from: www.oecd.org/edu/tertiary/review)

OECD (2002a), Frascati Manual 2002: Proposed Standard Practice for Surveys on Research and Experimental Development. Paris: OECD.

OECD (2002b), Benchmarking Industry-Science Relationships. Paris: OECD.

OECD (2003), Turning Science into Business: Patenting and Licensing at Public Research Organisations. Paris: OECD.

OECD (2004a), OECD Thematic Review of Tertiary Education: Guidelines for Country Participation in the Review. Paris: OECD (available from: www.oecd.org/edu/tertiary/review).

OECD (2004b), OECD Handbook for Internationally Comparative Education Statistics: Concepts, Standards, Definitions and Classifications. Paris: OECD.

OECD (2004c), Education at a Glance, OECD Indicators 2004. Paris: OECD.

OECD (2004d), Quality and recognition in higher education: The crossborder challenge. Paris: OECD.

OECD (2005a), Education at a Glance: OECD Indicators 2005. Paris: OECD (see www.oecd.org/edu/eag2005).

OECD (2005b), Economic Survey of New Zealand. Paris: OECD.

OECD (2005c), Main Science and Technology Indicators, Volume 2004/2. Paris: OECD.

OECD (2005d), Guidelines for quality provision in cross-border higher education. Paris: OECD.

OECD (2006), OECD Factbook 2006: Economic, Environmental and Social Statistics. Paris: OECD.

Patterson, G. (2005), Collaboration/Competition Crossroads: National/Supranational Tertiary Education Policies on a Collision Course. Tertiary Education and Management, 11, pp. 355-368.

Webb, C. and C. Grant (2003), Economic Transformation: An Implementation Framework. Wellington: Tertiary Education Commission. www.tec.govt.nz 
Van der Steen, M. (ed) (2001), Industrial Property, Innovation and the Knowledge-based Economy, Beleidsstudies Technologie Economie (BTE) (Policy studies Technology Economy) 37. The Hague: Ministry of Economic Affairs.

Vossensteyn, H. (2005), Perception of student price-responsiveness. A behavioural economics exploration of the relationship between socioeconomic status, perceptions of financial incentives and student choice. Enschede/Prague: CHEPS/Unitisk. 


\section{Appendix 1: The OECD Review Team}

\section{Laara Fitznor}

Professor, Faculty of Education

University of Manitoba, Canada

Leo Goedegebuure (Rapporteur)

Professor, Centre for Higher Education Policy and Management, University of New England, Australia

Paulo Santiago (Co-ordinator)

Administrator, Education and Training Policy Division

Directorate for Education, OECD

Bjørn Stensaker

Programme Director, Studies of Higher Education Institutions,

NIFU-STEP, Studies in Innovation, Research and Education, Norway

Marianne van der Steen

Professor, Faculty of Technology, Policy and Management

Delft University of Technology, The Netherlands 



\section{Appendix 2: National Co-ordinator, National Advisory Committee, and Authors of the Country Background Report}

\section{National Co-ordinator for New Zealand}

Roger Smyth, Head of the Tertiary Sector Performance Analysis and Reporting Unit, Ministry of Education. Assisted by Jason McClelland, Senior Research Analyst, Tertiary Sector Performance Analysis and Reporting Unit, Ministry of Education in the role of Project Manager.

\section{National Advisory Committee}

Elizabeth Eppel, Ministry of Education, Chair.

Matt Davies (Aotearoa Tertiary Students' Association);

Lloyd Woods (Association of Staff in Tertiary Education);

Rebecca Matthews, Erin Polaczuk (Association of University Staff of New Zealand);

Susan Kosmala and Nilanka Fonseka (Career Services);

Lesley Haines (Department of Labour);

Jim Doyle (The Institutes of Technology and Polytechnics of New Zealand);

Tony Davies, Dillon Burke and Jo Doyle (New Zealand Qualifications Authority);

Andrew Kirton (New Zealand University Students' Association);

Lindsay Taiaroa (New Zealand Vice-Chancellors' Committee);

Colin Webb (Tertiary Education Commission);

Claire Douglas and Paul O'Connell (The Treasury).

Other stakeholders were also canvassed for comment as required, namely: Dave Geurin (Independent Tertiary Institutions), Jan Esquilant (Ministry of Research, Science and Technology), Kellie Coombes (Ministry of Social Development) and Turoa Royal (Te Tau Ihu nga Wānanga - association of Wānanga).

The Ministry of Education Advisory Committee also assisted the participation of New Zealand in the review. Its composition consisted of: Jane von Dadelszen, Caroline Holmes, Peter Mellor, Nick Montague, Frances Kelly, Neil Scotts, Elizabeth Eppel, Paula Rawiri, Paul Lister and Rob Maclean. 


\section{Authors of the Country Background Report}

The report was prepared by Ministry of Education staff and independent contractors. The following were the authors of the report:

Ministry of Education: Roger Smyth, Jason McClelland, Paul Lister and Kyla Steenhart.

Independent contractors: Allan Sargison (Tertiary Advice Ltd.), Keith Westwater (Westwater Hobbs Consulting), Nicholas Green and Nyk Huntington.

The report was edited by Christine Williams (Wordsmiths). 


\section{Appendix 3: Programme of the Review Visit}

\section{Monday 6 February, Wellington}

17:30 - 18:30 Introductions with National Co-ordinator, Roger Smyth, and Project Manager, Jason McClelland.

\section{Tuesday 7 February, Wellington}

08:45 - 09:20 Minister for Tertiary Education, Hon Dr Michael Cullen

09:30 - 10:30 Tertiary Education Leadership Overview Group

Secretary for Education, Ministry of Education;

Chief Executive and Chair, Tertiary Education Commission;

Acting Chief Executive and Acting Chair, New Zealand Qualifications Authority.

Theme: Leadership and Capability

10:30 - 11:30 Ministry of Education; Tertiary Education Commission; and New Zealand Qualifications Authority

Theme: Policy and Strategy

11:30 - 13:00 Ministry of Education, Tertiary Education Commission, New Zealand Qualifications Authority and Quality Assurance Bodies (Committee on University Academic Programmes, Institutes of Technology and Polytechnics Quality, New Zealand Universities Academic Audit Unit)

Theme: Quality Assurance

13:30 - 14:30 Deparment of Labour; Career Services; Ministry of Education and Tertiary Education Commission.

Theme: Links to the Labour Market 
14:30 - 15:30 Ministry of Education; Ministry of Research, Science and Technology; Foundation of Research Science and Technology; Ministry of Economic Development.

Theme: Research and Innovation

15:30 - 16:30 Ministry of Education; The Treasury; and Tertiary Education Commission

Theme: Resourcing and Governance

16:30 - 17:30 StudyLink, Inland Revenue Department; Ministry of Social Development; and Tertiary Education Commission.

Theme: Student Support

\title{
Wednesday 8 February, Auckland
}

\author{
09:00 - 13:00 Visit: The University of Auckland \\ Part 1: \\ Council and Management \\ Academic Staff Representatives \\ Student Representatives \\ Part 2: \\ Centres of Research Excellence (CoREs) \\ Commercial and collaborative activities \\ (Uniservices/Partnerships for Excellence/Auckland regional \\ Development Strategy) \\ 13:30 - 17:00 Visit: Manukau Institute of Technology \\ Part 1: \\ Council and Management \\ Academic Staff Representatives \\ Student Representatives \\ Part 2: \\ Educational Alliances \\ Community focus (including Curriculum Alignment project, \\ developing aspirations of Pasifika peoples)
}




\section{Thursday 9 February, Palmerston North}

08:30 - 11:45 Visit: Massey University

Part 1:

Council and Management

Student Representatives

Part 2:

Distance Education/ Academic Staff Representatives

12:20 - 15:30 Visit: Universal College of Learning (UCoL)

Council and Management

Academic Staff Representatives

Student Representatives

\section{Friday 10 February, Wellington}

08:30 - 11:00 Natcoll Design Technology

Owners and Management

Academic Staff Representatives

Student Representatives

12:00 - 15:00 Wellington Institute of Technology

Council and Management

Academic Staff Representatives

Student Representatives

16:00 - 17:00 Business New Zealand, Skill New Zealand (Tertiary Education Commission), New Zealand Council of Trade Unions, and Industry Training Federation.

Theme: Business Community Perspectives

\section{Sunday 12 February, Wellington}

Review Team meetings 


\section{Monday 13 February, Wellington and Otaki}

08:45 - 09:45 Student Organisations

New Zealand University Students' Association, Medical Student Association, individual students.

09:45 - 11:00 Academic Staff Organisations

Association of Staff in Tertiary Education and Association of University Staff New Zealand.

12:00 - 16:30 Te Wānanga o Raukawa (TWoR)

Powhiri (welcome)

Part 1:

Council and Management

Academic Staff Representatives

Student Representatives

Part 2:

Marae-based studies

\section{Tuesday 14 February, Christchurch and Wellington}

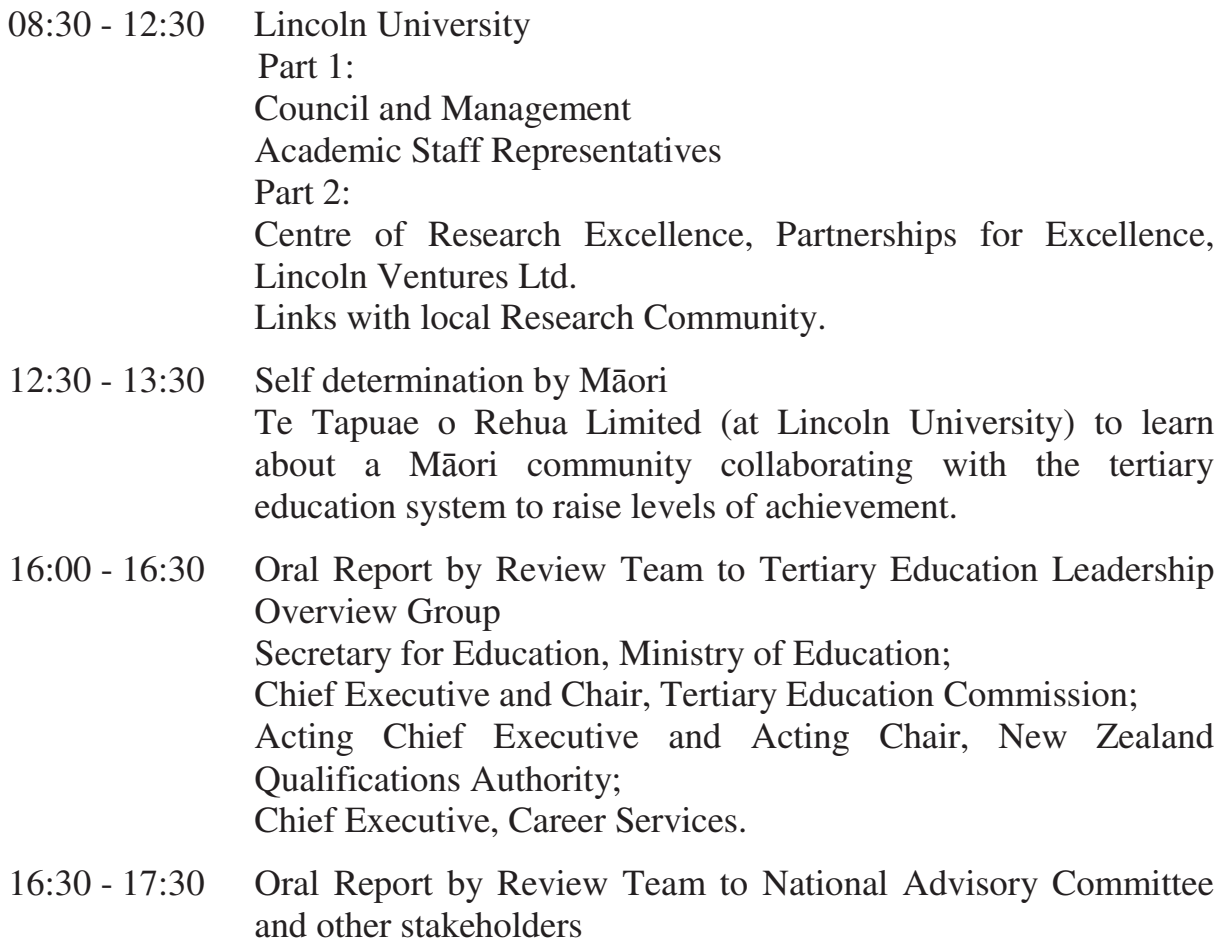
about a Māori community collaborating with the tertiary education system to raise levels of achievement.

16:00 - 16:30 Oral Report by Review Team to Tertiary Education Leadership Overview Group

Secretary for Education, Ministry of Education;

Chief Executive and Chair, Tertiary Education Commission; Acting Chief Executive and Acting Chair, New Zealand Qualifications Authority;

Chief Executive, Career Services.

16:30 - 17:30 Oral Report by Review Team to National Advisory Committee and other stakeholders 


\section{Appendix 4: Chronology of Key Reforms of the New Zealand Tertiary Education System}

Note: This information is reproduced from New Zealand's Country Background Report (Ministry of Education, 2006)

\begin{tabular}{|c|c|}
\hline \multirow[t]{6}{*}{1970 - 1989} & Before the reforms: \\
\hline & $\begin{array}{l}\text { The universities were regulated through the University Grants } \\
\text { Committee (UGC). The UGC managed the system's accountability to } \\
\text { government and allocated government funding to universities under a } \\
\text { quinquennial system, using the equivalent full-time student (EFTS) as } \\
\text { a funding metric. }\end{array}$ \\
\hline & $\begin{array}{l}\text { While the universities funding was received as a bulk fund, the } \\
\text { government controlled major capital investments. }\end{array}$ \\
\hline & $\begin{array}{l}\text { The management of the institutes of technology and polytechnics and } \\
\text { colleges of education was closely controlled by the Department of } \\
\text { Education. }\end{array}$ \\
\hline & $\begin{array}{l}\text { Tuition fees were low and much of the fee was paid through the } \\
\text { student support system. }\end{array}$ \\
\hline & ○ A tertiary grants system supported students' living costs. \\
\hline \multirow[t]{4}{*}{$1989-1990$} & The first round of reforms: \\
\hline & $\begin{array}{l}\text { The Education Act } 1989 \text { was enacted - setting the statutory } \\
\text { framework for all tertiary education. The UGC and the Department of } \\
\text { Education were abolished. The Ministry of Education and NZ } \\
\text { Qualifications Authority (NZQA) were created. }\end{array}$ \\
\hline & $\begin{array}{l}\text { All tertiary education institutions (TEIs) were given autonomy. } \\
\text { Councils had a governance role, with chief executive responsible for } \\
\text { management. }\end{array}$ \\
\hline & $\begin{array}{l}\text { Funding was delivered to all as a bulk fund, using EFTS as the metric, } \\
\text { with the amount of funding dependent on the number of EFTS in } \\
\text { different funding categories. The principle of equal funding for similar } \\
\text { courses underpinned the funding system. TEIs had control over their } \\
\text { capital spending. }\end{array}$ \\
\hline
\end{tabular}




\begin{tabular}{|c|c|}
\hline & $\begin{array}{l}\text { O Quality assurance responsibilities were split between the NZQA and } \\
\text { the NZ Vice-Chancellors' Committee. } \\
\text { Awarding of non-university degrees was permitted. } \\
\text { O The standard tertiary fee was created. } \\
\text { The tertiary grants scheme was replaced by student allowances - with } \\
\text { targeting on the basis of parents' income for those under } 20 \text { years. } \\
\text { TEIs were free to enrol international students on a full-cost-recovery } \\
\text { basis. }\end{array}$ \\
\hline 1991 - 1992 & $\begin{array}{l}\text { The second round of reforms: } \\
\text { The standard tertiary fee was abolished, with TEIs given the freedom } \\
\text { to set their own fees, including the right to set fees with differences } \\
\text { between levels of study and/or fields of study. } \\
\text { Some limited funding was made available for private training } \\
\text { establishments (PTEs). } \\
\text { Targeting of student allowances was extended to the age of } 25 \text { years. } \\
\text { The Student Loan Scheme was created. } \\
\text { A moving cap on the number of EFTS places that could be funded } \\
\text { was set. } \\
\text { The Studyright policy was implemented - introducing funding } \\
\text { differentials between students of different age groups. } \\
\text { Industry Training Act was enacted - enabling industries to develop } \\
\text { qualifications and implement work-based training arrangements that } \\
\text { are responsive to the needs of industry. }\end{array}$ \\
\hline 1993 - 1998 & $\begin{array}{l}\text { Over this time, additional spending was put into funding additional student } \\
\text { places. There was also a series of funding rate cuts. Fees rose in } \\
\text { consequence. }\end{array}$ \\
\hline 1994 & $\begin{array}{l}\text { Publication of Education for the } 21^{\text {st }} \text { Century a statement of the } \\
\text { government's strategy for tertiary education. }\end{array}$ \\
\hline 1995 & $\begin{array}{l}\text { The Ministerial Consultative Group was set up to examine tertiary } \\
\text { education resourcing - and in particular, the issue of the balance of the } \\
\text { public and private contributions to the costs of tertiary education. }\end{array}$ \\
\hline $1997-1998$ & $\begin{array}{l}\text { The government developed a series of green and white papers on tertiary } \\
\text { education. While many of the reforms proposed in these papers were } \\
\text { never enacted, some of the changes were implemented - for instance, } \\
\text { improved monitoring and improved information systems. }\end{array}$ \\
\hline
\end{tabular}




\begin{tabular}{|c|c|}
\hline 1999 & $\begin{array}{l}\text { The third round of reforms: } \\
\text { The moving cap was lifted - funding in the TEIs became demand } \\
\text { driven. } \\
\text { At levels } 3 \text { and above, the funding of PTEs was put on a level footing } \\
\text { with TEI tuition funding. }\end{array}$ \\
\hline $2000-2001$ & $\begin{array}{l}\text { The Tertiary Education Advisory Commission (TEAC) was established to } \\
\text { map out a new direction for tertiary education. It proposed: } \\
\text { The creation of a tertiary education commission - a new government } \\
\text { agency to allocate government funding } \\
\text { The creation of a tertiary education strategy and statement of tertiary } \\
\text { education priorities to ensure better alignment of tertiary education } \\
\text { with national priorities } \\
\text { The system of charters and profiles to help the commission influence } \\
\text { the direction of tertiary education organisations and to improve } \\
\text { alignment with the strategy } \\
\text { The separation of research funding from funding for teaching and } \\
\text { learning }\end{array}$ \\
\hline 2000 & $\begin{array}{l}\text { The government introduced fee stabilisation, providing extra funding in } \\
\text { exchange to tertiary education providers in exchange for an undertaking } \\
\text { to hold fees. Fee stabilisation remained in place for three years. } \\
\text { The government also moved to write off the interest of student loans for } \\
\text { those in study. }\end{array}$ \\
\hline 2002 & $\begin{array}{l}\text { Limits were placed on funding for PTEs; The first Centres of Research } \\
\text { Excellence were established. }\end{array}$ \\
\hline $2002-2003$ & $\begin{array}{l}\text { The fourth round of reforms: } \\
\text { Amendments to the Education Act } 1989 \text { gave effect to many of the TEAC } \\
\text { proposals, including the creation of the Tertiary Education } \\
\text { Commission. The legislation also provided for the Performance-Based } \\
\text { Research Fund and for fee and course costs maxima. } \\
\text { The Tertiary Education Strategy } 2002 / 07 \text { was published. }\end{array}$ \\
\hline 2003 - 2005 & $\begin{array}{l}\text { Limits were placed on growth in some areas of tertiary education provided } \\
\text { by TEIs. } \\
\text { Government removes interest on student loan scheme borrowers for those } \\
\text { that remain in New Zealand. }\end{array}$ \\
\hline
\end{tabular}





\section{Appendix 5: Comparative Indicators on Tertiary Education}

\begin{tabular}{|c|c|c|c|c|}
\hline & $\begin{array}{c}\text { New } \\
\text { Zealand }\end{array}$ & $\begin{array}{c}\text { OECD } \\
\text { mean }\end{array}$ & $\begin{array}{c}\text { New } \\
\text { Zealand's } \\
\text { rank }^{1}\end{array}$ & $\begin{array}{l}\% \text { to } \\
\text { OECD } \\
\text { mean }^{2}\end{array}$ \\
\hline \multicolumn{5}{|l|}{ OUTCOMES } \\
\hline \multicolumn{5}{|l|}{$\begin{array}{l}\% \text { of the population aged } 25-64 \text { with tertiary } \\
\text { qualifications }(2003)\end{array}$} \\
\hline Tertiary-type B - Total & 15 & 8 & $6 / 24$ & 188 \\
\hline Males & 11 & 7 & $7 / 24$ & 157 \\
\hline Females & 18 & 8 & $5 / 25$ & 225 \\
\hline \multirow{3}{*}{$\begin{array}{r}\text { Tertiary-type A and } \\
\text { programmes }- \text { Total } \\
\text { Males } \\
\text { Females }\end{array}$} & 16 & 16 & $14 / 30$ & 100 \\
\hline & 17 & 18 & $12 / 30$ & 94 \\
\hline & 15 & 15 & $16 / 30$ & 100 \\
\hline \multicolumn{5}{|l|}{$\begin{array}{l}\% \text { of the population aged } 25-34 \text { with tertiary } \\
\text { qualifications }(2003)\end{array}$} \\
\hline Tertiary-type B & 12 & 9 & $10 / 25$ & 133 \\
\hline $\begin{array}{l}\text { Tertiary-type A and advanced research } \\
\text { programmes }\end{array}$ & 21 & 20 & $16 / 30$ & 105 \\
\hline \multicolumn{5}{|l|}{$\begin{array}{l}\% \text { of the population aged 55-64 with tertiary } \\
\text { qualifications }(2003)\end{array}$} \\
\hline Tertiary-type B & 17 & 5 & $1 / 25$ & 340 \\
\hline $\begin{array}{l}\text { Tertiary-type A and advanced research } \\
\text { programmes }\end{array}$ & 10 & 12 & $18 / 30$ & 83 \\
\hline \multicolumn{5}{|l|}{$\begin{array}{l}\% \text { of the population aged } 25-64 \text { with tertiary } \\
\text { qualifications - time trends }\end{array}$} \\
\hline 1991 & 23 & 18 & $6 / 21$ & 128 \\
\hline 2003 & 31 & 24 & $9 / 30$ & 129 \\
\hline \multicolumn{5}{|l|}{$\begin{array}{l}\% \text { of the population aged } 25-34 \text { with tertiary } \\
\text { qualifications - time trends }\end{array}$} \\
\hline 1991 & 23 & 20 & $7 / 21$ & 115 \\
\hline 2003 & 32 & 29 & $15 / 30$ & 110 \\
\hline Average years in formal education $(2003)^{3}$ & 12.6 & 12.0 & $13 / 30$ & 105 \\
\hline
\end{tabular}




\begin{tabular}{|c|c|c|c|c|}
\hline & $\begin{array}{c}\text { New } \\
\text { Zealand }\end{array}$ & $\begin{array}{c}\text { OECD } \\
\text { mean }\end{array}$ & $\begin{array}{c}\text { New } \\
\text { Zealand's } \\
\text { rank }^{1}\end{array}$ & $\begin{array}{l}\% \text { to } \\
\text { OECD } \\
\text { mean }^{2}\end{array}$ \\
\hline \multicolumn{5}{|l|}{ Survival rates in tertiary education (2003) } \\
\hline \multicolumn{5}{|l|}{$\begin{array}{l}\text { Number of graduates divided by the number of } \\
\text { new entrants in the typical year of entrance }\end{array}$} \\
\hline Tertiary-type A education & - & 70 & - & - \\
\hline Tertiary-type B education & - & 73 & - & - \\
\hline Advanced research programmes & - & 58 & - & - \\
\hline \multicolumn{5}{|l|}{$\begin{array}{l}\text { Average duration of tertiary studies (in } \\
\text { years) (year varies) }\end{array}$} \\
\hline All tertiary education & - & 4.2 & - & - \\
\hline Tertiary-type B education & - & 2.2 & - & - \\
\hline $\begin{array}{l}\text { Tertiary-type A and advanced research } \\
\text { programmes }\end{array}$ & - & 4.7 & - & - \\
\hline \multicolumn{5}{|l|}{ Tertiary graduates by field of study ${ }^{5}(2002)$} \\
\hline \multicolumn{5}{|l|}{ Tertiary-type A } \\
\hline Education & 12.3 & - & $14 / 27$ & \\
\hline Humanities and arts & 11.9 & - & $12 / 27$ & \\
\hline Social sciences, business and law & 37.8 & - & $8 / 27$ & \\
\hline Science & 13.6 & - & $5 / 27$ & \\
\hline $\begin{array}{l}\text { Engineering, manufacturing and } \\
\text { construction }\end{array}$ & 5.2 & - & $27 / 27$ & \\
\hline Agriculture & 1.4 & - & $16 / 27$ & \\
\hline Health and welfare & 14.9 & - & $8 / 27$ & \\
\hline Services & 2.2 & - & $16 / 27$ & \\
\hline Not known or unspecified & 0.7 & - & - & \\
\hline All fields & 100 & - & - & \\
\hline \multicolumn{5}{|l|}{ Tertiary-type B } \\
\hline Education & 15.4 & - & $6 / 20$ & \\
\hline Humanities and arts & 18.0 & - & $4 / 25$ & \\
\hline Social sciences, business and law & 25.0 & - & $15 / 24$ & \\
\hline Science & 11.6 & - & $8 / 23$ & \\
\hline $\begin{array}{l}\text { Engineering, manufacturing and } \\
\text { construction }\end{array}$ & 3.2 & - & $2 / 23$ & \\
\hline Agriculture & 1.7 & - & $9 / 22$ & \\
\hline Health and welfare & 9.2 & - & $17 / 22$ & \\
\hline Services & 15.1 & - & $4 / 23$ & \\
\hline Not known or unspecified & - & - & - & \\
\hline All fields & 100 & - & - & \\
\hline
\end{tabular}




\begin{tabular}{|c|c|c|c|c|}
\hline & $\begin{array}{c}\text { New } \\
\text { Zealand }\end{array}$ & $\begin{array}{c}\text { OECD } \\
\text { mean }\end{array}$ & $\begin{array}{c}\text { New } \\
\text { Zealand's } \\
\text { rank }^{1}\end{array}$ & $\begin{array}{c}\% \text { to } \\
\text { OECD } \\
\text { mean }^{2}\end{array}$ \\
\hline \multicolumn{5}{|l|}{ Advanced research programmes } \\
\hline Education & 8.1 & - & $6 / 23$ & \\
\hline Humanities and arts & 9.3 & - & $19 / 27$ & \\
\hline Social sciences, business and law & 24.0 & - & $18 / 26$ & \\
\hline Science & 32.9 & - & $5 / 27$ & \\
\hline $\begin{array}{l}\text { Engineering, manufacturing and } \\
\text { construction }\end{array}$ & 7.9 & - & $22 / 26$ & \\
\hline Agriculture & 4.5 & - & $15 / 26$ & \\
\hline Health and welfare & 11.7 & - & $21 / 27$ & \\
\hline Services & 1.5 & - & $10 / 22$ & \\
\hline Not known or unspecified & - & - & - & \\
\hline All fields & 100 & - & - & \\
\hline
\end{tabular}

\section{Tertiary graduates by field of $\operatorname{study}^{5}$ per \\ 10000 population (2002)}

Tertiary-type A

Education

$\begin{array}{ccc}9.68 & - & 8 / 27 \\ 9.36 & - & 8 / 27 \\ 29.85 & - & 3 / 27 \\ 10.69 & - & 4 / 27 \\ 4.09 & - & 23 / 27 \\ 1.14 & - & 9 / 27 \\ 11.74 & - & 5 / 27 \\ 1.76 & - & 10 / 27 \\ 0.57 & - & - \\ 78.88 & - & 4 / 27\end{array}$

Tertiary-type B

Humanities and arts

Social sciences, business and law

Science

Engineering, manufacturing and construction

Agriculture

Health and welfare

Services

Not known or unspecified

All fields

Education

$5.91 \quad-\quad 3 / 22$

Humanities and arts

6.91

$2 / 25$

Social sciences, business and law

9.60

$6 / 24$

Science

4.44

$3 / 23$

Engineering, manufacturing and construction

$1.22 \quad-\quad 15 / 23$

Agriculture

Health and welfare

$3.52 \quad-\quad 9 / 22$

Services

Not known or unspecified 


\begin{tabular}{|c|c|c|c|c|}
\hline & $\begin{array}{c}\text { New } \\
\text { Zealand }\end{array}$ & $\begin{array}{l}\text { OECD } \\
\text { mean }\end{array}$ & $\begin{array}{c}\text { New } \\
\text { Zealand's } \\
\text { rank }^{1} \\
\end{array}$ & $\begin{array}{c}\% \text { to } \\
\text { OECD } \\
\text { mean }^{2} \\
\end{array}$ \\
\hline \multicolumn{5}{|l|}{ Advanced research programmes } \\
\hline Education & 0.11 & - & $7 / 23$ & \\
\hline Humanities and arts & 0.12 & - & $22 / 27$ & \\
\hline Social sciences, business and law & 0.32 & - & $12 / 26$ & \\
\hline Science & 0.43 & - & $14 / 27$ & \\
\hline $\begin{array}{l}\text { Engineering, manufacturing and } \\
\text { construction }\end{array}$ & 0.10 & - & $22 / 26$ & \\
\hline Agriculture & 0.06 & - & $18 / 26$ & \\
\hline Health and welfare & 0.15 & - & $20 / 27$ & \\
\hline Services & 0.02 & - & $11 / 21$ & \\
\hline Not known or unspecified & - & - & - & \\
\hline All fields & 1.32 & - & $21 / 27$ & \\
\hline \multirow{2}{*}{\multicolumn{5}{|c|}{$\begin{array}{l}\text { Employment ratio and educational } \\
\text { attainment }^{\mathbf{6}} \text { (2003) } \\
\text { Number of } 25 \text { to } 64 \text {-year-olds in employment as } \\
\text { a percentage of the population aged } 25 \text { to } 64 \\
\text { Lower secondary education }\end{array}$}} \\
\hline & & & & \\
\hline Males & 74 & 73 & $15 / 30$ & 101 \\
\hline Females & 54 & 49 & $9 / 30$ & 110 \\
\hline \multicolumn{5}{|l|}{ Upper secondary education (ISCED 3A) } \\
\hline Males & 88 & 81 & $5 / 29$ & 109 \\
\hline Females & 71 & 62 & $9 / 29$ & 115 \\
\hline \multicolumn{5}{|l|}{ Post-secondary non-tertiary education } \\
\hline Males & 89 & 84 & $5 / 18$ & 106 \\
\hline Females & 74 & 72 & $7 / 18$ & 103 \\
\hline \multicolumn{5}{|l|}{ Tertiary education, type B } \\
\hline Males & 87 & 88 & $18 / 26$ & 99 \\
\hline Females & 74 & 77 & $21 / 26$ & 96 \\
\hline \multicolumn{5}{|l|}{$\begin{array}{l}\text { Tertiary education, type } \mathrm{A} \text { and advanced } \\
\text { research programmes }\end{array}$} \\
\hline Males & 88 & 89 & $20 / 30$ & 99 \\
\hline Females & 80 & 79 & $16 / 30$ & 101 \\
\hline $\begin{array}{l}\text { Employment ratio and educational } \\
\text { attainment (2003) }\end{array}$ & & & & \\
\hline \multicolumn{5}{|l|}{$\begin{array}{l}\text { Number of } 30 \text { to } 34 \text {-year-olds in employment as } \\
\text { a percentage of the population aged } 30 \text { to } 34 \\
\text { Lower secondary education }\end{array}$} \\
\hline Males & 73.5 & 75.8 & $19 / 26$ & 97 \\
\hline Females & 46.5 & 47.6 & $17 / 26$ & 98 \\
\hline \multicolumn{5}{|l|}{ Upper secondary education (ISCED 3A) } \\
\hline Males & 80.4 & 84.2 & $23 / 26$ & 95 \\
\hline Females & 57.8 & 58.3 & $15 / 26$ & 99 \\
\hline
\end{tabular}




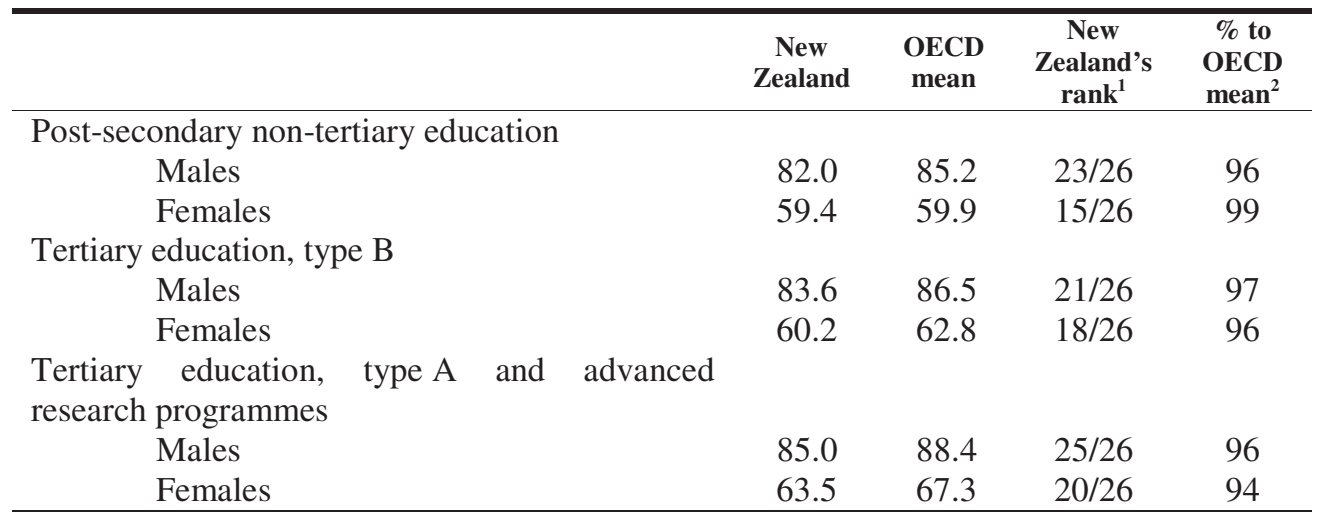

Unemployment ratio and educational attainment $^{7}$ (2003)

Number of 25 to 64-year-olds who are unemployed as a percentage of the population aged 25 to 64

Lower secondary education

Males

$\begin{array}{llll}5.0 & 9.8 & 23 / 28 & 51\end{array}$

Females

Upper secondary education (ISCED 3A)

Males

4.8

11.0

$22 / 27$

44

Females

2.6

7.1

$22 / 23$

37

2.7

10.6

$24 / 25$

25

Post-secondary non-tertiary education

Males

2.6

5.9

$7 / 10$

44

Females

4.4

6.9

$7 / 11$

64

Tertiary education, type B

Males

$\begin{array}{llll}3.2 & 3.9 & 13 / 18 & 82\end{array}$

Females

4.4

$7 / 16$

64

Tertiary education, type A and advanced research programmes
Males
Females

3.5

3.6

$14 / 27$

97

3.1

4.1

$15 / 27$

76

\section{Unemployment ratio and educational attainment (2003)}

Number of 30 to 34-year-olds who are unemployed as a percentage of the population aged 30 to 34

Lower secondary education

Males

Females

Upper secondary education (ISCED 3A)

$\begin{array}{llll}3.5 & 9.6 & 20 / 26 & 36\end{array}$

Males

Females

6.8

$24 / 26$ 37 


\begin{tabular}{|c|c|c|c|c|}
\hline & $\begin{array}{c}\text { New } \\
\text { Zealand }\end{array}$ & $\begin{array}{c}\text { OECD } \\
\text { mean }\end{array}$ & $\begin{array}{c}\text { New } \\
\begin{array}{c}\text { Zealand's } \\
\text { rank }^{1}\end{array} \\
\end{array}$ & $\begin{array}{c}\% \text { to } \\
\text { OECD } \\
\text { mean }^{2} \\
\end{array}$ \\
\hline \multicolumn{5}{|l|}{ Post-secondary non-tertiary education } \\
\hline Males & 4.5 & 6.8 & $22 / 26$ & 66 \\
\hline Females & 2.8 & 6.6 & $20 / 26$ & 42 \\
\hline \multicolumn{5}{|l|}{ Tertiary education, type B } \\
\hline Males & 4.4 & 6.3 & $20 / 26$ & 70 \\
\hline \multicolumn{5}{|l|}{$\begin{array}{l}\text { Tertiary education, type A and advanced } \\
\text { research programmes }\end{array}$} \\
\hline Males & 4.3 & 5.6 & $19 / 26$ & 77 \\
\hline Females & 3.3 & 5.7 & $18 / 26$ & 58 \\
\hline
\end{tabular}

Ratio of the population not in the labour force and educational attainment (2002)

Number of 25 to 64-year-olds not in the labour force as a percentage of the population aged 25 to 64

Lower secondary education

Males

Females

$\begin{array}{llll}20.4 & 19.9 & 14 / 30 & 103\end{array}$

$\begin{array}{llll}43.2 & 45.5 & 22 / 30 & 95\end{array}$

Upper secondary education (ISCED 3A)

Males

$\begin{array}{llll}9.7 & 12.7 & 23 / 29 & 76\end{array}$

Females

$\begin{array}{llll}27.1 & 29.8 & 16 / 29 & 91\end{array}$

Post-secondary non-tertiary education

Males

$\begin{array}{llll}7.0 & 10.7 & 13 / 16 & 65\end{array}$

Females

23.3

$22.0 \quad 7 / 16 \quad 106$

Tertiary education, type B

Males

$\begin{array}{llll}10.9 & 8.9 & 9 / 25 & 119\end{array}$

Females

$22.7 \quad 20.5 \quad 5 / 25$

Tertiary education, type A and advanced research programmes

Males

Females

\section{Ratio of the population not in the labour} force and educational attainment (2002)

Number of 30 to 34-year-olds not in the labour force as a percentage of the population aged 30 to 34

Lower secondary education

Males

Females

Upper secondary education (ISCED 3A)

Males

Females

\begin{tabular}{cccc}
16.0 & 10.5 & $5 / 29$ & 152 \\
50.0 & 39.3 & $5 / 29$ & 127 \\
& & & \\
9.4 & 6.6 & $6 / 28$ & 142 \\
32.3 & 25.8 & $6 / 28$ & 125 \\
\hline
\end{tabular}




\begin{tabular}{|c|c|c|c|c|}
\hline & $\begin{array}{c}\text { New } \\
\text { Zealand }\end{array}$ & $\begin{array}{c}\text { OECD } \\
\text { mean }\end{array}$ & $\begin{array}{c}\text { New } \\
\begin{array}{c}\text { Zealand's } \\
\text { rank }^{1}\end{array}\end{array}$ & $\begin{array}{l}\% \text { to } \\
\text { OECD } \\
\text { mean }^{2}\end{array}$ \\
\hline \multicolumn{5}{|l|}{ Post-secondary non-tertiary education } \\
\hline Males & 3.7 & 3.3 & $9 / 18$ & 112 \\
\hline Females & 33.3 & 17.5 & $1 / 18$ & 195 \\
\hline \multicolumn{5}{|l|}{ Tertiary education, type B } \\
\hline Males & 7.9 & 3.3 & $2 / 25$ & 239 \\
\hline Females & 27.2 & 16.3 & $3 / 25$ & 167 \\
\hline \multicolumn{5}{|l|}{$\begin{array}{l}\text { Tertiary education, type A and advanced } \\
\text { research programmes }\end{array}$} \\
\hline Males & 5.4 & 3.0 & $4 / 29$ & 180 \\
\hline Females & 23.8 & 15.2 & $5 / 29$ & 157 \\
\hline \multicolumn{5}{|l|}{$\begin{array}{l}\text { Earnings of tertiary graduates aged } 25-64 \\
\text { relative to upper secondary graduates aged } \\
25-64(2003) \text { (upper secondary }=100)\end{array}$} \\
\hline Tertiary-type B & 101 & 123 & $17 / 18$ & 82 \\
\hline Tertiary-type A & 150 & 162 & $13 / 19$ & 93 \\
\hline
\end{tabular}

Earnings of tertiary graduates aged 30-44 relative to upper secondary graduates aged 30-44 (2003) (upper secondary = 100)

Tertiary-type B

Trends in relative earnings of tertiary graduates aged 25-64 (upper secondary and post-secondary non-tertiary education $=100$ )

1997

148

148

$9 / 18$

100

2003

126

165

$9 / 9$

76

\section{PATTERNS OF PARTICIPATION}

\section{Participation rates of all persons aged 15 and} over by programme (2002)

Per cent of all persons aged 15 and over in tertiary type-5A programmes

Per cent of all persons aged 15 and over in tertiary type-5B programmes

Per cent of all persons aged 15 and over in tertiary type-6 programmes

\begin{tabular}{llll}
4.51 & 3.97 & $9 / 26$ & 114 \\
1.66 & 0.75 & $5 / 26$ & 221 \\
0.12 & 0.16 & $14 / 23$ & 75 \\
6.29 & 4.86 & $5 / 26$ & 129 \\
\hline
\end{tabular}

Per cent of all persons aged 15 and over in all tertiary programmes 


\begin{tabular}{|c|c|c|c|c|}
\hline & $\begin{array}{c}\text { New } \\
\text { Zealand }\end{array}$ & $\begin{array}{c}\text { OECD } \\
\text { mean }\end{array}$ & $\begin{array}{c}\text { New } \\
\text { Zealand's } \\
\text { rank }^{1}\end{array}$ & $\begin{array}{l}\% \text { to } \\
\text { OECD } \\
\text { mean }^{2}\end{array}$ \\
\hline \multicolumn{5}{|l|}{$\begin{array}{l}\text { Index of change in total tertiary enrolment } \\
(2003)(1995=100)\end{array}$} \\
\hline \multicolumn{5}{|l|}{ Total } \\
\hline Attributable to change in population ${ }^{8}$ & - & 96 & - & - \\
\hline Attributable to change in enrolment rates ${ }^{9}$ & - & 143 & - & - \\
\hline
\end{tabular}

\section{Enrolment rates (2003)}

Full-time and part-time students in public and private institutions, by age

Students aged 15-19 as a percentage of the population aged 15-19

$\begin{array}{llll}67.0 & 79.1 & 26 / 28 & 85\end{array}$

Students aged 20-29 as a percentage of the population aged 20-29

$\begin{array}{llll}28.7 & 23.6 & 8 / 28 & 122\end{array}$

Students aged 30-39 as a percentage of the population aged 30-39

$\begin{array}{llll}11.3 & 5.4 & 4 / 28 & 209\end{array}$

Students aged 40 and over as a percentage of the population aged 40 and over

\section{Age distribution of enrolments (2003)}

Persons aged 35 and over as a per cent of all enrolments in tertiary type-5A programmes

Persons aged 35 and over as a per cent of all enrolments in tertiary type-5B programmes

Persons aged 35 and over as a per cent of all enrolments in tertiary type- 6 programmes

Persons aged 35 and over as a per cent of all enrolments in total tertiary programmes

Persons aged less than 25 as a per cent of all enrolments in tertiary type-5A programmes

Persons aged less than 25 as a per cent of all enrolments in tertiary type-5B programmes

Persons aged less than 25 as a per cent of all enrolments in tertiary type- 6 programmes

Persons aged less than 25 as a per cent of all enrolments in total tertiary programmes

Persons aged less than 20 as a per cent of all enrolments in tertiary type-5A programmes

Persons aged less than 20 as a per cent of all enrolments in tertiary type-5B programmes

$\begin{array}{llll}4.5 & 1.6 & 3 / 25 & 281\end{array}$

$\begin{array}{llll}20.6 & 10.3 & 4 / 24 & 200 \\ 33.4 & 16.2 & 3 / 21 & 206 \\ 50.8 & 30.2 & 2 / 22 & 168 \\ 24.6 & 11.7 & 2 / 24 & 210\end{array}$

$\begin{array}{llll}58.8 & 63.9 & 18 / 26 & 92\end{array}$

$\begin{array}{llll}39.1 & 58.9 & 21 / 26 & 66\end{array}$

$\begin{array}{llll}7.5 & 10.2 & 12 / 21 & 74\end{array}$

$\begin{array}{llll}52.6 & 61.5 & 19 / 27 & 86\end{array}$

$\begin{array}{llll}13.9 & 13.9 & 14 / 27 & 100\end{array}$

$\begin{array}{cccc}9.7 & 17.2 & 19 / 27 & 56 \\ - & 0.4 & - & - \\ 12.5 & 15.0 & 16 / 27 & 83\end{array}$

Persons aged less than 20 as a per cent of all enrolments in tertiary type- 6 programmes

Persons aged less than 20 as a per cent of all enrolments in total tertiary programmes 


\begin{tabular}{|c|c|c|c|c|}
\hline & $\begin{array}{l}\text { New } \\
\text { Zealand }\end{array}$ & $\begin{array}{l}\text { OECD } \\
\text { mean }\end{array}$ & $\begin{array}{c}\text { New } \\
\text { Zealand's } \\
\text { rank }^{1}\end{array}$ & $\begin{array}{l}\text { \% to } \\
\text { OECD } \\
\text { mean }^{2}\end{array}$ \\
\hline \multicolumn{5}{|l|}{ Gender distribution of enrolments (2003) } \\
\hline $\begin{array}{l}\text { Females as a per cent of enrolments in tertiary } \\
\text { type- } 5 \mathrm{~A} \text { programmes }\end{array}$ & 58.8 & 53.2 & $5 / 29$ & 111 \\
\hline $\begin{array}{l}\text { Females as a per cent of enrolments in tertiary } \\
\text { type- } 5 \mathrm{~B} \text { programmes }\end{array}$ & 58.2 & 54.8 & $11 / 29$ & 106 \\
\hline $\begin{array}{l}\text { Females as a per cent of enrolments in tertiary } \\
\text { type- } 6 \text { programmes }\end{array}$ & 49.2 & 44.0 & $8 / 28$ & 112 \\
\hline Females as a per cent of total tertiary enrolments & 58.5 & 53.2 & $4 / 29$ & 110 \\
\hline \multicolumn{5}{|l|}{$\begin{array}{l}\text { Net entry rates into tertiary education }{ }^{10} \\
(\mathbf{2 0 0 3 )} \\
\text { Tertiary-type } \mathrm{B}\end{array}$} \\
\hline Total & 52.9 & 15.6 & $1 / 23$ & 339 \\
\hline Males & 46.3 & 14.2 & $2 / 22$ & 326 \\
\hline Females & 59.1 & 17.0 & $1 / 23$ & 348 \\
\hline \multicolumn{5}{|l|}{ Tertiary-type A } \\
\hline Total & 80.7 & 52.5 & $2 / 26$ & 154 \\
\hline Males & 66.0 & 46.6 & $1 / 25$ & 142 \\
\hline Females & 95.2 & 57.1 & $3 / 25$ & 167 \\
\hline \multicolumn{5}{|l|}{$\begin{array}{l}\text { Distribution of students in tertiary education } \\
\text { by type of institution }{ }^{11}(2003)\end{array}$} \\
\hline Tertiary-type B education, public & 77.8 & 67.5 & $14 / 27$ & 115 \\
\hline $\begin{array}{l}\text { Tertiary-type B education, government- } \\
\text { dependent private }\end{array}$ & 22.1 & 19.5 & $10 / 19$ & 113 \\
\hline Tertiary-type B education, independent private & - & 13.1 & - & - \\
\hline $\begin{array}{l}\text { Tertiary-type A and advanced research } \\
\text { programmes, public }\end{array}$ & 98.4 & 77.6 & $7 / 27$ & 127 \\
\hline $\begin{array}{l}\text { Tertiary-type A and advanced research } \\
\text { programmes, government-dependent private }\end{array}$ & 1.5 & 11.5 & $11 / 13$ & 13 \\
\hline $\begin{array}{l}\text { Tertiary-type A and advanced research } \\
\text { programmes, independent private }\end{array}$ & 0.1 & 10.9 & $17 / 17$ & 1 \\
\hline \multicolumn{5}{|l|}{$\begin{array}{l}\text { Distribution of students in tertiary education } \\
\text { by mode of study (2003) } \\
\text { Tertiary-type B education }\end{array}$} \\
\hline Full-time & 51.2 & 78.3 & $23 / 29$ & 65 \\
\hline Part-time & 48.8 & 22.5 & $7 / 18$ & 217 \\
\hline $\begin{array}{l}\text { Tertiary-type A and advanced } \\
\text { programmes }\end{array}$ & & & & \\
\hline Full-time & 56.1 & 83.4 & $27 / 29$ & 67 \\
\hline Part-time & 43.9 & 16.6 & $3 / 18$ & 264 \\
\hline
\end{tabular}




\begin{tabular}{|c|c|c|c|c|}
\hline & $\begin{array}{l}\text { New } \\
\text { Zealand }\end{array}$ & $\begin{array}{c}\text { OECD } \\
\text { mean }\end{array}$ & $\begin{array}{c}\text { New } \\
\begin{array}{c}\text { Zealand's } \\
\text { rank }^{1}\end{array}\end{array}$ & $\begin{array}{l}\% \text { to } \\
\text { OECD } \\
\text { mean }^{2}\end{array}$ \\
\hline \multicolumn{5}{|l|}{$\begin{array}{l}\text { Age distribution of net entrants into tertiary } \\
\text { education, tertiary-type } A(2003)\end{array}$} \\
\hline $\begin{array}{l}\text { Age at } 20^{\text {th }} \text { percentile }(20 \% \text { of new entrants are } \\
\text { below this age) }\end{array}$ & 19.4 & 19.2 & $8 / 23$ & 101 \\
\hline $\begin{array}{l}\text { Age at } 50^{\text {th }} \text { percentile }(50 \% \text { of new entrants are } \\
\text { below this age) }\end{array}$ & 22.6 & 20.8 & $4 / 23$ & 109 \\
\hline $\begin{array}{l}\text { Age at } 80^{\text {th }} \text { percentile ( } 80 \% \text { of new entrants are } \\
\text { below this age) }\end{array}$ & - & 24.9 & - & - \\
\hline 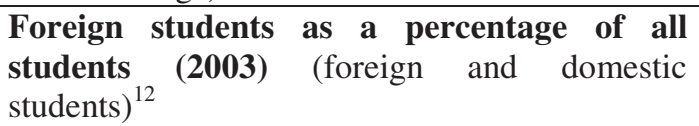 & 13.5 & 6.4 & $4 / 27$ & 211 \\
\hline $\begin{array}{l}\text { Index of change in foreign students as a } \\
\text { percentage of all students }(\mathbf{2 0 0 3}) \text { (foreign and } \\
\text { domestic students) }(1998=100)\end{array}$ & 368 & - & $1 / 22$ & - \\
\hline $\begin{array}{l}\text { National students enrolled abroad in other } \\
\text { reporting countries relative to total tertiary } \\
\text { enrolment }^{13}(\mathbf{2 0 0 3 )}\end{array}$ & 3.5 & 4.0 & $10 / 29$ & 88 \\
\hline $\begin{array}{l}\text { Expected changes of the } 20-29 \text { age group by } \\
2012 \text { relative to } 2002(2002=100)^{14}\end{array}$ & 111 & 96 & $2 / 30$ & 116 \\
\hline Upper secondary attainment rates (2003) & & & & \\
\hline $\begin{array}{l}\% \text { of persons aged } 25-34 \text { with at least upper } \\
\text { secondary education }\end{array}$ & 84 & 75 & $13 / 30$ & 112 \\
\hline $\begin{array}{l}\text { Expected years of tertiary education under } \\
\text { current conditions }(\mathbf{2 0 0 2}) \\
\text { Full-time and part-time }\end{array}$ & 3.5 & 2.8 & $8 / 28$ & 125 \\
\hline
\end{tabular}

\section{EXPENDITURE}

Annual expenditure on tertiary education institutions per student, public and private institutions (2002)

In equivalent US dollars converted using PPPs, based on full-time equivalents

All tertiary education (including R\&D activities)

Tertiary-type B education (including R\&D activities)

Tertiary-type A and advanced research programmes (including R\&D activities)

All tertiary education excluding R\&D activities 


\begin{tabular}{|c|c|c|c|c|}
\hline & $\begin{array}{l}\text { New } \\
\text { Zealand }\end{array}$ & $\begin{array}{c}\text { OECD } \\
\text { mean }\end{array}$ & $\begin{array}{c}\text { New } \\
\text { Zealand's } \\
\text { rank }^{1}\end{array}$ & $\begin{array}{l}\text { \% to } \\
\text { OECD } \\
\text { mean }^{2}\end{array}$ \\
\hline \multirow{2}{*}{\multicolumn{5}{|c|}{$\begin{array}{l}\text { Annual expenditure on tertiary education } \\
\text { institutions per student relative to GDP per } \\
\text { capita, public and private institutions (2002) } \\
\text { Based on full-time equivalents }\end{array}$}} \\
\hline & & & & \\
\hline $\begin{array}{l}\text { All tertiary education (including R\&D } \\
\text { activities) }\end{array}$ & - & 43 & - & \\
\hline $\begin{array}{l}\text { Tertiary-type B education (including R\&D } \\
\text { activities) }\end{array}$ & - & 29 & - & \\
\hline $\begin{array}{l}\text { Tertiary-type A and advanced research } \\
\text { programmes (including R\&D activities) }\end{array}$ & - & 42 & - & \\
\hline All tertiary education excluding R\&D activities & - & 34 & - & \\
\hline \multicolumn{5}{|l|}{$\begin{array}{l}\text { Cumulative expenditure on educational } \\
\text { institutions per student over the average } \\
\text { duration of tertiary studies }{ }^{16}(\mathbf{2 0 0 2}) \\
\text { In equivalent US dollars converted using PPPs }\end{array}$} \\
\hline All tertiary education & - & 45812 & - & - \\
\hline Tertiary-type B education & - & - & - & - \\
\hline $\begin{array}{l}\text { Tertiary-type A and advanced } \\
\text { programmes }\end{array}$ & - & - & - & - \\
\hline
\end{tabular}

Change in tertiary education expenditure per student relative to different factors

Index of change between 1995 and 2002

(1995 = 100, 2002 constant prices)

Change in expenditure

Change in the number of students

Change in expenditure per student

Change in tertiary education expenditure per student

In equivalent US dollars converted using PPPs

(2001 constant prices and 2001 constant PPPs)

$\begin{array}{llll}1995 & - & 9284 & 122\end{array}$

$2001 \quad-\quad 10052 \quad 126$

Expenditure on tertiary education

institutions as a percentage of GDP, from public and private sources

All tertiary education, 2002

$\begin{array}{llll}1.5 & 1.4 & 8 / 28 & 107\end{array}$

Tertiary-type B education, 2002

$\begin{array}{llll}0.3 & 0.1 & 2 / 10 & 300\end{array}$

Tertiary-type A education, 2002

$1.2 \quad 1.1$

$6 / 17 \quad 109$

All tertiary education, 1995

$1.1 \quad 1.3 \quad 14 / 25$

85 


\begin{tabular}{|c|c|c|c|c|}
\hline & $\begin{array}{c}\text { New } \\
\text { Zealand }\end{array}$ & $\begin{array}{l}\text { OECD } \\
\text { mean }\end{array}$ & $\begin{array}{c}\text { New } \\
\text { Zealand's } \\
\text { rank }^{1}\end{array}$ & $\begin{array}{l}\text { \% to } \\
\text { OECD } \\
\text { mean }^{2}\end{array}$ \\
\hline \multicolumn{5}{|l|}{$\begin{array}{l}\text { Relative proportions of public and private } \\
\text { expenditure on educational institutions, for } \\
\text { tertiary education }\end{array}$} \\
\hline $\begin{array}{l}\text { Distribution of public and private sources of } \\
\text { funds for educational institutions after transfers } \\
\text { from public sources }\end{array}$ & & & & \\
\hline Public sources, 2002 & 62.5 & 78.1 & $19 / 27$ & 80 \\
\hline Private sources, household expenditure, 2002 & 37.5 & 18.5 & $4 / 24$ & 203 \\
\hline $\begin{array}{l}\text { Private sources, expenditure of other private } \\
\text { entities, } 2002\end{array}$ & - & 7.6 & - & - \\
\hline Private sources, all private sources, 2002 & 37.5 & 21.9 & $5 / 27$ & 171 \\
\hline $\begin{array}{l}\text { Private sources, private, of which subsidised, } \\
2002\end{array}$ & - & 1.3 & - & - \\
\hline Public sources, 1995 & - & 80.8 & - & - \\
\hline Private sources, household expenditure, 1995 & - & 14.4 & - & - \\
\hline $\begin{array}{l}\text { Private sources, expenditure of other private } \\
\text { entities, } 1995\end{array}$ & - & 11.0 & - & - \\
\hline Private sources, all private sources, 1995 & - & 19.2 & - & - \\
\hline $\begin{array}{l}\text { Private sources, private, of which subsidised, } \\
1995\end{array}$ & - & 5.4 & - & - \\
\hline
\end{tabular}

\section{Distribution of total public expenditure on} tertiary education (2002)

Public expenditure on tertiary education transferred to educational institutions and public transfers to the private sector, as a percentage of total public expenditure on tertiary education Direct public expenditure on public institutions Direct public expenditure on private institutions Indirect public transfers and payments to the private sector

$\begin{array}{cccc}52.9 & 71.1 & 24 / 25 & 74 \\ 2.8 & 11.5 & 15 / 20 & 24 \\ 44.2 & 17.4 & 1 / 27 & 254\end{array}$

Expenditure on tertiary education institutions as a proportion of total expenditure on all educational institutions (2002) Public and private institutions

\section{Total public expenditure on tertiary education (2002)}

Direct public expenditure on tertiary institutions plus public subsidies to households (which include subsidies for living costs, and other private entities)

As a percentage of total public expenditure ${ }^{17}$ 


\begin{tabular}{|c|c|c|c|c|}
\hline & $\begin{array}{c}\text { New } \\
\text { Zealand }\end{array}$ & $\begin{array}{l}\text { OECD } \\
\text { mean }\end{array}$ & $\begin{array}{c}\text { New } \\
\text { Zealand's } \\
\text { rank }^{1}\end{array}$ & $\begin{array}{l}\text { \% to } \\
\text { OECD } \\
\text { mean }^{2}\end{array}$ \\
\hline \multicolumn{5}{|l|}{$\begin{array}{l}\text { Subsidies for financial aid to students as a } \\
\text { percentage of total public expenditure on } \\
\text { tertiary education }(\mathbf{2 0 0 2})\end{array}$} \\
\hline Scholarships / other grants to households & 13.3 & 9.2 & $8 / 26$ & 145 \\
\hline Student loans & 30.9 & 7.6 & $1 / 15$ & 407 \\
\hline $\begin{array}{l}\text { Scholarships / other grants to households } \\
\text { attributable for educational institutions }\end{array}$ & - & 1.1 & - & - \\
\hline $\begin{array}{l}\text { Annual expenditure per student on } \\
\text { instruction, ancillary services and R\&D } \\
(\mathbf{2 0 0 2 )} \\
\text { Expenditure on tertiary education institutions in } \\
\text { US dollars converted using PPPs from public } \\
\text { and private sources, by type of service }\end{array}$ & & & & \\
\hline Educational core services & - & 7173 & - & - \\
\hline $\begin{array}{l}\text { Ancillary services (transport, meals, housing } \\
\text { provided by institutions) }\end{array}$ & - & 342 & - & - \\
\hline Research and development & - & 2795 & - & - \\
\hline \multicolumn{5}{|l|}{$\begin{array}{l}\text { Expenditure on tertiary education institutions } \\
\text { by resource category (2002) } \\
\text { Distribution of total and current expenditure on } \\
\text { tertiary education institutions from public and } \\
\text { private sources } \\
\text { Percentage of total expenditure }\end{array}$} \\
\hline Current & - & 88.4 & - & - \\
\hline Capital & - & 11.6 & - & - \\
\hline \multicolumn{5}{|l|}{ Percentage of current expenditure } \\
\hline Compensation of teachers & - & 42.3 & - & - \\
\hline Compensation of other staff & - & 22.2 & - & - \\
\hline Compensation of all staff & - & 66.1 & - & - \\
\hline Other current & - & 33.9 & - & - \\
\hline
\end{tabular}

\section{LITERACY LEVELS}

IALS achievement levels of graduates aged 25-34 (1994-1995) Source: IALS

Graduates aged 25-34 at IALS levels 1 and 2 as a per cent of total graduates aged 25-34

$24 \quad 19 \quad 6 / 21 \quad 126$

Graduates aged 25-34 at IALS levels 4 and 5 as a per cent of total graduates aged 25-34

$\begin{array}{llll}36 & 40 & 12 / 21 & 90\end{array}$




\begin{tabular}{lcccc}
\hline & $\begin{array}{c}\text { New } \\
\text { Zealand }\end{array}$ & $\begin{array}{c}\text { OECD } \\
\text { mean }\end{array}$ & $\begin{array}{c}\text { New } \\
\text { Zealand's } \\
\text { rank }^{1}\end{array}$ & $\begin{array}{c}\text { \% to } \\
\text { OECD } \\
\text { mean }^{2}\end{array}$ \\
\hline PATTERNS of PROVISION & & \\
\hline
\end{tabular}

\section{Ratio of students to teaching staff in tertiary} education $^{18}$ (2003)

Based on full-time equivalents, Public and private institutions.

\begin{tabular}{lccccc} 
Type B $\mathrm{B}$ & 7.4 & 14.1 & $13 / 15$ & 52 \\
$\begin{array}{l}\text { Type A and advanced } \\
\text { programmes }\end{array}$ & research & 9.0 & 15.7 & $18 / 18$ & 57 \\
Tertiary education all & & 8.5 & 14.9 & $23 / 23$ & 57 \\
\hline
\end{tabular}

\begin{tabular}{lll}
\hline $\begin{array}{l}\text { EXPECTATIONS } \\
\text { STUDENTS }\end{array}$ & OF & 15-YEAR-OLD \\
\hline
\end{tabular}

Students' expected educational levels (2003)

Source: PISA 2003 (OECD, 2004)

Per cent of 15-year-old students who expect to complete secondary education, general $\begin{array}{llll}76.0 & 48.9 & 5 / 28 & 155\end{array}$ programmes (ISCED 3A)

Per cent of 15-year-old students who expect to complete secondary education, vocational programmes (ISCED 3B or C)

$\begin{array}{llll}85.4 & 29.9 & 1 / 26 & 286\end{array}$

Per cent of 15-year-old students who expect to complete post-secondary non-tertiary education (ISCED 4)

Per cent of 15-year-old students who expect to complete tertiary-type B education (ISCED 5B)

Per cent of 15-year-old students who expect to complete tertiary-type A education or an advanced research qualification (ISCED

$\begin{array}{llll}41.4 & 16.4 & 1 / 21 & 252\end{array}$

$\begin{array}{llll}32.3 & 20.5 & 4 / 26 & 158\end{array}$
$5 \mathrm{~A}$ or 6 )

\section{RESEARCH AND DEVELOPMENT}

Gross domestic expenditure on Research and Development $(\mathrm{R} \& D)$ as a percentage of GDP Source: OECD (2005)

\begin{tabular}{lllll}
2003 & 1.16 & 2.24 & $15 / 19$ & 52 \\
1991 & 0.98 & 2.21 & $20 / 26$ & 44 \\
\hline $\begin{array}{l}\text { Higher education }{ }^{19} \text { expenditure on R\&D as a } \\
\text { percentage of GDP }\end{array}$ & & & & \\
Source: OECD (2005) & & & & \\
2003 & 0.33 & 0.42 & $13 / 19$ & 79 \\
1991 & 0.28 & 0.36 & $15 / 23$ & 78 \\
\hline
\end{tabular}




\begin{tabular}{|c|c|c|c|c|}
\hline & $\begin{array}{c}\text { New } \\
\text { Zealand }\end{array}$ & $\begin{array}{l}\text { OECD } \\
\text { mean }\end{array}$ & $\begin{array}{c}\text { New } \\
\begin{array}{c}\text { Zealand's } \\
\text { rank }^{1}\end{array}\end{array}$ & $\begin{array}{l}\text { \% to } \\
\text { OECD } \\
\text { mean }^{2}\end{array}$ \\
\hline \multicolumn{5}{|l|}{ Percentage of gross domestic expenditure on } \\
\hline \multirow{2}{*}{\multicolumn{5}{|c|}{$\begin{array}{l}\text { R\&D by sector of performance } \\
\text { Source: OECD }(2005)\end{array}$}} \\
\hline & & & & \\
\hline higher education & 28.4 & 18.7 & $4 / 18$ & 152 \\
\hline (higher education in 1991) & 28.6 & 16.3 & $7 / 23$ & 175 \\
\hline business enterprise & 40.5 & 67.3 & $16 / 18$ & 60 \\
\hline government & 31.1 & 10.9 & $4 / 18$ & 285 \\
\hline private non-profit sector & - & 3.1 & - & - \\
\hline \multicolumn{5}{|l|}{$\begin{array}{l}\text { Percentage of higher education expenditure } \\
\text { on R\&D financed by industry Source: OECD } \\
(2005)\end{array}$} \\
\hline 2001 & 5.3 & 6.1 & $16 / 25$ & 87 \\
\hline 1991 & 4.6 & 5.5 & $15 / 22$ & 84 \\
\hline \multicolumn{5}{|l|}{$\begin{array}{l}\text { Total researchers per thousand total } \\
\text { employment Source: OECD }(2005)\end{array}$} \\
\hline 2001 & 9.1 & 6.3 & $4 / 22$ & 144 \\
\hline 1991 & 4.0 & 5.9 & $13 / 19$ & 68 \\
\hline \multicolumn{5}{|l|}{$\begin{array}{l}\text { Researchers as a percentage of national total } \\
\text { (full time equivalent) (2001) Source: OECD } \\
(2005)\end{array}$} \\
\hline higher education & 65.9 & 40.1 & $2 / 11$ & 164 \\
\hline (higher education in 1993) & 39.4 & 23.8 & $10 / 23$ & 166 \\
\hline business enterprise & 19.0 & 43.4 & $20 / 23$ & 44 \\
\hline government & 15.1 & 15.8 & $11 / 23$ & 96 \\
\hline \multicolumn{5}{|l|}{$\begin{array}{l}\text { Share in OECD total "triadic" patent } \\
\text { families }{ }^{20}(\%) \\
\text { Source: OECD (2005) }\end{array}$} \\
\hline 2001 & 0.08 & - & $20 / 30$ & - \\
\hline 1991 & 0.06 & - & $21 / 30$ & - \\
\hline $\begin{array}{l}\text { Foreign PhD students as a per cent of total } \\
\text { PhD enrolments (2003) }\end{array}$ & 10.6 & 13.7 & $9 / 17$ & 77 \\
\hline
\end{tabular}




\section{Notes for the Tables}

\section{Sources:}

All data are from Education at a Glance, OECD Indicators 2004 and 2005, unless indicated otherwise in the table.

\section{Other sources:}

Eurydice (2005), Key data on education in Europe 2005, Eurydice, Brussels.

IALS, International adult literacy survey database.

OECD (2004), Learning for Tomorrow's World, First Results from PISA 2003, OECD, Paris.

OECD (2005), Main Science and Technology Indicators, volume 2005/2, OECD, Paris.

\section{General notes:}

1. "New Zealand's rank" indicates the position of New Zealand when countries are ranked in descending order from the highest to lowest value on the indicator concerned. For example, on the first indicator "\% of the population aged 25-64 with tertiary qualifications, Tertiary-type $B$ - Total", the rank " $x / x$ ” indicates that New Zealand recorded the $\mathrm{xx}^{\mathrm{st}}$ highest value of the $\mathrm{xx}$ OECD countries that reported relevant data. The symbol "=" means that at least one other country has the same rank.

2. "\% to OECD mean" indicates New Zealand's value as a per cent of the OECD value. For example, on the first indicator "\% of the population aged 25-64 with tertiary qualifications, Tertiary-type $B$ - Total", the percentage " $x x$ " indicates that New Zealand's value is equivalent to $\mathrm{xx} \%$ of the OECD mean.

3. The calculation of the average years in formal education is based upon the weighted theoretical duration of schooling to achieve a given level of education, according to the current duration of educational programmes as reported in the UOE data collection.

4. Two alternative methods were employed to calculate the average duration of tertiary studies: the approximation formula and the chain method. For both methods, it should be noted that the result does not give the average duration needed for a student to graduate since all students participating in tertiary education are taken into account, including drop-outs. Hence, the figure can be interpreted as the average length of time for which students stay in tertiary education until they either graduate or drop out.

5. These indicators show the ratio of graduates as a proportion to all fields of studies. The fields of education used follow the ISCED classification by field of education.

6. The employed are defined as those who during the survey reference week: $i$ ) work for pay (employees) or profit (self-employed and unpaid family workers) for at least one hour, or $i$ ) have a job but are temporarily not at work (through 
injury, illness, holiday, strike or lockout, educational or training leave, maternity or parental leave, etc.) and have a formal attachment to their job.

7. The unemployed are defined as individuals who are without work, actively seeking employment and currently available to start work.

8. The impact of demographic change on total enrolment is calculated by applying the enrolment rates measured in 1995 to the population data for 2003: population change was taken into account while enrolment rates by single year of age were kept constant at the 1995 level.

9. The impact of changing enrolment rates is calculated by applying the enrolment rates measured in 2003 to the population data for 1995: the enrolment rates by single year of age for 2003 are multiplied by the population by single year of age for 1995 to obtain the total number of students that could be expected if the population had been constant since 1995 .

10. The net entry rates represent the proportion of persons of a synthetic age cohort who enter a certain level of tertiary education at one point during their lives.

11. Educational institutions are classified as either public or private according to whether a public agency or a private entity has the ultimate power to make decisions concerning the institution's affairs. An institution is classified as private if it is controlled and managed by a non-governmental organisation (e.g. a Church, a Trade Union or a business enterprise), or if its Governing Board consists mostly of members not selected by a public agency. The terms "government-dependent" and "independent" refer only to the degree of a private institution's dependence on funding from government sources. A governmentdependent private institution is one that receives more than 50 per cent of its core funding from government agencies. An independent private institution is one that receives less than 50 per cent of its core funding from government agencies.

12. Students are classified as foreign students if they are not citizens of the country for which the data are collected. Countries unable to provide data or estimates for non-nationals on the basis of their passports were requested to substitute data according to a related alternative criterion, $e . g$. the country of residence, the nonnational mother tongue or non-national parentage.

13. The number of students studying abroad is obtained from the report of the countries of destination. Students studying in countries which did not report to the OECD are not included in this indicator.

14. This indicator covers residents in the country, regardless of citizenship and of educational or labour market status.

15. School expectancy (in years) under current conditions excludes all education for children younger than five years. It includes adult persons of all ages who are enrolled in formal education. School expectancy is calculated by adding the net enrolment rates for each single year of age.

16. The estimates of cumulative expenditure on education over the average duration of tertiary studies were obtained by multiplying annual expenditure per student by an estimate of the average duration of tertiary studies. 
17. Total public expenditure on all services, excluding education, includes expenditure on debt servicing (e.g. interest payments) that are not included in public expenditure on education.

18. "Teaching staff" refers to professional personnel directly involved in teaching students.

19. "Higher Education" includes all universities, colleges of technology and other institutions of post-secondary education, whatever their source of finance or legal status. It also includes all research institutes, experimental stations and clinics operating under the direct control of or administered by or associated with higher education institutions. For detail, see OECD (2002), Frascati Manual 2002: Proposed Standard Practice for Surveys on Research and Experimental Development.

20. "Triadic patent" means patents filed all together to the European Patent Office (EPO), the US Patent and Trademark Office (USPTO) and the Japanese Patent Office (JPO). This indicator shows each country's share in total triadic patents filed by OECD countries. Reference year is when the priority patent is filed. Data is estimated by the OECD Secretariat and provisional. Because a few countries share large proportion of triadic patents, other countries have small share. 
OECD PUBLICATIONS, 2, rue André-Pascal, 75775 PARIS CEDEX 16 PRINTED IN FRANCE

(91 2008111 P) ISBN-978-92-64-03927-8- No. 563012008 


\section{OECD Reviews of Tertiary Education}

\section{NEW ZEALAND}

In many OECD countries, tertiary education systems have experienced rapid growth over the last decade. With tertiary education increasingly seen as a fundamental pillar for economic growth, these systems must now address the pressures of a globalising economy and labour market. Within governance frameworks that encourage institutions, individually and collectively, to fulfil multiple missions, tertiary education systems must aim for the broad objectives of growth, full employment and social cohesion.

In this context, the OECD launched a major review of tertiary education with the participation of 24 nations. The principal objective of the review is to assist countries in understanding how the organisation, management and delivery of tertiary education can help them achieve their economic and social goals. New Zealand is one of 14 countries which opted to host a Country Review, in which a team of external reviewers carried out an in-depth analysis of tertiary education policies. This report includes:

- an overview of New Zealand's tertiary education system;

- an account of trends and developments in tertiary education in New Zealand;

- an analysis of the strengths and challenges in tertiary education in New Zealand; and

- recommendations for future policy development.

This Review of Tertiary Education in New Zealand forms part of the OECD Thematic Review of Tertiary Education, a project conducted between 2004 and 2008 (www.oecd.org/edu/tertiary/review). 